\title{
A NOVEL PHOSPHATASE MODULATING THE DNA DAMAGE RESPONSE AND THE TUMOR SUPPRESSOR P53
}

\section{PhD Thesis}

\author{
in partial fulfillment of the requirements \\ for the degree "Doctor of Philosophy (PhD)" \\ in the Molecular Biology Program \\ at the Georg August University Göttingen, \\ Faculty of Biology
}

submitted by

Konstantina Marinoglou

born in

Athens, Attica, Greece 



\section{AFFIDAVIT}

Herewith I declare, that I prepared the PhD Thesis:

"A novel phosphatase modulating the DNA damage response and the tumor suppressor P53" on my own and with no other sources and aids than quoted.

Göttingen, 30.09.10 


\section{List of Publications:}

"An siRNA screen to identify phosphatases that modulate the DNA damage response" Konstantina Marinoglou, Matthias Dobbelstein

University of Goettingen, Germany

Poster - Cancer Conference NCRI, Birmingham - UK, October 2008

"The Bactrocera oleae homologues of Drosophila melanogaster sex-determining genes" Lagos D., Marinoglou K., Pappas V. \& K. Komitopoulou Dept. of Genetics \& Biotechnology, School of Biology, University of Athens, Panepistimiopolis 15784 Athens Greece Poster - Proceedings of 26th Scientific Conference, Volos - Greece, May 2004, Hellenic Society for Biological Sciences 


\section{Table of Contents:}

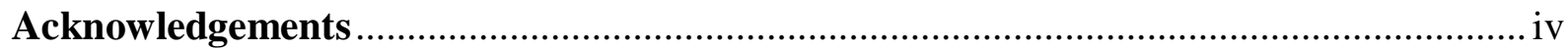

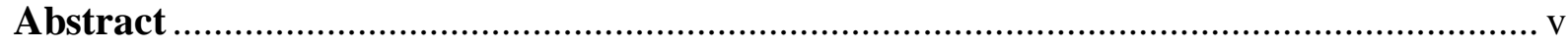

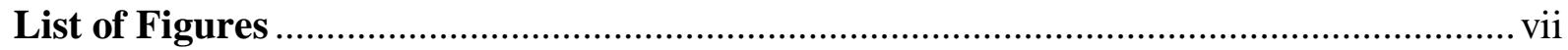

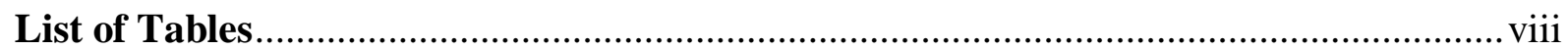

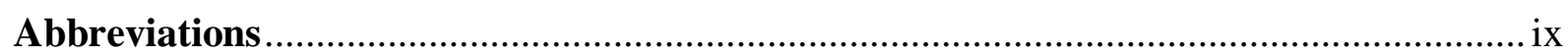

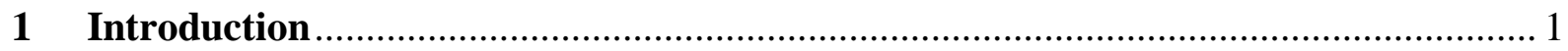

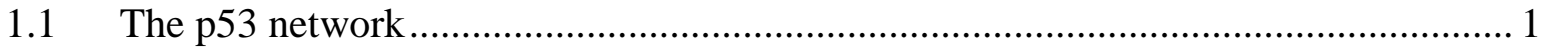

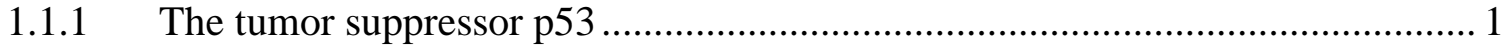

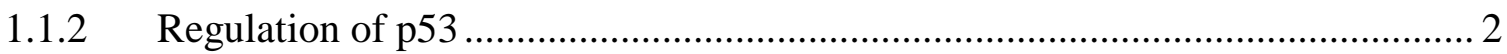

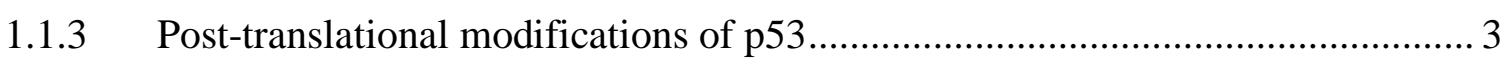

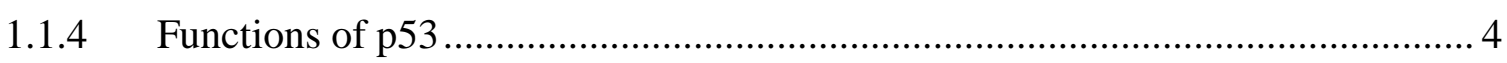

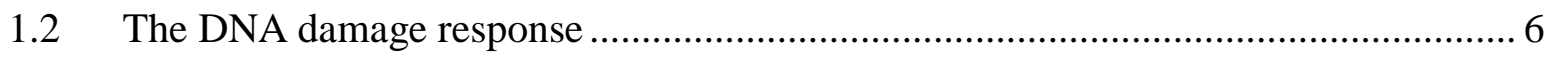

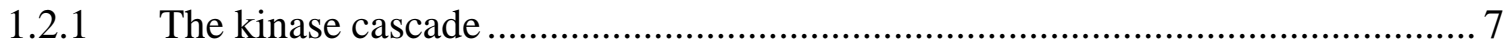

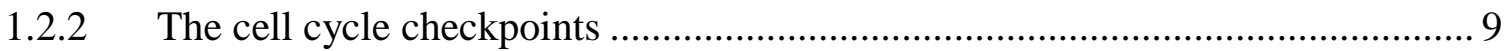

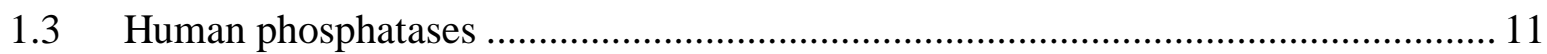

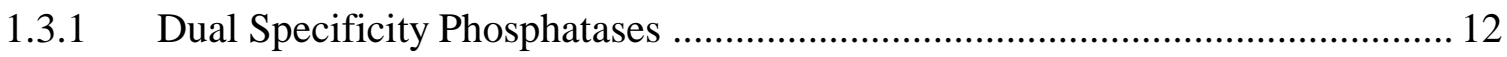

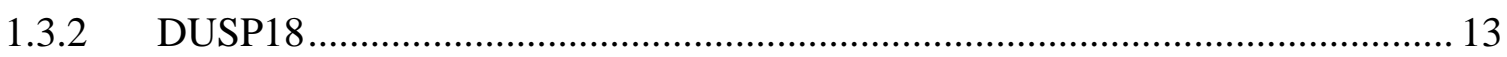

1.3.3 Implication of phosphatases in the DNA damage response ............................ 15

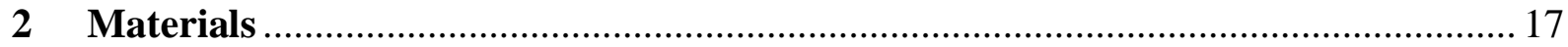

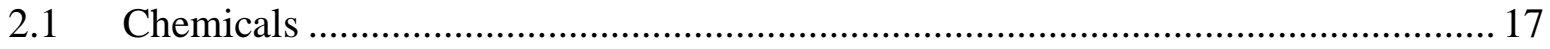

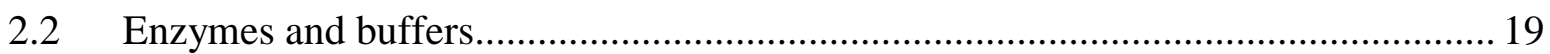

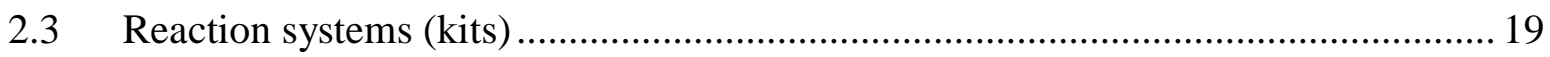

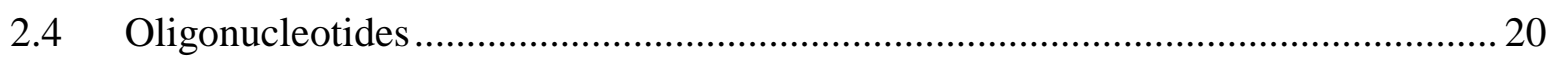

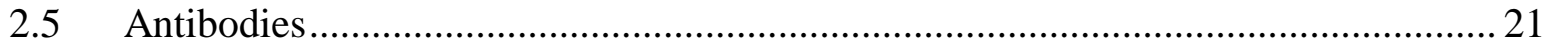

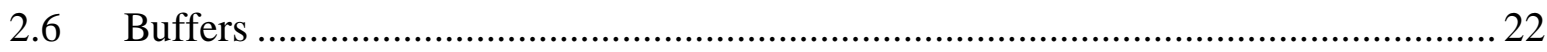

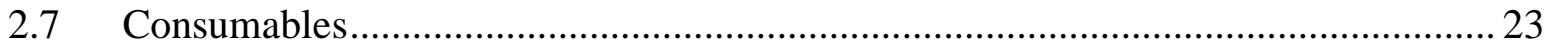

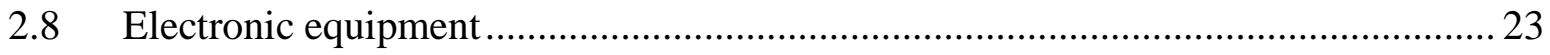

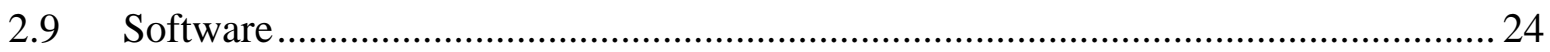

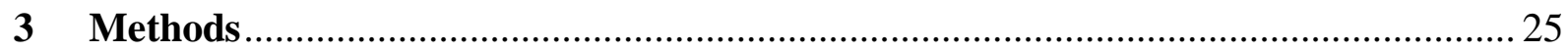

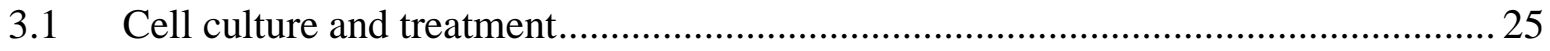

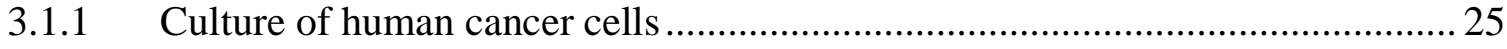

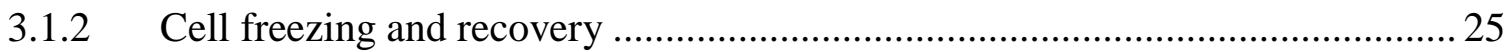




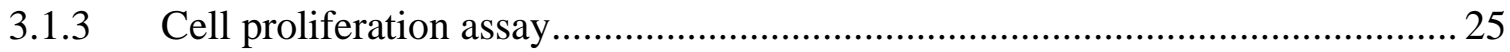

3.1.4 Generation of polyclonal stable U2OS cell lines ........................................... 26

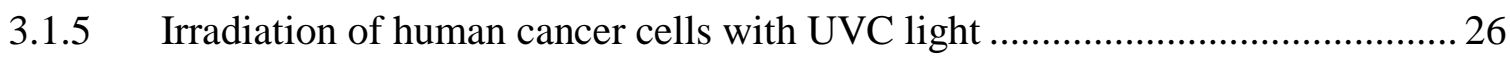

3.1.6 Transfection of human cancer cells with Lipofectamine 2000 ......................... 26

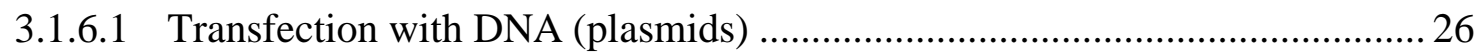

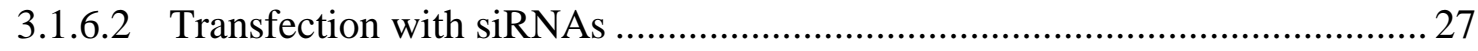

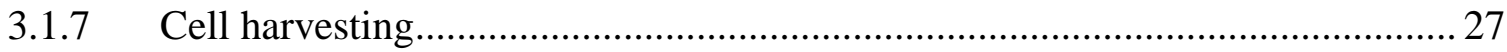

3.1.7.1 Cell harvesting and fixation for cell cycle analysis with a FACS machine.... 27

3.1.7.2 Preparation of cell lysates for immunoblotting analysis ............................. 27

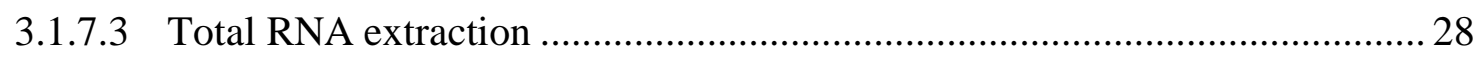

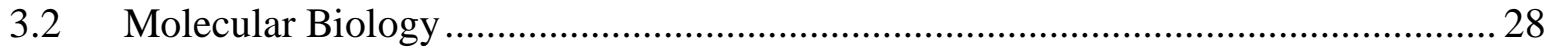

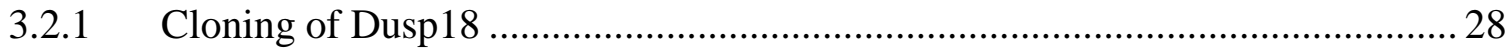

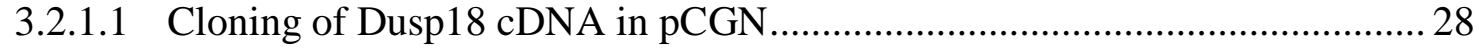

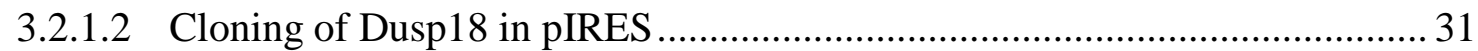

3.2.2 Quantitative Polymerase Chain Reaction (qPCR).......................................... 32

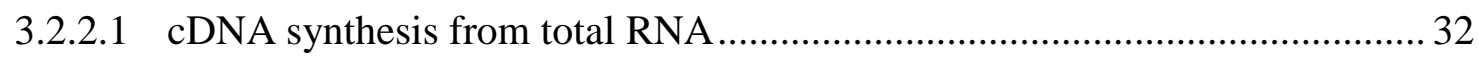

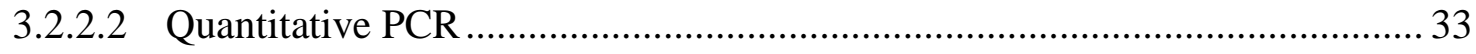

3.2.2.2.1 Preparation of qPCR homemade mastermix:......................................... 33

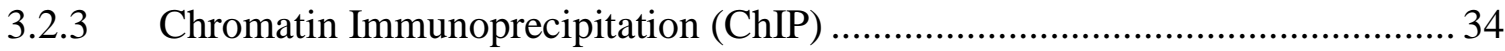

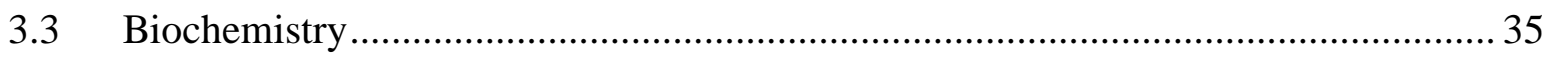

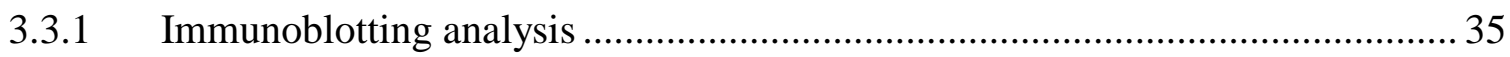

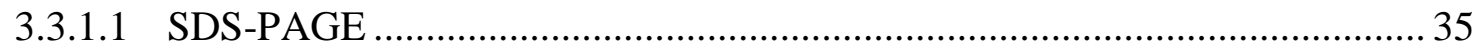

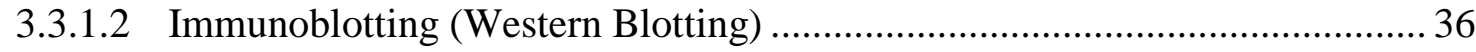

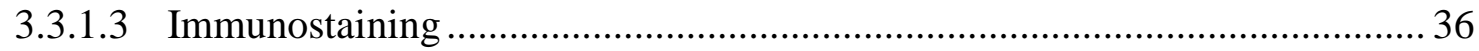

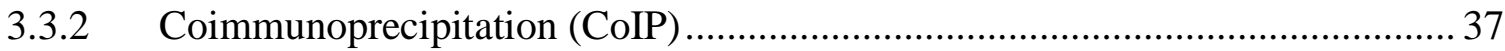

3.4 Human phosphatase siRNA library screening .................................................. 37

3.4.1 Transfection of U2OS cells with the phosphatase library siRNAs ................... 37

3.4.2 Fixation and immunofluorescence staining of the U2OS cells ......................... 38

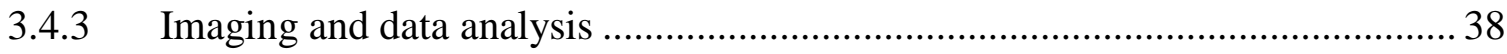

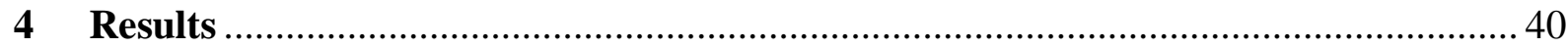

4.1 Identification of novel phosphatases as potential players in the DNA damage and

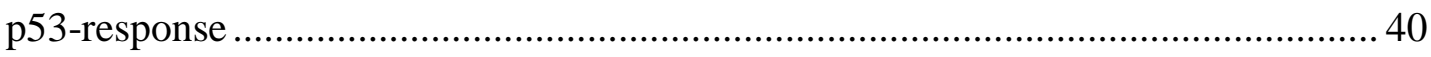

4.1.1 Screening of the human phosphatase siRNA library ........................................ 40

4.2 Investigation of Dusp18 as a novel regulator of the p53 pathway ........................... 44 
4.2.1 Subcellular localization of human Dusp18 .................................................. 44

4.2.2 The knockdown of Dusp18 induces the p53 pathway in different cell lines ..... 46

4.2.3 Depletion of Dusp18 does not increase the phosphorylation or acetylation of p53

4.2.4 The interaction of p53 with Mdm2 was not disrupted upon Dusp18

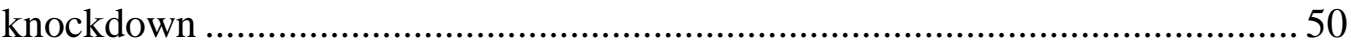

4.2.5 P53 accumulated and was activated to induce p21 transcription by depletion of Dusp18

4.3 Dusp18 is necessary for cell survival and proper cell cycle progression .................. 54

4.3.1 Cells depleted of Dusp18 undergo spontaneous apoptosis ................................ 54

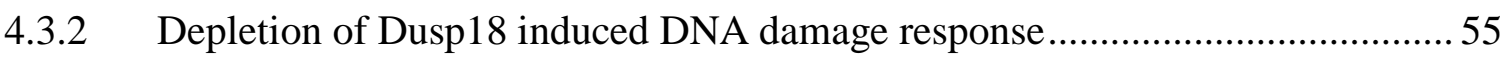

4.3.3 Removal of Dusp18 caused an accumulation of cells in S phase which correlated with reduced cell proliferation. ...................................................... 57

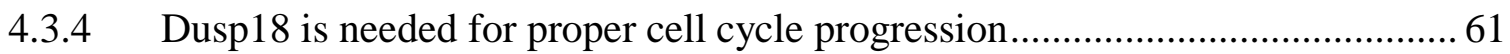

4.3.5 Dusp18 knockdown sensitized HCT116 p53 +/+ cells to gemcitabine ............. 63

\section{Discussion.}

5.1 Identification of novel phosphatases that modulate the DNA damage response and the 553 pathway. 65

5.2 The depletion of Dusp18 induced the p53 pathway 66

5.2.1 Human Dusp18 was not localized in mitochondria in our system 66

5.2.2 The depletion of Dusp18 induced p53 and p21 accumulation in several cell lines

5.3 The survival of tumor cells depends on Dusp18

5.4 Dusp18 depletion induces $\gamma \mathrm{H} 2 \mathrm{Ax}$ and initiates the DNA damage response cascade 70

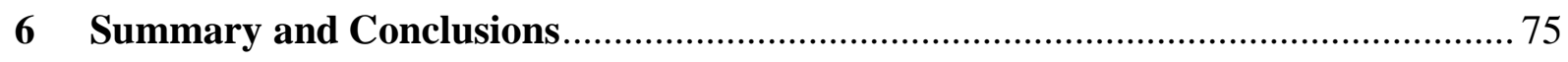

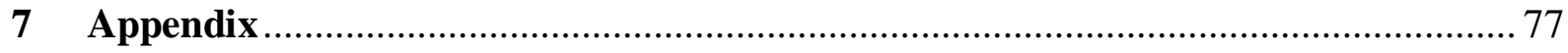

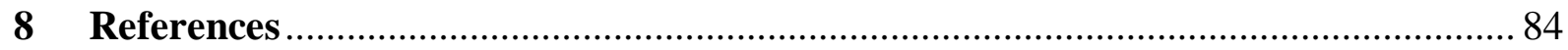




\section{ACKNOWLEDGEMENTS}

Although it is not the traditional way, I want to first of all, thank God. He knows why.

Even though I could have restricted my acknowledgements to thanking three little moles digging in the garden, I feel very grateful to many people and would like to take this chance to thank them.

First of all, I want to thank my supervisor and mentor Professor Matthias Dobbelstein, for his scientific, but also personal, support and advice. He has always encouraged my initiatives and ideas, and through our very helpful discussions I have learned a lot about the exciting field of cancer research. His guidance and will to help were critical for the fulfillment of this work, and I will always be grateful for his contribution in turning a student into a scientist.

I greatly appreciate the advice and guidance of my internal committee members, Professors Andreas Wodarz and Herbert Jäckle. I would like to thank them both very much, not only for taking the time to regularly monitor and discuss the progress of this work, but also for their genuine interest and encouragement.

I can only hope that my further steps will bring me into a working environment as wonderful as the department of Molecular Oncology in Göttingen, although I fear that I can nowhere else meet, and work with, such great people. Despite my fears when coming to Germany, they accepted me and taught me that the people of this country can be very genuine, funny, honest, supportive and warm, and I feel very lucky to have them as colleagues and friends. I would like to especially thank my younger clone Franziska Schmidt for creating the pIRES-Dusp18-HA clone and for the Dusp18 localization and NPM studies presented in this work. Additionally, I am grateful to Monika Bug and Magda Morawska for kindly contributing material used in this study.

My life in Göttingen would have been much more difficult without the Molecular Biology program, and I am especially grateful to Steffen, Kerstin and Ivana for all their help and support during my time here.

I have shared the best moments of the past 5 years with many lovely and just-weirdenough-to-like-me people, so here I d like to thank: Adema, Ieva, Kathy and Mara for 3+ wonderful years of living together, Martina, for sharing the thesis-writing time and a large glass of Nutella with me, Christoph, for saving the work of ten days and for making me happy, and Achim and Andrew, for proof-reading, and for being especially fun-tional friends.

My family has given me everything a family can give; I am forever grateful to my parents and my brother for their love and support, and for always being there for me in happy and difficult times, despite the geographical distance.

I acknowledge here the financial support of this work by a Lichtenberg Stipend (Molecular Biology program), a GGNB stipend (GGNB) and a DFG Stipend (Graduiertenkollegs 1034). 


\section{AbSTract}

The cellular genome is constantly exposed to harmful endogenous and exogenous factors. Unrepaired DNA lesions and mismatches promote genomic instability, a major cause of cancer. Therefore, the prompt recognition and repair of damaged DNA, and the senescence or elimination of cells with persistent damage, are crucial to preserve genomic stability and suppress transformation. These processes depend on a cascade of phosphorylations known as the DNA damage response. The phosphorylation of histone H2Ax on Ser139 is one of the earliest events upon activation of the cascade, and the phosphorylated histone, $\gamma \mathrm{H} 2 \mathrm{Ax}$, serves as a marker of the damaged chromatin areas. Several kinases initiate the signal from the sites of the damage and transduce it to effector proteins, such as the tumor suppressor p53. The activation of p53 induces cell cycle arrest via the increased transcription of the Cdk inhibitor $\mathrm{p} 21$, and it promotes apoptosis mainly via the transcription of proapoptotic genes. The balance of phosphorylated versus unphosphorylated proteins regulate most of the known steps in the DNA damage response. Thus phosphatases are expected to act as modulators of this cascade; however, our knowledge regarding their precise role is very limited.

To identify novel phosphatases that modulate the response to genotoxic stress, a highthroughput screen was performed using an siRNA library targeting the human phosphatase subunits. UVC irradiation was used to induce DNA damage in siRNA-transfected U2OS cells, an osteosarcoma-derived cell line with wild-type p53. The levels of p53 and $\gamma \mathrm{H} 2 \mathrm{Ax}$ were quantified by immunofluorescence in cells previously exposed or non-exposed to UVC irradiation. In this way, 39 phosphatase subunits were identified as potential regulators of the early DNA damage response and the tumor suppressor p53. Among them, the dual specificity phosphatase 18 (Dusp18) was a prominent negative regulator of $\mathrm{p} 53$. The depletion of Dusp18 induced the accumulation and activation of p53 and p21 in several cell lines. Dusp18 knockdown did not detectably increase the post-translational modifications of p53, nor did it abolish its interaction with its negative regulator Mdm2. The induction of p21 was p53dependent, and chromatin immunoprecipitation showed an increased amount of p53 bound to the $p 21$ promoter in cells transfected with siRNAs against Dusp18. Interestingly, Dusp18 depletion alone could induce apoptosis that was not dependent on p53, but was augmented in cells with wild-type p53. In addition, it promoted the activation of the DNA damage response cascade, as detected by the enhanced phosphorylation of Chk2 and H2Ax. Analysis of the cell cycle profile of Dusp18-depleted cells revealed an arrest in G1 and S phases, which was accompanied by reduced proliferation of these cells. Finally, the siRNAs against Dusp18 increased the sensitivity of tumor cells to the $\mathrm{S}$ phase specific genotoxic drug gemcitabine. 
Hence, the depletion of Dusp18 inhibits the proliferation and promotes the apoptotic death of tumor cells. Furthermore, the knockdown of Dusp18 can enhance the cytotoxic effect of therapeutic drugs like gemcitabine. These results identify Dusp18 as a novel phosphatase needed for the survival and proliferation of cancer cells, and as a suppressor of the DNA damage response and the p53 pathway, potentially identifying Dusp18 as a cancer drug candidate. 


\section{LIST OF FigureS}

Figure 1-1 : The domains of human p53 and Mdm2. ......................................................... 1

Figure 1-2 : The p53 - Mdm2 - p14ARF network................................................................... 3

Figure 1-3 : Some promoter selection mechanisms for differential activation of p53 target

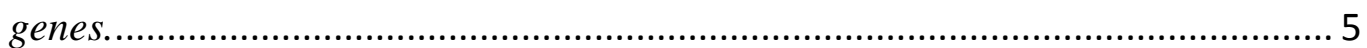

Figure 1-4 : The DNA damage response cascade. ............................................................. 6

Figure 1-5 : Examples of kinases involved in DNA damage response and cancer

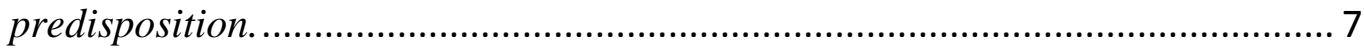

Figure 1-6 : A simplified view of the MAP kinase signaling pathways. .................................. 9

Figure 1-7 : The activation of the DNA damage response cascade leads to the arrest of the

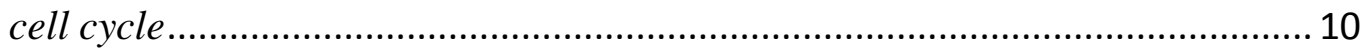

Figure 1-8 : The different phosphatase families................................................................... 12

Figure 1-9 : Several MKPs are misregulated in different forms of cancer. ........................... 13

Figure 1-10: The structure of human Dusp 18. ................................................................. 14

Figure 4-1 : Immunofluorescence detection of $p 53$ and $\gamma H 2 A x$ in UVC-exposed U2OS cells.40

Figure 4-2 : Human phosphatase siRNA library screen selected results. 42

Figure 4-3 : Groups of phosphatases identified and further evaluated as potential regulators of DNA damage- and p53-response.

Figure 4-4 : Validation of selected screen targets by immunoblotting................................... 44

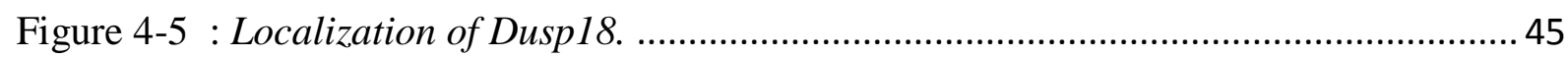

Figure 4-6 : Alignment of Human and Murine Dusp18 proteins and MitoProt mitochondrial

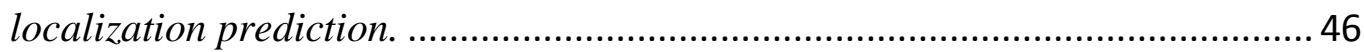

Figure 4-7 : Knockdown efficiency of Dusp18 siRNAs. ..................................................... 47

Figure 4-8 : Induction of 553 and p21 upon Dusp18 depletion in different cell lines. ........... 48

Figure 4-9 : p53 modification upon Dusp18 knockdown. ................................................ 50

Figure 4-10: Co-immunoprecipitation of p53 and Mdm2 after Dusp18 knockdown. .............. 51

Figure 4-11: p21 mRNA levels after Dusp18 knockdown. .................................................. 52

Figure 4-12: Binding of p53 on p21 promoter upon Dusp18 knockdown............................. 53

Figure 4-13: Combined knockdown of Dusp18 and SP1 in HCT116 p53 +/+ cells............... 54

Figure 4-14: Apoptosis detection in HCT116 cells after Dusp18 knockdown. ....................... 55

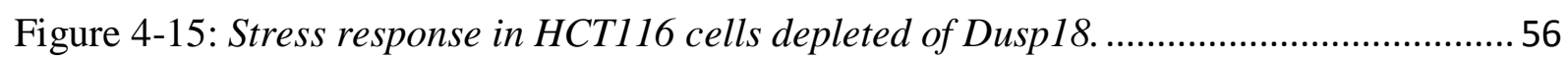

Figure 4-16: Nucleophosmin localization in U2OS cells depleted of Dusp18........................ 57

Figure 4-17: Cell cycle distribution of HCT116 p53 +/+ cells depleted of Dusp18................ 58

Figure 4-18: Cell cycle distribution of U2OS (wt p53) cells depleted of Dusp18................... 58

Figure 4-19: Cell cycle distribution of U2OS (wt p53) cells depleted of Dusp18 (ModFit

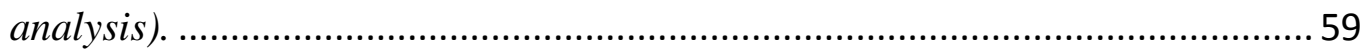

Figure 4-20: Cell cycle distribution of HCT116 p53 -/- cells depleted of Dusp18. ................. 59

Figure 4-21: Proliferation of HCT116 cells depleted of Dusp18 ........................................... 60

Figure 4-22: Cell cycle distribution of HCT116 p53 +/+ cells depleted of Dusp18 and trapped in G2/M with Nocodazole (ModFit analysis)..................................................... 62

Figure 4-23: Cell cycle distribution of U2OS cells depleted of Dusp18 and trapped in G2/M

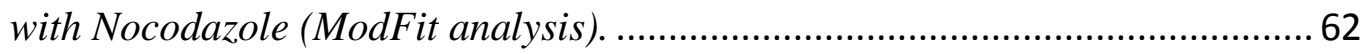


Figure 4-24: Cell cycle distribution of HCT116 p53 +/+ and U2OS cells depleted of Dusp18 trapped in $G 2$ with Nocodazole.

Figure 4-25: $\gamma H 2 A x$ in HCT116 p53 +/+ cells depleted of Dusp18 after treatment with gemcitabine. 64

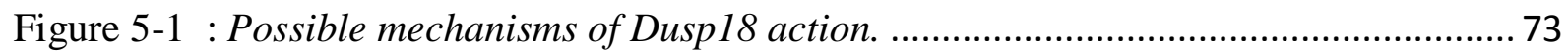

Figure 7-1 : Human phosphatase siRNA library screen results........................................... 78

Figure 7-2 : Validation of selected screen results using immunofluorescence. ...................... 79

Figure 7-3 : Mdm2 protein levels in cells depleted of Dusp 18........................................... 80

Figure 7-4 : Binding of SP1 and RNA pol II along the p21 gene upon Dusp18 knockdown. . 81

Figure 7-5 : Cell cycle distribution of HCT116 p53 +/+ cells depleted of Dusp18................ 82

Figure 7-6 : Proliferation of HCT116 cells depleted of Dusp18.......................................... 82

Figure 7-7 : Proliferation of HCT116 p21 -/- cells depleted of Dusp18............................... 83

\section{LIST OF TABLES}

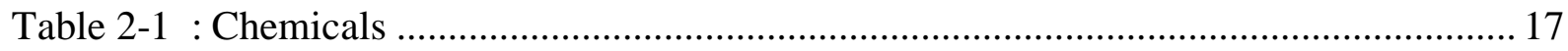

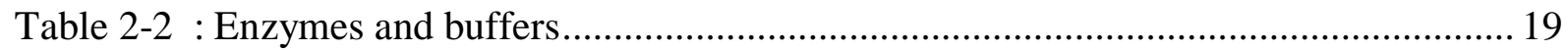

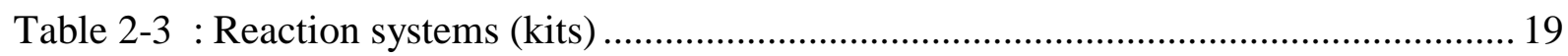

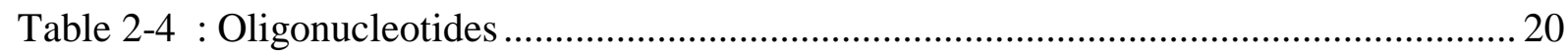

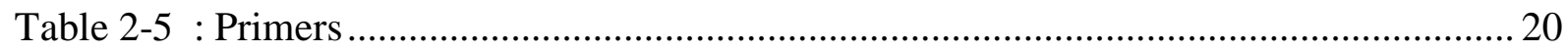

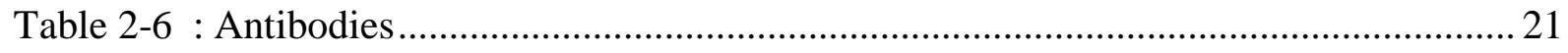

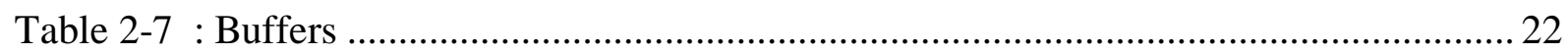

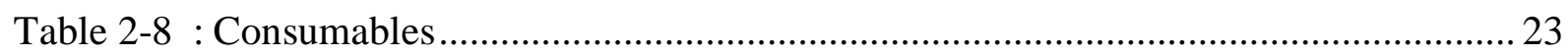

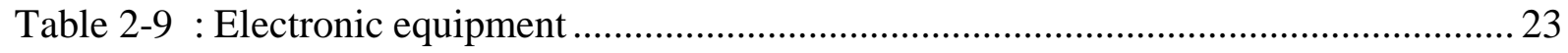

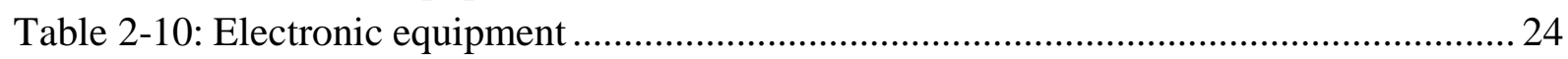

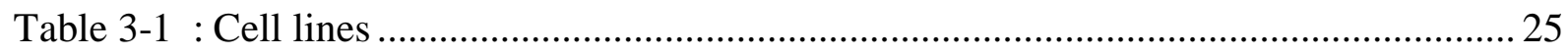

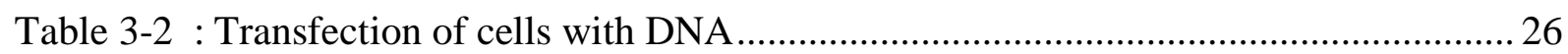

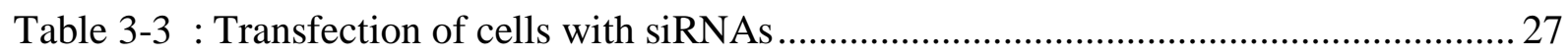

Table 3-4 : Reaction setup for the PCR amplification of Dusp18 ......................................... 28

Table 3-5 : Cycling conditions for the PCR amplification of Dusp18 I ............................... 29

Table 3-6 : Setup of the restriction digestion reaction of the Dusp18 PCR product I............ 29

Table 3-7 : Setup of the restriction digestion reaction of the pCGN-HA-E1B plasmid ......... 29

Table 3-8 : Setup of the ligation reaction of Dusp18 in pCGN............................................ 30

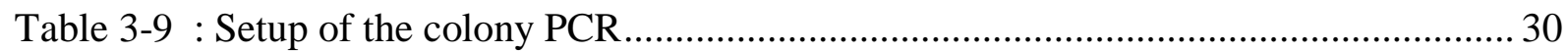

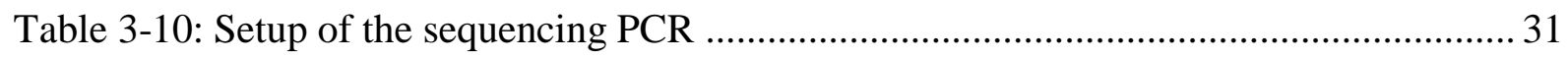

Table 3-11: Reaction setup for the PCR amplification of Dusp18 II .................................. 31

Table 3-12: Setup of the restriction digestion reaction for the cloning of Dusp18 in pIRES .. 31

Table 3-13: Setup of the ligation reaction of Dusp18 in pIRES ............................................ 32

Table 3-14: Reaction setup for cDNA synthesis from total RNA part I ................................. 32

Table 3-15: Reaction setup for cDNA synthesis from total RNA part II............................... 33

Table 3-16: Preparation of home-made 10x PCR mix .......................................................... 33

Table 3-17: Preparation of home-made qPCR Mastermix ....................................................... 33

Table 3-18: Preparation of the final primer-specific qPCR mastermix................................... 34

Table 3-19: SDS-polyacrylamide gel preparation for protein electrophoresis......................... 35 viii 


\section{Abbreviations}

Ac-

Acetyl-

APS

Ammonium persulfate

ARF

Alternative Reading Frame

ARF-BP1

ARF- binding protein 1

ATM

Ataxia Telangiectasia Mutated

ATR

BAK

BAX

BRCA

BSA

buff.

buffer

CDC

$\mathrm{Cdk}$

CDKN1A

cDNA

CDS

ChIP

Chk

CIP

CK

CMV

CoIP

COP-1

DBD

DMEM

DMSO

DNA

DNA-PK

dNTPs

DOC

Deoxycholate

DTT

Dithiothreitol

Dusp

E2F1

EDTA

ERK

Dulbecco's Modified Eagle Medium

Dimethyl sulfoxide

Deoxyribonucleic acid

DNA-dependent protein kinase

deoxyribonucleotides

Dual specificity phosphatase

E2 transcription factor 1

Ethylene-Diamine-Tetra-Acetate

Extracellular signal-Regulated Kinase 
New England Biolabs 
WAF1

WB

WIP

XPC

YT wild-type p53-Activated Fragment 1

Western Blot

Wild-type p53-Inducible Phosphatase Xeroderma Pigmentosum C

Yeast extract-Tryptone

Note: genes names are mentioned in italics; protein names start with a capital letter. 


\section{INTRODUCTION}

\subsection{The p53 network}

\subsubsection{The tumor suppressor $\mathrm{p} 53$}

P53 is a tumor suppressor that has rightly been named the "guardian of the genome" (Lane, 1992). It is mutated in more than $50 \%$ of all human cancers, and its function is indirectly impaired in most of the remaining cases (Hainaut and Hollstein, 2000; Vogelstein et al., 2000; Levine et al., 1991). The structure of the p53 protein is depicted in Figure 1-1. Many functions of p53 depend on its N-terminal transcription domain, which interacts with the transcriptional machinery to activate the expression of its target genes. The central DNA binding domain of p53 is of critical importance, as demonstrated by the vast majority (80\%) of p53 inactivating mutations restricted to this area. An oligomerization domain follows the p53 nuclear localization signal and is needed for the tetramerization of p53, which is required for optimal DNA binding (McLure and Lee, 1998). Finally the last 30 amino acids of p53 form a regulatory domain.

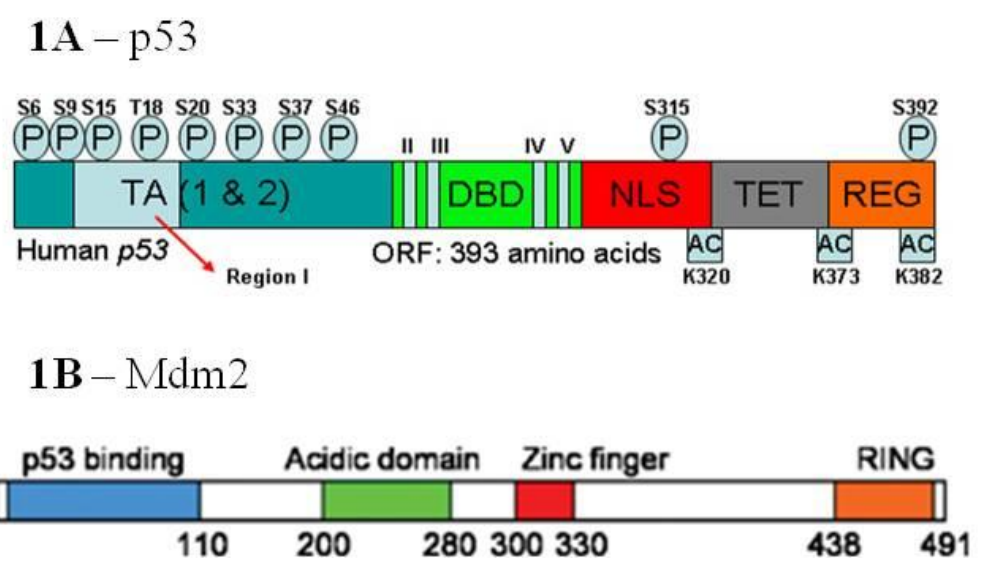

Figure 1-1: The domains of human $p 53$ and Mdm2.

1A: Protein domains and post-translational modifications of human P53.

TA: transcriptional activation domain; DBD: DNA binding domain; NLS: nuclear localization signal; TET: tetramerization domain; $\boldsymbol{R E G : ~ n e g a t i v e ~ r e g u l a t i o n ~ d o m a i n ; ~} \boldsymbol{P}$ : phosphorylation; $\boldsymbol{A C}$ : acetylation. (modified from Villiard et al., 2007)

1B: Protein domains of human Mdm2.

RING: (Really Interesting New Gene) finger domain. (modified from Linke et al., 2008) 


\subsubsection{Regulation of p53}

The activation of p53 in a cell induces 3 main physiological events: DNA repair, cell cycle arrest and/or senescence, and apoptosis. In a healthy cellular environment, p53 is kept inactive and at low levels through constant targeting for proteasomal degradation by its main ubiquitin E3 ligase, Mdm2 (mouse double minute 2) (Haupt et al., 1997; Kubbutat et al., 1997). Mdm2 is not the only ubiquitin ligase for p53 (several others have been identified, namely COP-1 (Dornan et al., 2004), Pirh2 (Leng et al.,2003), ARF-BP1 (Chen et al., 2005) and Synoviolin (Yamasaki et al., 2007)), but mouse $m d m 2-/-$ models have revealed that Mdm2 is necessary and sufficient to suppress p53 function (Jones et al., 1995; Montes de Oca Luna et al., 1995; de Rozieres S et al., 2000). The structure of p53 is presented in Figure 1-1. Mdm2 has an N-terminal p53 binding domain, a central acidic domain (which contains residues that are post-translationally modified to regulate its function) and a C-terminal RING domain necessary for the E3-ligase function. Not only does Mdm2 mark p53 for degradation, but Mdm2 binding also conceals the region of p53 that interacts with the transcriptional machinery (conserved region I, N-terminus, Figure 1-1), thereby suppressing the transcriptional activity of p53. Furthermore, Mdm2 binding induces the nuclear export of p53. P53 and Mdm2 form a negative feedback loop in the p53 network, since p53 induces the transcription of the $m d m 2$ gene (Barak et al., 1993). Hence the activation and accumulation of p53 requires the initial impairment of its interaction with Mdm2, but shortly after activation an increase in Mdm2 levels can quench the p53 activity.

The tumor suppressor p14ARF (p14 Alternative Reading Frame; ARF) plays an important role in impairing the function of Mdm2 upon oncogenic stress (Figure 1-2). ARF forms nuclear bodies with Mdm2 and p53 and inhibits their nuclear export, while inhibiting the ubiquitination of $\mathrm{p} 53$ and promoting Mdm2 degradation (Zhang et al., 1998). ARF is localized in the nucleolus in unstressed normal and tumor cells, where the nucleolar protein nucleophosmine (NPM) stabilizes it but also prevents it from binding Mdm2 and p53. DNA damage or other kinds of stress induce the relocalization of NPM and ARF from the nucleoli to the nucleoplasm, where ARF can inhibit Mdm2 and induce p53. The knockout of NPM in mice is embryonic lethal, due to wide-spread DNA damage, p53 activation and apoptosis (Colombo et al., 2005). In cells derived from these mice, ARF is no longer localized in the nucleoli and is instead dispersed in the nucleoplasm. The action of p14ARF in inducing the activation of p53 is associated with an increase in apoptosis rather than other p53 functions such as cell cycle arrest. However, ARF also prevents the overgrowth and excessive proliferation of cells, as it can be activated by aberrant function of E2F1 to form a negative 
feedback loop that inhibits the proliferative but not the pro-apoptotic function of E2F1 (Eymin et al., 2001; Mason et al., 2002; Rizos et al., 2007).

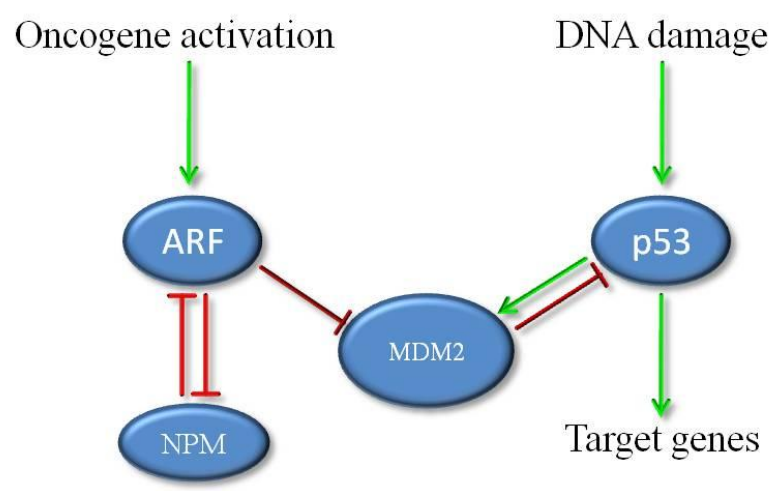

Figure 1-2: The p53 - Mdm2 - p14ARF network.

Activation of ARF by oncogenic stress inhibits Mdm2-mediated p53 degradation and thus induces cell cycle arrest and apoptosis.

\subsubsection{Post-translational modifications of $\mathrm{p} 53$}

The de-repression of $\mathrm{p} 53$ by Mdm2 upon cellular stress has been proposed to be vital for the appropriate activation of the p53 pathway (Kruse \& Gu, 2009). According to the classical model of p53 activation, the post-translational modification of both p53 and Mdm2 contributes to the disruption of their interaction and/or the impairment of Mdm2 E3 ligase function towards p53, allowing the accumulation and activation of the latter. The N-terminus of p53 containing the Mdm2 binding domain is shown to be phosphorylated in vitro by many stress-activated kinases. In particular the serine residues at the positions 6, 9, 15, 20, 33, 37, 46 as well as the threonine 18 of the p53 protein have been postulated to constitute stressresponsive kinase phosphorylation sites (Figure 1-1). These amino acids have been shown to be in vitro phosphorylated under different conditions of cellular stress by kinases such as the PI3K-like family (ATM, ATR and DNA-PK), the checkpoint kinases Chk1 and Chk2, the casein kinases 1 and 2 (CK1, CK2), MAP kinases (JNK, p38) and HIPK2 (reviewed in Lakin \& Jackson, 1999). The majority, but not all of these phosphorylation events lead to the activation of p53. Furthermore, the C-terminus of p53 is also subject to phosphorylation and other modifications, such as acetylation (reviewed in Lakin \& Jackson, 1999). Finally, similar modifications occur on the p53 antagonist Mdm2, and the two proteins can be phosphorylated by the same kinase with an opposite consequence on their function (Shinozaki et al., 2003; Cheng et al., 2009).

For example, the phosphorylation of p53 on Ser15 by ATM and ATR is known to inhibit Mdm2 binding in vitro (Siliciano et al., 1997; Shieh et al., 1997), and mutational 
studies by Ashcroft et al. have demonstrated that this is a major phosphorylation site in cells (Ashcroft et al., 1999). The same authors and others have shown that individual phosphorylations are not sufficient for inhibiting the p53-Mdm2 interaction, nor are they necessary for the induction and transcriptional activity of p53 (Ashcroft et al., 1999; Blattner et al., 1999). Nevertheless, some combinations of these modifications have been associated with a more stable p53 polypeptide, particularly the combinatory phosphorylation of serines 15 and 37 (Ashcroft et al., 1999). Furthermore, the phosphorylation of p53 can increase its affinity for other activating factors (such as acetyl-transferases) and hence induce its modification on other sites of the protein, for instance its acetylation at the C-terminus of p53. This region of p53 exerts an inhibitory role on the sequence-specific DNA binding of p53, as shown by deletion experiments of the last 30 amino acids of $\mathrm{p} 53$, as well as by the induction of DNA binding by the monoclonal antibody pAb421 (which binds at the C-terminal region of p53) (Kaku et al., 2001; Sakaguchi et al., 1998). The acetylation of p53 in this domain is believed to relieve this inhibition and increase the affinity of p53 for its DNA target sequence. More specifically, the histone acetyl-transferases p300 and PCAF acetylate p53 at the lysines 382 (p53 C-terminal inhibitory domain) and 320 (nuclear localization signal) respectively, enhancing the sequence specific binding of p53 to the chromatin. These C-terminal acetylation events depend on the phosphorylation of the N-terminus of p53 (Lambert et al., 1998; Sakaguchi et al., 1998; Chao et al., 2003). Importantly, the acetylation of p53 at Lys382 by p300 has been shown to inhibit its ubiquitination by Mdm2 (Li et al., 2002).

\subsubsection{Functions of p53}

When the p53 protein is no longer efficiently targeted by Mdm2 for destruction, it accumulates in the nucleus and together with transcriptional co-factors can activate its target genes. Except for inhibiting the Mdm2 binding, post-translational modifications on p53 modulate its interaction with specific promoters, influencing the selectivity of its transcriptional activity. For instance, the phosphorylation of p53 Ser46 has been associated with the induction of proapoptotic target genes such as puma and noxa, and not proarresting genes like $p 21$ (Feng et al., 2006). In addition, different transcriptional cofactors can direct the p53 transactivation of genes that induce either apoptosis or cell cycle arrest, thus deciding the cell fate according to the extent of cellular damage (Figure 1-3). Under conditions of high stress, the interaction of p53 with the prolyl isomerase Pin1 is augmented, and Pin1-mediated isomerization of p53 proline residues favors the activation of proapoptotic genes (Das et al., 2008). On the other hand, the monoubiquitination of p53 on Lys320 competes with the acetylation of this residue by PCAF and promotes the activation of cell cycle arresting genes 
(Jentsch et al., 2009). The association of p53 with the hematopoietic zink finger protein (Hzf) also facilitates the survival of cells versus apoptosis (Das et al., 2008).

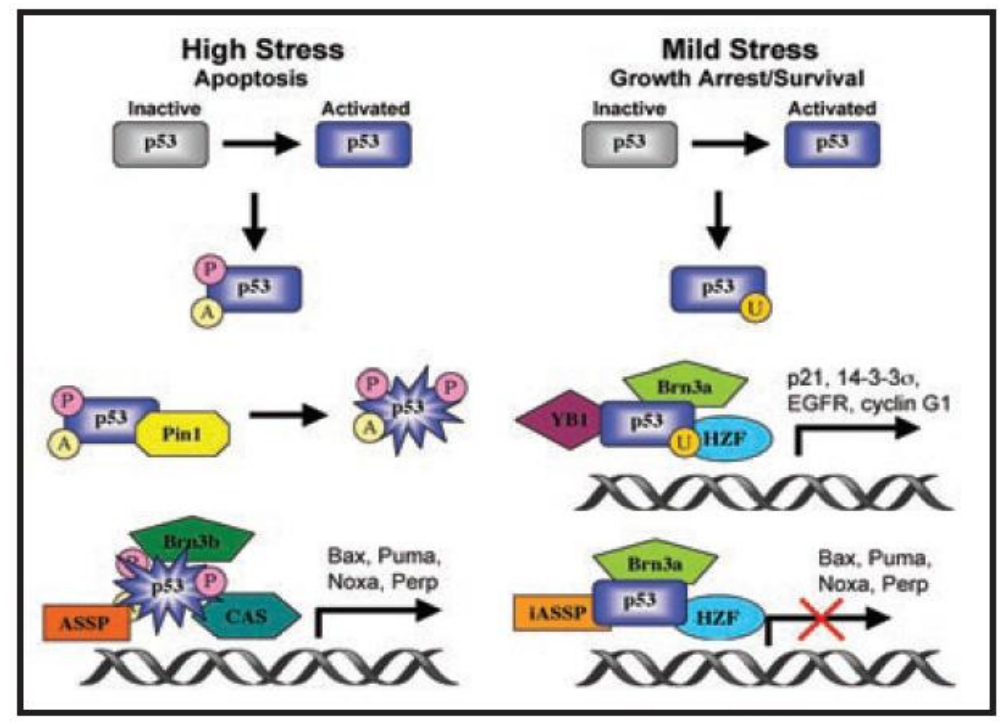

Figure 1-3: Some promoter selection mechanisms for differential activation of 553 target genes. The diverse modifications on $p 53$ and its binding to different co-activators direct the specificity of target gene expression (from Das et al., 2008).

Damaged DNA also constitutes a major signal for the activation of p53 by phosphorylation and acetylation following the induction of the DNA damage response cascade. The transcriptional targets of p53 thereafter accumulate to mediate cell cycle arrest or apoptosis. The cyclin-dependent kinase inhibitor p21 (also known as WAF1, CDKN1A and CIP1) is a principle p53 target gene. P21 binds and inhibits cyclins and cyclin-dependent kinases, thus inducing cell cycle arrest (Harper et al., 1993), and can also impair the function of PCNA, thereby hindering the synthesis of DNA (Bendjennat et al., 2003). Other factors have been implicated in the p53-dependent and/or p53-independent induction of the $p 21$ gene, like components of the mediator of transcription complex (Donner et al., 2007), transcription factors of the KLF family, such as KLF4 (Yoon et al., 2003), the ubiquitous transcription factor SP1 (Moustakas \& Kardassis, 1998), and histone modifying proteins such as HDACs (Gui et al., 2004). Interestingly, the transcriptional activity of some can also be regulated in response to DNA damage. Upon genotoxic stress and ATM activation, SP1 phosphorylation at Ser101 is greatly increased, promoting its binding to the chromatin (reviewed in Tan \& Khachigian, 2009). In addition to $p 21$, SP1 also collaborates with p53 in activating the transcription of the proapoptotic genes puma and bak (Koutsodontis \& Kardassis, 2004). As previously discussed, in highly stressed cells or cells with irreparable DNA damage the transcriptional activity of p53 induces the expression of proapoptotic genes (a few examples 
are puma, noxa, bax, bak and pig3). Apart from that, p53 plays a direct role in promoting the intrinsic apoptotic pathway by localizing to the mitochondria and inducing the permeabilization of their outer membrane (Moll et al., 2005).

\subsection{The DNA damage response}

Damage on the DNA occurs constantly in our cells by both endogenous and exogenous factors. The recognition and repair of the damaged DNA or the induction of cell death in case of irreparable damage is vital for the cell and for the whole organism, as persistent errors or breaks in the DNA lead to genomic instability, which is a leading cause of cancer initiation and progression. Several years of scientific research have revealed that the cellular response to damaged DNA is a cascade of phosphorylation events, which recognize, transduce and amplify the damage signal in the cell (Figure 1-4). There are at least two palpable advantages in this. First of all, phosphorylations allow for fast and efficient activation of the cascade, and, secondly, the reversibility of these modifications provides an easy and rapid way of quenching the signal.

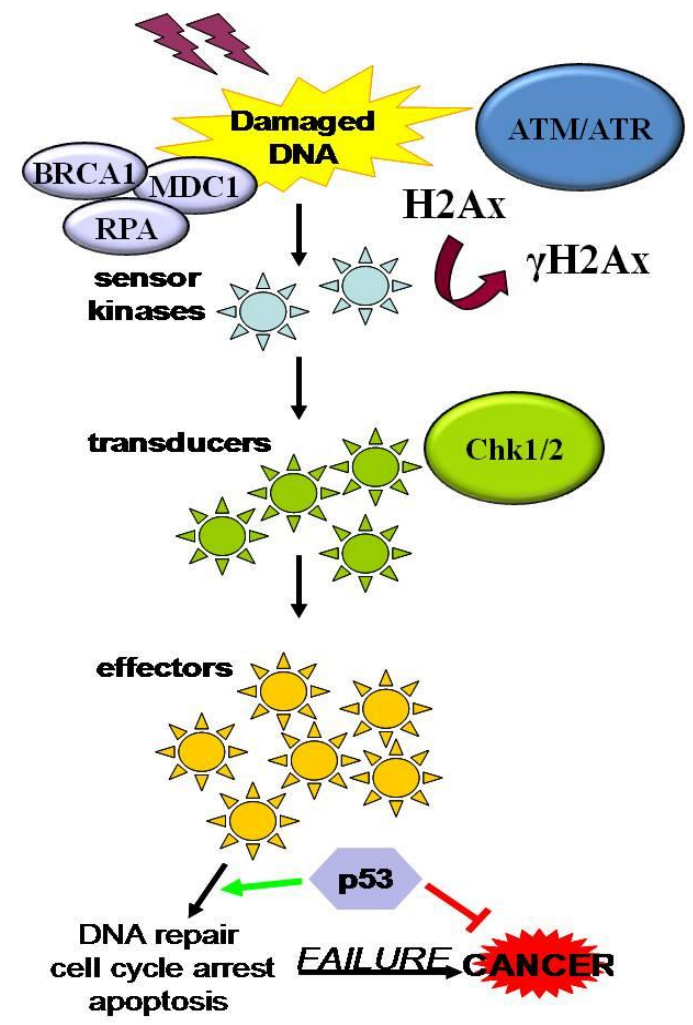

Figure 1-4: The DNA damage response cascade.

Large protein complexes are recruited at the sites of damaged DNA. The activation of the kinases ATM/ATR initiates the signal amplification and transduction. The phosphorylation of $\gamma H 2 A x$ is an early event of the cascade that marks the damaged chromatin. The activation of transducers such as the Chk1/2 kinases leads to the phosphorylation of several downstream effector proteins, including the tumor suppressor p53. P53 is critical for activating the cell cycle checkpoints and DNA repair, and for the induction of apoptotic death in case of severe damage. 


\subsubsection{The kinase cascade}

The human genome contains 518 confirmed and putative kinase encoding genes, of which approximately half are mapped at a chromosomal locus associated with cancer or another disease (Manning et al., 2002). Many kinases are known today to play a role in modulating the DNA damage response, and inactivating mutations in proteins-nodes in the cascade have been linked to genetic diseases associated with an increased risk for cancer development (reviewed in Kastan \& Bartek, 2004).

\begin{tabular}{l} 
Table 1 Human cancer susceptibility linked to DNA-damage response \\
\hline Disease
\end{tabular}

Figure 1-5: Examples of kinases involved in DNA damage response and cancer predisposition. (from Kastan \& Bartek, 2004)

One of the earliest events of the DNA damage response activation is the phosphorylation of the histone variant H2Ax on Ser139, termed $\gamma \mathrm{H} 2 \mathrm{Ax}$. Depending on the kind of genotoxic stress, this modification is performed directly on the chromatin by different kinases: ATM, ATR, DNA-PK and MAPKs (p38, JNK). In this way, $\gamma \mathrm{H} 2 \mathrm{Ax}$ marks the sites of damaged DNA (lesions or pyrimidine dimers), and extends approximately 2 megabases around them forming characteristic foci (Mah et al., 2010). The extent of $\mathrm{H} 2 \mathrm{Ax}$ phosphorylation depends on exogenous factors, such as the nature of the damaging source, and endogenous factors, such as the cell cycle phase in which a cell is found at the time of the exposure. Cells that are exposed to genotoxic stress while they replicate their DNA are more sensitive to the damage and show a more intense and wide-spread $\gamma \mathrm{H} 2 \mathrm{Ax}$ signal (Suzuki et $a l .$, 2006). Large protein complexes are recruited to the sites of DNA damage, initiating the response cascade and amplifying the signal. The replication associated proteins (RPAs), BRCA-1, MDC-1 and the MRN complex (MRE11, NBS1 and Rad50) are important components of these complexes that directly bind to the chromatin at the $\gamma \mathrm{H} 2 \mathrm{Ax}$ foci (reviewed in Kastan \& Bartek, 2004). Mutations in proteins-members of these complexes are also associated with the development of cancer (i.e. BRCA-1: breast cancer; NBS1: Nijmegen 
breakage syndrome, Figure 1-5). As these complexes remain on the chromosomal damage sites, other kinases play the role of transducing the signal from the foci to the nucleoplasm. The checkpoint kinases Chk-1 and Chk-2 are activated by ATM/ATR-dependent phosphorylation and diffuse from the $\gamma \mathrm{H} 2 \mathrm{Ax}$ foci to transduce the damage signal. Chk 1 and Chk2 play a prominent role in the arrest of the cell cycle, to facilitate the repair of damaged DNA or to remove cells with impaired chromosomes from the proliferating cell population. Both Chk kinases phosphorylate and thereby target for degradation the phosphatase CDC25, which is needed for mitotic onset (reviewed in Kastan \& Bartek, 2004). In addition, Chk1 inhibits the polo-like kinase 1 (plk1), which also regulates the entry and progression of mitosis (Lee et al., 2010). The activation of the tumor suppressor p53 as one of the final steps of the DNA damage response cascade is important for efficient cell cycle arrest and the induction of apoptosis in severely damaged cells. Notably, all the phosphorylation events occur in many different directions, and feedback loops are also formed, especially in the early events of the DNA damage response on the chromatin. Thus the response cascade does not form a pathway, but rather a network of kinases, where each connection can be also a regulation point by phosphatases.

Mitogen-Activated Protein Kinases (MAPKs) also regulate the response of cells to stress and to damaged DNA. The MAPKs are divided in 3 groups: the ERKs (Extracellular signaling Regulated Kinases), the JNKs/SAPKs (c-Jun-N-terminal Kinases/ Stress Activated Protein Kinases) and the p38 kinases (protein $38 \mathrm{kDa}$ ) (for the respective pathways, see Figure 1-6). Of these, the ERK kinases are responsive to extracellular signals such as growth factors, while JNK and p38 are activated upon cellular stress. MAPKs have a T-X-Y motif (where $\mathrm{X}$ is any amino acid) in their activation loop, and both the tyrosine and the threonine residue need to be phosphorylated to activate the enzyme (Torres, 2003). Therefore dephosphorylation of either of these amino acids will inactivate the kinase. Cytotoxic and genotoxic drugs, UV irradiation and other kinds of stress lead to JNK and p38 signaling activation, which is enhanced if the exposed cells are actively proliferating (Damrot et al., 2008). For example, both JNK and p38 become phosphorylated within a few minutes after exposure of cells to UV irradiation, in an ATR- and XPC (Xeroderma Pigmentosum C)dependent manner (Damrot et al., 2008). The induction of these pathways promotes the apoptosis of cells with damaged DNA (Damrot et al., 2008), at least in part due to the interaction of $\mathrm{JNK}$ and p38 with p53, which results in the phosphorylation of the latter at Ser15 and Ser33 (Milne, 1995; Hu et al., 1997; Sanchez-Prieto et al., 2000; Kim et al., 2002; Lafarga et al., 2009). 


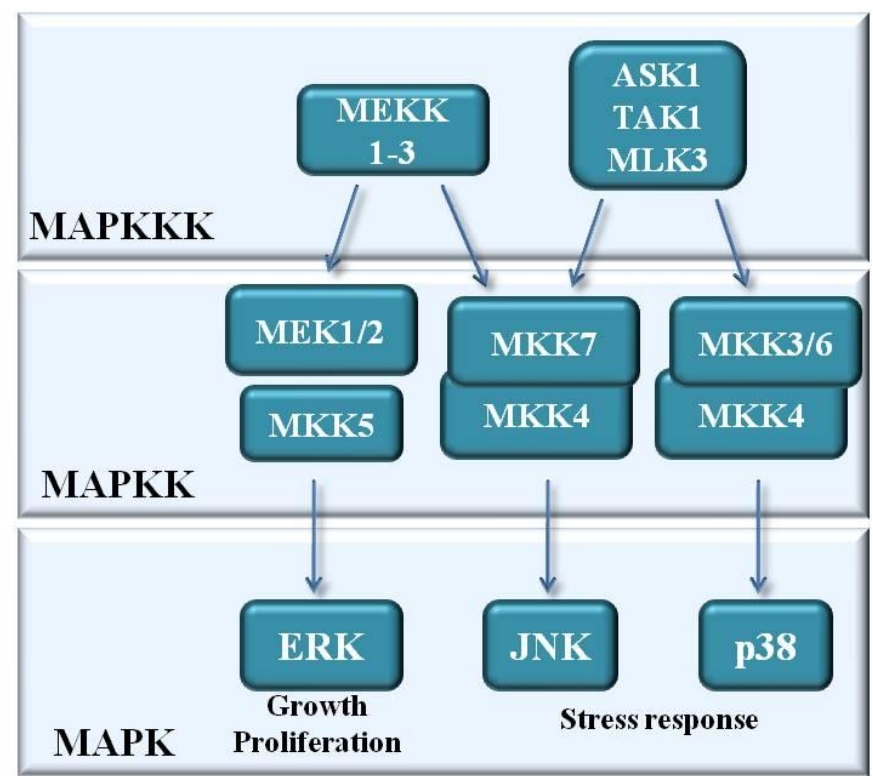

Figure 1-6: A simplified view of the MAP kinase signaling pathways. A MAPK pathway consists of a MAPK-kinase-kinase (MAPKKK), a MAPK-kinase (MAPKK) and a MAP kinase (MAPK). Each kinase phosphorylates its downstream kinase-target to activate it. The 3 branches are the ERK, the JNK and the p38 MAPK pathways.

\subsubsection{The cell cycle checkpoints}

The cellular growth and division requires many different mechanisms and pathways in the cell working together in a well-coordinated orchestra. The proper and error-free completion of certain processes, such as genomic replication and mitosis, before progressing to the next phase of the cell cycle, is necessary to ensure the viability of the cell and maintenance of genomic stability in the daughter cells. Upon genotoxic stress, it is vital for the cell to slow down or even stop the progression of the cell cycle, to acquire the time to correct the damage or permanently arrest a potentially harmful and unstable proliferation. Several checkpoints that can be activated at different phases of the cell cycle provide the mechanisms the cell needs to monitor and control the cell cycle progression.

In the beginning of the cell cycle, the G1 or G1 to S phase checkpoint can be activated by the action of ATM/ATR and subsequent induction of the Chk1 and Chk2 kinases, as well as the p53 pathway. The ATR-Chk1 branch has been suggested to play a permanent safeguard role in the $\mathrm{G} 1$ to $\mathrm{S}$ transition, by controlling the protein levels of CDC25A. CDC25A is a key phosphatase of the cell cycle whose action is needed to start DNA replication. ATR/Chk1 constantly phosphorylate a population of CDC25A and target it for degradation, and activation of the ATR/Chk1 pathway by DNA damage provides a fast mechanism of arresting the cell both in G1 and in S phase. This cell cycle arrest lasts only for a few hours and can be bypassed unless the p53 pathway is additionally induced. P53 and Mdm2 phosphorylation by 
ATM, ATR, Chk1 and Chk2 has opposite effects on their function, leading to accumulation and activation of $\mathrm{p} 53$. The induction of p21 by p53 can have a prolonged inhibitory effect on the progression of the cell cycle (Figure 1-7, reviewed in Kastan \& Bartek, 2004).

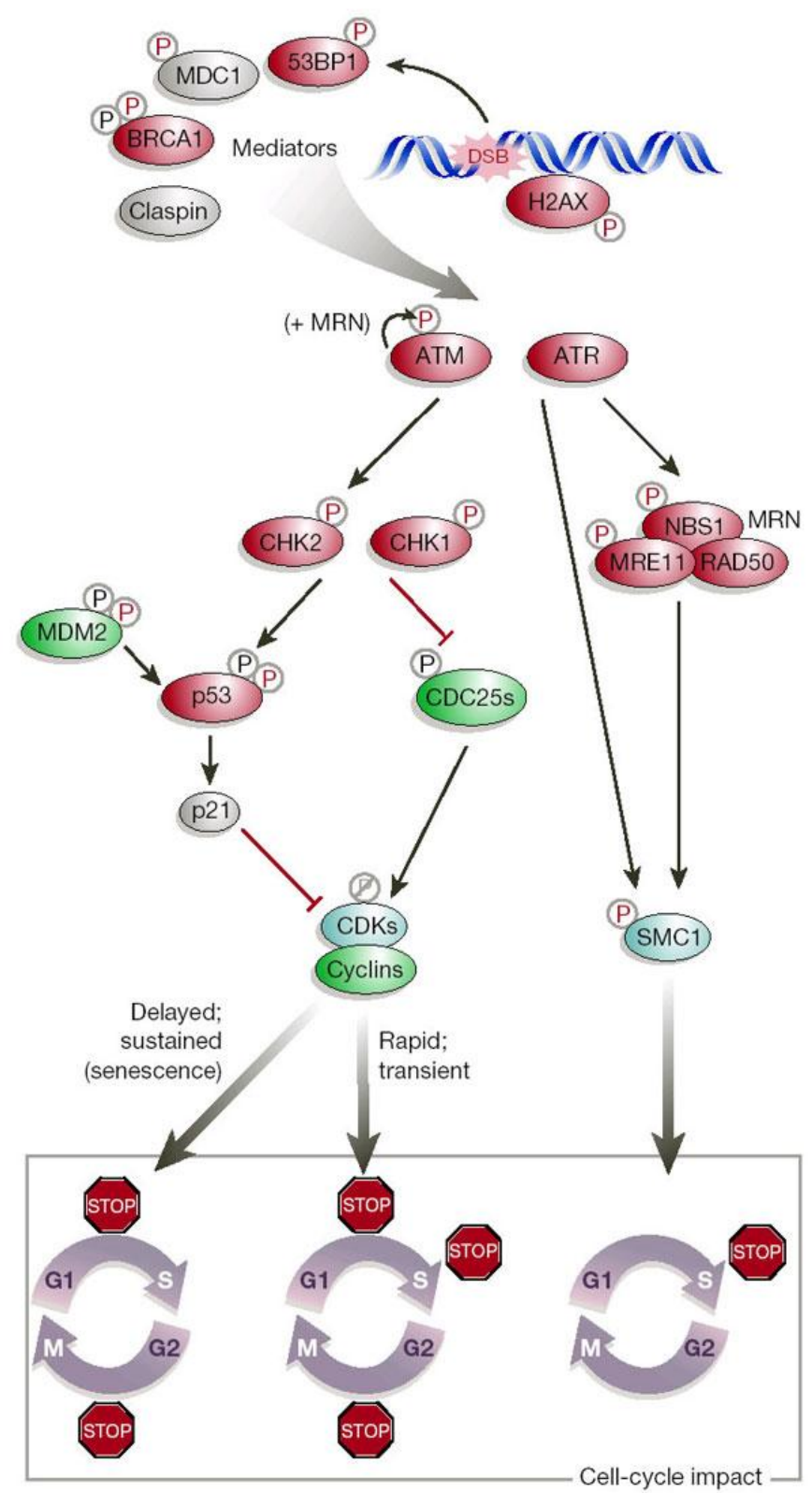

Figure 1-7: The activation of the DNA damage response cascade leads to the arrest of the cell cycle. The phosphorylation of H2Ax at sites of DNA damage recruits large protein complexes on the chromatin, and initiates the transduction of the damage signal via a phosphorylation cascade. The inhibition of CDC25 stalls the progression of the cell cycle, and activation of the p53 pathway can prolong and sustain the arrest in G1, S or G2 phase. P53-independent mechanisms can induce a G2 arrest (from Kastan \& Bartek, 2004).

If the DNA damage occurs when a cell has already started the genomic replication, the $\mathrm{S}$ phase checkpoint mechanisms prevent further replication origin firing, and stabilize the 
stalled replication forks to minimize the generation of DNA breaks. The ATR/Chk1/CDC25A pathway is induced in S phase in a similar way as in the G1 to prevent replication initiation. In addition, other mechanisms that involve the activation of ATM and subsequent phosphorylation of NBS1 and SMC1, as well as the inhibition of Cdk2 stop the progression of DNA replication. Another pathway involving the inhibition of $\mathrm{Cdc7}$, a kinase needed for replication initiation, through the activation of ATR also plays a role in the induction of an $\mathrm{S}$ phase arrest upon DNA damage (Costanzo et al., 2003).

The final control step before a cell starts its mitotic division is the G2 or G2/M checkpoint. The inhibition of $\mathrm{Cdk} 1 /$ cyclin B complex is the main target of different pathways involved in arresting the cells at the borders of $\mathrm{G} 2$ and $\mathrm{M}$ phases, such as ATM/ATR/Chk1/Chk2 pathways, p38 and p53/p21 activation, as well as the inhibition of CDC25C or its activator plk1. Other proteins like BRCA1 and 53BP1 (53 binding protein 1) are also involved in the induction of a G2/M arrest (Wang et al., 2002; Lou \& Chen, 2003). Interestingly, tumor cells with defective earlier checkpoints, such as cells without functional p53, tend to arrest in G2/M upon DNA damage, indicating that p53-independent pathways are sufficient to maintain this arrest (Kastan \& Bartek, 2004).

\subsection{Human phosphatases}

The human proteome contains many more kinases than known phosphatases. In addition, unlike the kinases, whose specificity is largely provided by structural differences in their catalytic domains, phosphatases often have similar structures in their active centers. These arguments led to the misconception that phosphatases might show a lower specificity towards their substrates than the respective kinases, which was in many cases in agreement with in vitro phosphatase assays data. The identification of all phosphatase encoding genes and in vivo experiments revealed that in fact the substrate specificity is often defined by interaction of the catalytic subunit with a variety of regulatory subunits. The regulatory subunits can direct the interaction of the catalytic subunit with its target, affect the localization of the phosphatase complex in specific cellular compartments or inhibit its activity. For example, the protein phosphatase 1 (PP1) is a protein complex consisting of the catalytic subunit PP1c and one or more of its more than 50 different regulatory subunits (Cohen, 2002). Other phosphatases do not form complexes and other mechanisms define their targeting, such as unique structures around their catalytic center, as is the case for many dual specificity phosphatases. However, the function and substrate specificity of most human phosphatases is completely unknown. 
Phosphatases are grouped into families according to their mode of catalysis. The phosphatase families are listed in Figure 1-8.

\begin{tabular}{|c|c|c|c|c|}
\hline Family & Class & $\begin{array}{l}\text { Number of } \\
\text { genes }\end{array}$ & Regulatory subunits & $\begin{array}{l}\text { Example of function } \\
\text { and/or (substrate) }\end{array}$ \\
\hline \multicolumn{5}{|c|}{ Ser/Thr phosphatases } \\
\hline \multirow[t]{7}{*}{ PPP family } & PP1 & 3 & $>90$ (e.g., Repo-Man) & Chromosome condensation \\
\hline & PP2A & 2 & $A, B^{\ddagger}, e^{-c^{5}}$ & Chromatid cohesion \\
\hline & PP4 & 1 & $\mathrm{R} 1, \mathrm{R} 2, \mathrm{R} 3 \alpha / \beta$, etc.' & DNA repair $(\gamma-\mathrm{H} 2 \mathrm{AX})$ \\
\hline & PP5 & 1 & None & Cellular stress \\
\hline & PP6 & 1 & SAP1-3, etc. $\pi$ & NFкB pathway \\
\hline & $\mathrm{PP} 2 \mathrm{~B}$ & 3 & Regulatory B, CaM & Immune response (NFAT) \\
\hline & PP7 & 2 & Unknown & \\
\hline PPM family & $\mathrm{PP} 2 \mathrm{C}$ & 18 & None & TGF $\beta$ signalling (SMADs) \\
\hline \multicolumn{5}{|c|}{ PTP superfamily $\left(C X_{5} R\right)$} \\
\hline \multirow{2}{*}{$\begin{array}{l}\text { Class I PTPs } \\
\text { (classic }^{\star} \text { ) }\end{array}$} & Receptor PTP & 21 & & Cell adhesion/cytoskeletal \\
\hline & Non-receptor PTP & 17 & & Insulin signalling (insulin receptor) \\
\hline \multirow{7}{*}{$\begin{array}{l}\text { Class I PTPs } \\
\text { (DSPs) }\end{array}$} & MAPKP & 11 & & MAPK signalling (MAPK) \\
\hline & Slingshots & 3 & & Actin dynamics (cofilin) \\
\hline & PRLs & 3 & & Unknown \\
\hline & Atypical DSP & 19 & & Mostly unknown (mRNA) \\
\hline & $\mathrm{CDC} 14$ & 4 & & Cytokinesis, mitotic exit \\
\hline & PTEN & 5 & & $\mathrm{PIP}_{3}$ phosphatase \\
\hline & Myotubularins & 16 & & $\begin{array}{l}\text { Ptdlns } 3 \mathrm{P}, \text { Ptdlns }(3,5) \mathrm{P}_{2} \\
\text { phosphatase }\end{array}$ \\
\hline Class II PTPs & CDC25s & 3 & & Promotes mitosis (CDKs) \\
\hline Class III PTPs & LMWPTP & 1 & & Unknown \\
\hline \multicolumn{5}{|c|}{ Asp-based catalysis (DXDXT/V) } \\
\hline \multirow{3}{*}{$\begin{array}{l}\mathrm{FCP} / \mathrm{SCP} \\
\text { family }\end{array}$} & FCP1 & 1 & RAP74 of TFIIF & Transcription (Pol II) \\
\hline & $\mathrm{SCP}$ & 3 & & TGF $\beta$ signalling (SMADs) \\
\hline & FCP/SCP-like ${ }^{\star \star}$ & 4 & & Unknown \\
\hline HAD family & & $5^{\# \#}$ & & Actin dynamics (cofilin) \\
\hline
\end{tabular}

Figure 1-8: The different phosphatase families. (from Moorhead et al., 2007)

\subsubsection{Dual Specificity Phosphatases}

The dual specificity phosphatases belong to the superfamily of protein tyrosine phosphatases (PTPs), which are distinguished by their catalytic motif $\mathrm{CX}_{5} \mathrm{R}$, where $\mathrm{X}$ is any amino acid and the cysteine is the catalytic amino acid (Moorhead et al., 2007). The name "dual specificity" originates from their ability to dephosphorylate both tyrosine and serine/threonine residues, although most of them show a preference for one of the two amino acids in in vitro assays. Members of the DUSP family are known to play regulatory roles in diverse signaling pathways in the cell, and thus modulate cell division (CDC14), cytoskeleton dynamics (slingshot phosphatases), and many of them are regulators of the MAPK signaling (MAPKP or MKPs, MAPK phosphatases; Trinkle-Mulcahy \& Lamond, 2006; Patterson et al., 2009).

The MKPs have two conserved domains that are important for their function: an Nterminal non-catalytic domain that contains the so-called kinase interaction motif (KIM) and also sequences that determine the localization of the protein, and the C-terminal catalytic 
domain. The physiological consequences of the MAPK signaling largely depend on the degree and the duration of the cascade activation. Therefore the response in the cell results from a balanced counteraction of inducing and suppressing mechanisms, and thus MKPs play a major part in the control of MAPK signaling. Since MAPK signaling controls functions such as cellular growth, division, migration and the response to damaged DNA, an improper activation or deactivation of these kinases can promote the development and progression of tumors (Dhanasekaran \& Johnson, 2007). MKPs are also misregulated in several cancers (Keyse, 2008; Figure 1-9), a fact that highlights their importance in attenuating the activity of MAPK signaling.

\begin{tabular}{|c|c|c|c|}
\hline Gene/MKP & Cancer & Nature of change & Correlation with clinical outcome \\
\hline \multirow[t]{7}{*}{ DUSP1/MKP-1 } & Colon & Over-expression in early stages of disease & ND \\
\hline & Prostate & but expression is lost as tumour becomes & \\
\hline & Bladder & more aggressive/invasive & \\
\hline & Prostate & $\begin{array}{l}\text { Increased expression levels of DUSP1/MKP-1 } \\
\text { showed inverse correlation with JNK activity } \\
\text { and apoptotic markers }\end{array}$ & ND \\
\hline & Ovarian & $\begin{array}{l}\text { Moderate to strong expression seen in about } \\
60 \% \text { of invasive ovarian carcinomas }\end{array}$ & $\begin{array}{l}\text { DUSP1/MKP-1 expression } \\
\text { correlated with shorter } \\
\text { progression-free survival }\end{array}$ \\
\hline & Breast & $\begin{array}{l}\text { Significant expression in poorly differentiated } \\
\text { and late stage tumours. Overexpression } \\
\text { correlated with lower JNK activity }\end{array}$ & ND \\
\hline & NSCLC & $\begin{array}{l}\text { Elevated expression levels. Bias towards nuclear } \\
\text { as opposed to nuclear/cytoplasmic localisation? }\end{array}$ & ND \\
\hline \multirow[t]{2}{*}{ DUSP4/MKP-2 } & Ovarian & $\begin{array}{l}\text { Expressed in serous borderline tumours (SBT) } \\
\text { but not serous carcinoma (SCA). Association } \\
\text { with more benign phenotype of the former? }\end{array}$ & ND \\
\hline & Breast & Co-expression with DUSP1/MKP-1 & ND \\
\hline \multirow[t]{2}{*}{ DUSP2/None } & Ovarian & Expression in serous carcinoma & $\begin{array}{l}\text { Associated with poor outcome } \\
\text { in terms of overall survival }\end{array}$ \\
\hline & Acute leukemia & $\begin{array}{l}\text { Expression associated with elevated levels of } \\
\text { ERK activation }\end{array}$ & ND \\
\hline DUSP6/MKP-3 & Pancreas & $\begin{array}{l}\text { Over-expression in dysplastic tissue and } \\
\text { carcinoma in situ but down regulation in } \\
\text { invasive carcinoma }\end{array}$ & ND \\
\hline DUSP7/MKP-X & Leukemias & $\begin{array}{l}\text { Elevated levels in acute myeloid leukaemia } \\
\text { and acute lymphoblastic leukemia }\end{array}$ & ND \\
\hline
\end{tabular}

Figure 1-9: Several MKPs are misregulated in different forms of cancer. (from Keyse, 2008)

\subsubsection{DUSP18}

Dusp18 (also known as Dsp18, Dsp/Dusp20 or LMWDSP20) was identified and characterized in 2002 by Hood and colleagues (Hood et al., 2002), and further in 2003, by the group of Yumin Mao (Wu et al., 2003). It belongs to the low molecular weight, atypical dual specificity phosphatases. The gene locus is located on chromosome 22 (22q12.1) and encodes for a protein of 188 amino acids (approximately $21 \mathrm{kDa}$ ). Dusp18 has a Dual Specificity 
Phosphatase (Protein Tyrosine Phosphatase) domain occupying most of the protein, which contains the characteristic $(\mathrm{H} / \mathrm{V}) \mathrm{CX}_{5} \mathrm{R}(\mathrm{S} / \mathrm{T})$ active site motif. Important amino acid residues for the catalysis are the cysteine within this motif (C104), and an aspartate residue (D73) that is about 30 amino acids upstream of this cysteine. Dusp18 does not contain the second domain conserved among DSPs, which is an N-terminal $\mathrm{CH} 2$-domain (homologous to Cdc25). Specific characteristics of Dusp18 that set it apart from other DSPs are its unusual optimal activity temperature $\left(55^{\circ} \mathrm{C}\right.$; Wu et al., 2003) and an extended C-terminal domain that folds to stabilize the protein, perhaps explaining in this way also its thermostability (Jeong et al., 2006). Furthermore, the regions surrounding the active site of Dusp18 are not similar to other DSPs suggesting that Dusp18 might have different substrates than other DSPs. The structure of Dusp18 (Figure 1-10) was solved in 2006 (Jeong et al., 2006).

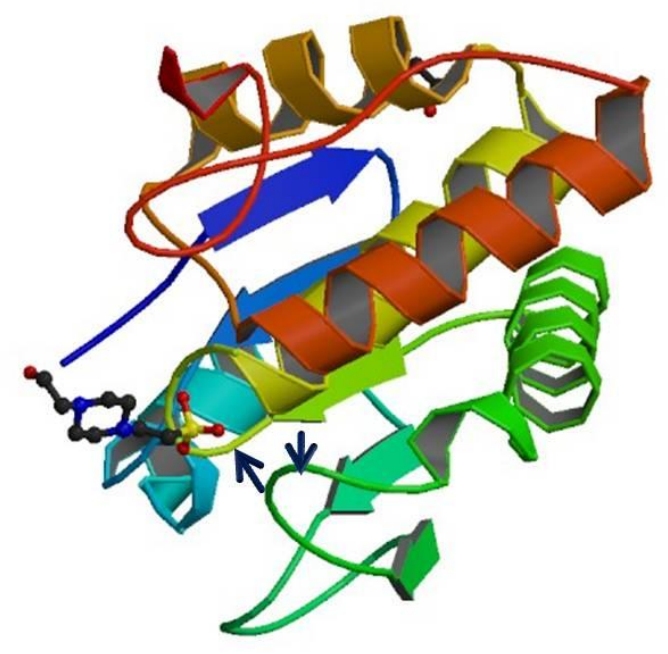

Figure 1-10: The structure of human Dusp18.

A 4-(2-hydroxyethyl)-1-piperazine ethanesulfonic acid is shown (ball cartoon) at the Dusp18 active site. The critical amino acids for the catalysis are the D73 (located close to the phosphate on the yellow loop, arrow) and the C104 (located opposite of the aspartate on the green loop, arrow). The $C$-terminal amino acids form a double-stranded $\beta$-sheet that stabilizes the catalytic center.

(modified from PDB entry 2ESB; Jeong et al., 2006)

$\mathrm{Wu}$ et al. further investigated the function of Dusp18. According to their group, Dusp18 is uniformly localized in the whole cell (overexpression studies) and can directly interact and dephosphorylate JNK but not p38 or ERK (Wu et al., 2006). However, two years later Rardin et al. published their research in which they describe Dusp18 as a mitochondrial protein, specifically localizing at the inner mitochondrial membrane (Rardin et al., 2008). They have further claimed that Wu et al. used N-terminally tagged Dusp18 that was then mislocalized to the cytoplasm because of the disruption of the $\mathrm{N}$-terminal mitochondrial 
signal, and that JNK cannot be a substrate for Dusp18 since it is not located in the mitochondria. Nevertheless, it should be noted that Rardin et al. performed all their experiments on the murine and rat homologue of Dusp18, which is similar but not identical to the human Dusp18 (Figure 4-6, Results).

\subsubsection{Implication of phosphatases in the DNA damage response}

Only during the last few years scientists have begun to solve the DNA damage response puzzle by investigating both phosphorylation and dephosphorylation regulatory mechanisms. Research in this direction has revealed several phosphatases that regulate either directly kinases involved in the DNA damage response, or they reverse their action by dephosphorylating their substrates. For example, PPM1D (also known as PP2C $\delta$ or WIP-1) is a p53 target gene that dephosphorylates and thus inactivates several checkpoint and p53activating kinases, such as Chk1, Chk2, ATM, p38, and even p53 itself (hence creating a negative feedback loop) (Le Guezennec \& Bulavin, 2010). PP5 has been implicated in dephosphorylating ATR (Zhang et al., 2005), while the dephosphorylation of $\gamma \mathrm{H} 2 \mathrm{Ax}$ is performed by several phosphatases including PP2A (Chowdhury et al., 2005), PP4 (Nakada et al., 2008), Wip1 (Moon et al., 2010) and PP6 (Douglas et al., 2010). PP2A is one of the most well-studied phosphatases that is in fact involved in many dephosphorylation events regulating the DNA damage response and the cell cycle checkpoints. Among the targets of PP2A are the polo-like kinase 1 (plk-1), dephosphorylated during the G2/M checkpoint (Jang et al., 2007), and the RPA $32 \mathrm{kDa}$ protein, targeted to promote the repair of DNA breaks during S phase (Feng et al., 2009). PP2A also binds the ATM dimer in unstressed cells and keeps it inactive by constant dephosphorylation of the autophosphorylation Ser1981 site. DNA breaks trigger the dissociation of PP2A from ATM, thus allowing the activation of the latter, and the initiation of the signaling cascade in the nucleus (Goodarzi et al., 2004). Hence, PP2A is an example of a phosphatase that plays both positive and negative roles in the activation of the DNA damage responsive mechanisms, by targeting a collection of diverse proteins. Therefore, yet unknown regulation mechanisms must exist to coordinate its action on all the different substrates.

The investigation of phosphatases in the context of cancer and specifically the response to damaged DNA opens a new exciting field that can provide new targets and therapies against tumor initiation, progression and metastasis. As phosphatases are also enzymes that can be inhibited in the cell by small molecules, understanding their role in malignancy is crucial, not only to promote the creation of novel drugs, but also to complete the picture of signaling networks that are affected during transformation. Hence, the aim of 
this study was to identify new phosphatases that modulate the response to DNA damage or are novel regulators of the p53 tumor suppressor network. For this purpose, a human phosphatase siRNA library screen was performed, which unveiled Dusp18 as a potential inhibitor of the p53 pathway. As described above, little is currently known about the function of this phosphatase. Here, the effect of Dusp18 depletion on the regulation and function of p53, as well as the possible mechanisms of Dusp18 action are addressed. Furthermore, the molecular details of the DNA damage response induced by siRNAs that target Dusp18 are examined. Finally, our efforts focused on understanding the physiological effects of Dusp18 depletion on the survival and proliferation of tumor cells. 


\section{MATERiALS}

\subsection{Chemicals}

Table 2-1: Chemicals

2-Mercaptoethanol Roth

2-Propanol Roth

a,a-Trehalose, Dihydrate ration

Acetic acid Roth

Agar

Agarose

Albumin Fraction V (Bovine Serum Albumin, BSA)

Ammonium persulfate (APS)

Ammonium sulfate

Ampicillin

Sigma Aldrich

Sigma Aldrich

Roth

Roth

Roth

AppliChem

Aprotinin

AppliChem

Bromophenol blue

Sigma Aldrich

Calcium chloride-dihydrate

Roth

Chelex100

Bio-Rad

Chloroform

Roth

Ciprofloxacin (Ciprobay®)

Bayer

Deoxycholic acid

AppliChem

di-Sodium hydrogen phosphate

Roth

Dithiothreitol (1,4-DTT)

Roth

DMEM

Invitrogen/GIBCO

DMSO, sterile

AppliChem

dNTP-Mix, 20mM

BioBudget

Promega

dNTPs, $25 \mu \mathrm{mol}$ each

Santa Cruz

ElectroZap

Ethanol 99,9\%

Applied Biosystems

Ethanol denatured 99,8\%

Merck

Ethidium bromide

Roth

Ethylene-diamine-tetra-acetate (EDTA)

Roth

Roth

Fetal calf serum (FCS)

Hyclone (ThermoScientific)

Formaldehyde (37\%)

Sigma Aldrich

Gemcitabine

Sigma Aldrich

GeneRuler DNALadder Mix

Fermentas

Geneticin

Invitrogen

Glycerin

Sigma Aldrich

Glycine

Roth

GlycoBlue

Guava ICF Cleaning solution

Applied Biosystems

Guava Instrument Cleaning Fluid (ICF)

Millipore

Guava Nexin

Millipore

Guava Viacount reagent

Millipore

$\mathrm{HCl}$

Millipore

Roth 
HEPES

HiDye- Formamide

Hoechst 33342

Isoamylalcohol

Isopropanol, p.A.

Kanamycin

Leupeptin Hemisulfate

L-Glutamine

Lipofectamine 2000

Magnesium acetate tetrahydrate

Magnesium chloride hexahydrate

Magnesium sulfate heptahydrate

McCoy' 5A medium

Methanol

$\mathrm{MgSO}_{4}(25 \mathrm{mM})$

Milk powder, blotting grade

Monopotassium phosphate

Nocodazole

Nonidet P40 substitute

Nuclease free water

PageRuler Prestained Protein Ladder

Paraformaldehyde

PBS tablets

Pefabloc SC Protease Inhibitor

PEG6000

Penicillin / Streptomycin (P/S)

Pepstatin A

Ponceau

Potassium chloride

Propidium iodide solution

Protein A-Sepharose CL-4B

Protein G - Sepharose 4B

RNase Inhibitor, recombinant

Rotiphorese Gel 30

Sodium acetate

Sodium Azide $0,1 \mathrm{M}$ solution

Sodium bicarbonate solution

Sodium carbonate

Sodium chloride

Sodium deoxycholate (Na-DOC)

Sodium dihydrogenphosphate

Sodium dodecyl sulfate (SDS)

Sodium hydrogencarbonate

Sodium hydroxide tablets

Sonicated salmon sperm DNA

Sucrose
Roth

Applied Biosystems

Invitrogen

Roth

Geyer

AppliChem

AppliChem

Invitrogen/GIBCO

Invitrogen

Roth

Roth

AppliChem

Invitrogen/GIBCO

Geyer

Fermentas

Roth

Roth

Sigma Aldrich

Amersham

Applied Biosystems

Fermentas

Roth

Invitrogen/GIBCO

Roth

Fermentas

Invitrogen/GIBCO

AppliChem

Roth

Roth

Sigma Aldrich

Amersham

Invitrogen

NEB

Roth

Roth

Sigma Aldrich

Sigma Aldrich

Roth

Roth

AppliChem

Roth

Roth

Roth

Roth

Fermentas

Roth 
SYBR Green I

Roche

Tetracycline

Sigma Aldrich

Tetramethyl ammonium chloride

Roth

Tetramethylethylenediamine (TEMED)

Roth

Thimerosal

Trasylol

Sigma Aldrich

Trehalose

AppliChem

Tris (tris-hydroxymethyl-aminomethane)

USB Corporation

tri-Sodium citrate dihydrate

Roth

Triton $\mathrm{x}-100$

Roth

TRIzol Reagent

AppliChem

Invitrogen

Invitrogen

Trypsin/EDTA

Roth

Tryptone

AppliChem

Yeast Extract

Sigma Aldrich

\subsection{Enzymes and buffers}

Table 2-2: Enzymes and buffers

\begin{tabular}{lr}
\hline BamHI & Fermentas \\
BamHI buffer & Fermentas \\
Proteinase K & Invitrogen \\
T4 DNA ligase buffer & NEB \\
T4 DNA Ligase & NEB \\
Tango buffer & Fermentas \\
Taq polymerase LC & Fermentas \\
Hot-Start Taq polymerase & Axon Labortechnik \\
M-MuLV Reverse transcriptase & NEB \\
NEB Buffer Pack for M-MuLV Rev. Transcriptase & NEB \\
NotI & Fermentas \\
Pfu reaction buffer & Stratagene \\
PfuTurbo ${ }^{\circledR}$ DNA Polymerase & Stratagene \\
PfuUltra ${ }^{T M}$ High-Fidelity DNA Polymerase & Stratagene \\
XbaI & Fermentas \\
10x Taq Buffer & Fermentas \\
Calf Intestine Alkaline Phosphatase & Fermentas \\
RNAse A & Qiagen
\end{tabular}

\subsection{Reaction systems (kits)}

Table 2-3: Reaction systems (kits)

BigDye ${ }^{\circledR}$ Terminator v3.1 Cycle Sequencing Kit

Applied Biosystems

Guava Check Kit

Millipore

Invisorb® Spin Plasmid Mini Two Kit

InViTek

PureYield ${ }^{\mathrm{TM}}$ Plasmid Midiprep System

Promega

QIAquick PCR purification kit

Qiagen

RIDASCREEN@ Mycoplasma IFA

R-Biopharm AG 
SuperSignal West Dura Extended Duration Substrate

Pierce

SuperSignal West Femto Maximum Sensitivity Substrate

Pierce

ElectroMAX DH10B Electrocompetent Cells

Invitrogen

Plasmid Mini Kit

Qiagen

\subsection{Oligonucleotides}

Table 2-4: Oligonucleotides

poly-dT primer

Metabion

poly-dN primer

Metabion

Primers

Silencer® Select Human Phosphatase siRNA Library V4

Invitrogen

siRNAs (sequence-patented)

Applied Biosystems

Applied Biosystems

Table 2-5: Primers

\begin{tabular}{|c|c|c|c|}
\hline Primer & Sequence & Application & Target region \\
\hline CMV FW & GGC GTG TAC GGT GGG AGG TC & sequencing & CMV promoter \\
\hline dusp18 FW & GCT GAC TCC CCT AAC TCA CG & qPCR & dusp18 \\
\hline dusp18 REV & TGC CAA ACA ATT GGA ACT CA & qPCR & dusp18 \\
\hline dusp18 & GGA CCT TCT AGA ATG ACA GCA CCC & cloning & dusp18 \\
\hline FW_XbaI & TCG TGT G & & \\
\hline dusp18 & TTC TCA GGA TCC TCA CAG TGG AAT & cloning & dusp18 \\
\hline REV_BamHI & CAT CAA ACG & & \\
\hline p21 FW & TAG GCG GTT GAA TGA GAG G & qPCR & $\mathrm{p} 21$ \\
\hline p21 REV & AAG TGG GGA GGA GGA AGT AG & qPCR & $\mathrm{p} 21$ \\
\hline $\begin{array}{l}\text { p21 intron } 1 \\
\text { FW }\end{array}$ & GGC ATG TGT CCC GGG CTT CC & qPCR & $\mathrm{p} 21$ intron 1 \\
\hline $\begin{array}{l}\text { p21 intron } 1 \\
\text { REV }\end{array}$ & CCC CTG CCT CGT GTT GCC TG & qPCR & $\mathrm{p} 21$ intron 1 \\
\hline $\begin{array}{l}\text { p21 intron } 2 \\
\text { FW }\end{array}$ & GGG CCC GGC ATT GTG CTG AA & qPCR & p21 intron 2 \\
\hline $\begin{array}{l}\text { p21 intron } 2 \\
\text { REV }\end{array}$ & ATC CAT CAC CGC ACC CGC AC & qPCR & p21 intron 2 \\
\hline $\begin{array}{l}\text { dusp18 } \\
\text { FW_NotI }\end{array}$ & $\begin{array}{l}\text { GCC GCC GCG GCC GCG CCA CCA TGA } \\
\text { CAG CAC CCT CGT GTG CCT TCC }\end{array}$ & cloning & dusp18 \\
\hline p53 BS1 FW & $\begin{array}{l}\text { CCG GCC AGT ATA TAT TTT TAA TTG } \\
\text { AGA }\end{array}$ & ChIP & $\begin{array}{r}\mathrm{p} 21 \text { promoter, } \mathrm{p} 53 \\
\text { binding site at }-2283 \mathrm{bp}\end{array}$ \\
\hline p53 BS1 REV & $\begin{array}{l}\text { AGT GGT TAG TAA TTT TCA GTT TGC } \\
\text { TCA T }\end{array}$ & ChIP & $\begin{array}{r}\text { p21 promoter, } \mathrm{p} 53 \\
\text { binding site at }-2283 \mathrm{bp}\end{array}$ \\
\hline SP1 BS1 FW & AGT GCC AAC TCA TTC TCC AAG & ChIP & $\begin{array}{r}\mathrm{p} 21 \text { promoter, } \mathrm{SP} 1 \\
\text { binding site at }-282 \mathrm{bp}\end{array}$ \\
\hline SP1 BS1 REV & ACT TCG TGG GGA AAT GTG TC & ChIP & $\begin{array}{r}\text { p21 promoter, SP1 } \\
\text { binding site at }-282 \mathrm{bp}\end{array}$ \\
\hline $\begin{array}{l}\text { SP1 BS2 FW / } \\
\text { p21 +1 FW }\end{array}$ & GGG GCG GTT GTA TAT CAG G & ChIP & $\begin{array}{r}\text { p21 transcription start } \\
\text { site at }+1 \mathrm{bp}\end{array}$ \\
\hline $\begin{array}{l}\text { SP1 BS2 REV } \\
\text { / p21 +1 REV }\end{array}$ & AGT CAG TTC CTT GTG GAG CC & ChIP & $\begin{array}{r}\text { p21 transcription start } \\
\text { site at }+1 \mathrm{bp}\end{array}$ \\
\hline $\begin{array}{l}\text { p } 21+1500 \\
\text { FW }\end{array}$ & TGG GAG GAC TTG CGA GCG GT & ChIP & p21 gene at $+1500 b p$ \\
\hline
\end{tabular}




\begin{tabular}{|c|c|c|c|}
\hline $\begin{array}{l}\mathrm{p} 21+1500 \\
\text { REV }\end{array}$ & CCA CGC CCA AAG CAC GGG AT & ChIP & p21 gene at $+1500 \mathrm{bp}$ \\
\hline $\begin{array}{l}\text { p21 }+6000 \\
\text { FW }\end{array}$ & AGC AGG CTG AAG GGT CCC CA & ChIP & p21 gene at $+6000 \mathrm{bp}$ \\
\hline $\begin{array}{l}\text { p } 21+6000 \\
\text { REV }\end{array}$ & TCC GTG CAC ATG TCC GCA CC & ChIP & p21 gene at $+6000 \mathrm{bp}$ \\
\hline GAPDH FW & $\begin{array}{l}\text { TGA AGG TCG GAG TCA ACG GAT TTG } \\
\text { GT }\end{array}$ & qPCR & gapdh \\
\hline GAPDH REV & GCA GAG ATG ATG ACC CTT TTG GCT C & qPCR & gapdh \\
\hline
\end{tabular}

\subsection{Antibodies}

Table 2-6: Antibodies

\begin{tabular}{|c|c|c|c|}
\hline \\
\hline \multicolumn{4}{|c|}{$\begin{array}{l}\text { Primary Antibodies: } \\
\text { Antigen }\end{array}$} \\
\hline Acetyl-p53 & & Cell Signaling & 2525 \\
\hline \multicolumn{4}{|l|}{ Lys382 } \\
\hline Actin & & Abcam & ab6276-100 \\
\hline cleaved Caspase & & Cell Signaling & 9664 \\
\hline \multicolumn{4}{|l|}{3 (Asp175) } \\
\hline Dusp18 & DUSP18 (C-term) & Abgent & AP8480b \\
\hline Dusp18 & DUSP18 (N-19) & Santa Cruz & sc-79441 \\
\hline HA tag & HA.11 (16B12) & Covance & MMS-101R \\
\hline $\operatorname{Mdm} 2$ & 2A9 Hybridoma cell line & & $\begin{array}{l}\text { Chen et al., Mol Cell Biol. } \\
1993 \text { July; 13(7): 4107-4114 }\end{array}$ \\
\hline Nucleophosmin & & Invitrogen & $32-5200$ \\
\hline $\mathrm{p} 21$ & $\mathrm{Ab}-1, \mathrm{EA} 10$ & Calbiochem & OP 64 \\
\hline p53 & DO-1 & SANTA CRUZ & sc-126 \\
\hline p53 & pAb421 & Calbiochem & OP03 \\
\hline p53 & $\mathrm{fl} 393$ & SANTA CRUZ & sc-6243 \\
\hline PARP-1 & $\mathrm{Ab}-2$ & Calbiochem & AM30 \\
\hline phopsho-p53 & $16 \mathrm{G} 8$ & Cell Signaling & 9286 \\
\hline \multicolumn{4}{|l|}{ Ser15 } \\
\hline phospho-Chk-1 & phospho-Chk1(Ser317) & CellSignaling & 2344 \\
\hline phospho-Chk-2 & phospho-Chk2 (Thr68) & Cell Signaling & 2661 \\
\hline phospho-p38 & $\begin{array}{l}\text { phospho-p38 } \\
\text { Thr180/Tyr182 }\end{array}$ & Cell Signaling & 9216 \\
\hline \multicolumn{3}{|l|}{ Ser46 } & 2521 \\
\hline SP1 & & Millipore & $07-645$ \\
\hline B-galactosidase & anti-ß-gal & Promega & 2378B \\
\hline$\gamma \mathrm{H} 2 \mathrm{Ax}$ & phosphoH2Ax Ser139 & Millipore & $05-636$ \\
\hline
\end{tabular}


Secondary Antibodies:

Antibody

Company

Cat. Number

AlexaFluor546 goat anti-mouse

Invitrogen

A-11003

AlexaFluor488 goat anti-rabbit

Invitrogen

A-11034

HRP-coupled affiniPure $F\left(a b^{\prime}\right) 2$ fragment, anti-

Jackson

715-036-150

rabbit $\operatorname{IgG}(\mathrm{H}+\mathrm{L})$

ImmunoResearch

Jackson

711-036-152

mouse IgG $(\mathrm{H}+\mathrm{L})$

ImmunoResearch

\subsection{Buffers}

Table 2-7: Buffers

\begin{tabular}{|c|c|c|c|}
\hline 2YT medium & 2YT-Agar & 6x DNA gel load. buff. & 50x TAE buffer \\
\hline 1,6\% (w/v) Tryptone & $15 \%(w / v)$ Agar & $40 \%(w / v)$ sucrose & 2 M Tris-Base \\
\hline $1 \%(\mathrm{w} / \mathrm{v})$ yeast extrakt & in 2YT-Medium & $10 \%(w / v)$ glycerin & $1 \mathrm{M}$ acetic acid \\
\hline $0,5 \%(w / v) \mathrm{NaCl}$ & & $\begin{array}{l}0,25 \%(\mathrm{w} / \mathrm{v}) \text { bromophenol } \\
\text { blue }\end{array}$ & 100 mM EDTA \\
\hline 10x PBS & $\mathbf{P B S}^{++}$ & 10x Western salts & WB Transfer buffe \\
\hline $239,9 \mathrm{mM} \mathrm{NaCl}$ & 1x PBS & 1,9 M Glycin & 1x Western Salts \\
\hline $8,1 \mathrm{mM} \mathrm{Na} 2 \mathrm{HPO} 4$ & $1 \mathrm{mM} \mathrm{CaCl}_{2}$ & $0,02 \%(w / v) \operatorname{SDS}$ & $15 \%(\mathrm{v} / \mathrm{v})$ Methanol \\
\hline $2,7 \mathrm{mM} \mathrm{KCl}$ & $0,5 \mathrm{mM} \mathrm{MgCl}_{2}$ & $\begin{array}{c}250 \text { mM Tris- } \mathrm{HCl} \\
\mathrm{pH} 8,3\end{array}$ & \\
\hline \multicolumn{4}{|l|}{ 1,5 mM KH2PO4 } \\
\hline RIPA lysis buffer & 6x Laem. buffer & ChIP buffer & ChIP buffer ${ }^{+++}$ \\
\hline $\begin{array}{l}1,4 \% \text { Trasylol } \\
(100000 \mathrm{KIE})\end{array}$ & 350 mM Tris-HCl pH 6,8 & $150 \mathrm{mM} \mathrm{NaCl}$ & $\begin{array}{l}\text { ChIP buffer } \\
\text { containing }\end{array}$ \\
\hline $0,1 \%(\mathrm{v} / \mathrm{v})$ Triton X-100 & $30 \%(\mathrm{v} / \mathrm{v})$ glycerin & 5 mM EDTA pH 8,0 & $1 \mu \mathrm{g} / \mathrm{ml}$ Pepstatin A \\
\hline $0,1 \%(\mathrm{v} / \mathrm{v}) \mathrm{Na}-\mathrm{DOC}$ & $10 \%(\mathrm{w} / \mathrm{v}) \mathrm{SDS}$ & $50 \mathrm{mM}$ Tris- $\mathrm{HCl} \mathrm{pH} 8,0$ & $1 \mathrm{mM}$ Pefabloc \\
\hline $0,1 \%(\mathrm{w} / \mathrm{v}) \mathrm{SDS}$ & $9,3 \%(\mathrm{w} / \mathrm{v}) 1,4-\mathrm{DTT}$ & $0,5 \%(\mathrm{v} / \mathrm{v}) \mathrm{NP}-40$ & $\begin{array}{l}1 \mu \mathrm{g} / \mathrm{ml} \text { Leupeptin/ } \\
\text { Aprotinin }\end{array}$ \\
\hline 1 mM EDTA & $\begin{array}{l}0,02 \%(\mathrm{w} / \mathrm{v}) \text { bromophenol } \\
\text { blue }\end{array}$ & $1 \%(\mathrm{v} / \mathrm{v})$ Triton-X-100 & \\
\hline \multicolumn{4}{|l|}{$9 \mathrm{mM} \mathrm{NaCl}$} \\
\hline \multicolumn{4}{|l|}{2 mM Tris- $\mathrm{HCl} \mathrm{pH} 8.5$} \\
\hline Co-IP buffer & CoIP buffer ${ }^{++}$ & & \\
\hline $\begin{array}{c}300 \mathrm{mM} \mathrm{NaCl} \\
50 \mathrm{mM} \text { Tris-HCl } \\
\text { pH 7,5 }\end{array}$ & $\begin{array}{l}\text { CoIP buffer containing } \\
1 \mu \mathrm{g} / \mathrm{ml} \text { Leupeptin/ } \\
\text { Aprotinin }\end{array}$ & & \\
\hline $1 \%(\mathrm{v} / \mathrm{v}) \mathrm{NP} 40$ & $1 \mathrm{mM}$ Pefabloc & & \\
\hline $0,25 \%(w / v)$ Na-DOC & & & \\
\hline
\end{tabular}




\subsection{Consumables}

Table 2-8: Consumables

$1,5 \mathrm{ml}$ safe-lock reaction tubes

Eppendorf

$10 \mu 1$ Filtertips, SafeSeal-Tips professional

Biozym

$1000 \mu 1$ Filtertips,Biosphere Filter Tips

Sarstedt

$1250 \mu 1$ Filtertips,SafeSeal-Tips professional

Biozym

$20 \mu 1$ Filtertips,Biosphere Filter Tips

Sarstedt

$200 \mu 1$ Filtertips,Biosphere Filter Tips

Sarstedt

$2 \mathrm{ml}$ safe-lock reaction tubes

Eppendorf

96 well plate, black

Greiner

96 well plate, clear

Axygen

Black with Clear Bottom 96-well Microtest ${ }^{\mathrm{TM}}$ Optilux $^{\mathrm{TM}}$ Plate

BD Biosciences

Cell scrapper, $16 \mathrm{~cm}$

Sarstedt

Cell scrapper, $25 \mathrm{~cm}$

Sarstedt

Gene Pulser electroporation cuvette

Bio-Rad

Hybond-P PVDF-Membrane

Omnilab

Latex gloves Safeskin PFE

Microseal B Seal sealing foil

Kimberly-Clark Professional

Multiplate 96-well white PCR plates

Bio-Rad

Neubauer cell counting chamber

Bio-Rad

Optical Film Sealing Kit for 96-well plates

Brand

OptiPlate TM 96

Bio-Rad

PCR reaction tubes $0,2 \mathrm{ml}$

Perkin Elmer

Sarstedt

Pipette tips $(10 \mu \mathrm{l} / 200 \mu \mathrm{l} / 1000 \mu \mathrm{l})$

Sterile cell culture dish $10 \mathrm{~cm}$

MBP/ Greiner/ Sarstedt

Sterile cell culture dish $15 \mathrm{~cm}$

Greiner

Sterile cell culture well-plates, 12-well

Greiner

Sterile cell culture well-plates, 24-well

Greiner

Sterile cell culture well-plates, 6-well

Greiner

Sterile cell culture well-plates, 96-well

Greiner

Sterile conical tube $15 \mathrm{ml}$

Greiner

Sterile conical tube $50 \mathrm{ml}$

Sarstedt

Sterile cryotubes, $1,8 \mathrm{ml}$

Sarstedt

U-40 Insulin syringe (26 Gauge)

Nunc

Whatmann paper for WB

B.Braun Petzold

Schleicher \& Schuell

\subsection{Electronic equipment}

Table 2-9: Electronic equipment

Analytical balance LE6238

Sartorius

BD Pathway 855 Imaging System

BD Biosciences

Biomek 3000 Laboratory Automation Workstation

Beckman Coulter

Bioruptor ${ }^{\circledR}$ sonication device

Diagenode

Celigo cell cytometer

Cyntellect Europe

Cooling centrifuge

Heraeus Instruments

Electrophoresis chamber

Harnischmacher Labortechnik 
Electroporator GenePulser® II

Eppendorf shaker „Thermomixer 5436“

Freezer $-80^{\circ} \mathrm{C}$,Hera freeze“

Freezer $-20^{\circ} \mathrm{C}$

Guava PCA-96 Base System for FACS

Incubator for bacterial culture

Incubator for cell culture „Hera Cell““

Chemiluminescence Imager „CHEMOCAM HR 16 3200“

UV imager „Gel Jet Imager“

Laminar flow cabinet "Hera safe"

Liquid Nitrogen tank LS4800

Magnetic stirrer „MR 3001“

Microwave

Mikroscope Axiovert 40C

Neubauer improved

PCR Cycler ,advanced Primus 25“

pH-Meter inoLab® Serie 720

Pipettes PIPETMAN® $P$

Power pack P25T

Real-Time PCR System "Chromo 4"

Refridgerator $4^{\circ} \mathrm{C}$

Rotator ,34528“

Shaker „PROMAX 2020“

Shaking incubator

Spectrophotometer "NanoDrop ${ }^{\mathrm{TM}} 1000$ "

Table centrifuge 5415R

Vortex mixer

Waterbath TW20 JULABO

Western Blot chamber
Bio-Rad

Eppendorf

Heraeus Instruments

Liebherr Hausgeräte

Millipore

Heraeus Instruments

Memmert

INTAS Imaging Instr.

INTAS Imaging Instr.

Heraeus Instruments

LabSystems Taylor Wharton

Heidolph Inst.

Cinex

Zeiss

Brand

Peqlab Biotechnologie

WTW

Gilson, Inc.

Biometra

Bio-Rad

Liebherr Hausgeräte

Schütt Labortechnik

Heidolph Inst.

Infors HAT

Peqlab Biotechnologie

Eppendorf

neoLab

Labortechnik

Bio-Rad

\subsection{Software}

Table 2-10: Electronic equipment

ApE- A Plasmid Editor

BD Pathway ${ }^{\mathrm{TM}}$ Software

BioEdit v7.0.5

Biomek 3000 Software

Celigo Software

CFX Manager Software for qPCR cycler

Chemiluminescence Imager software

Excel

Guava Express Software

INTAS labID

ModFit LT ${ }^{\mathrm{TM}}$

Nanodrop Software

UV imager software copyright M. Wayne Davis

BD Biosciences

copyright Tom Hall, Ibis Therapeutics

Beckman Coulter

Cyntellect

Bio-Rad

INTAS Imaging Instr.

Microsoft

Millipore

INTAS Imaging Instr.

Verity Software House

Peqlab Biotechnologie

INTAS Imaging Instr. 


\section{METHODS}

\subsection{Cell culture and treatment}

\subsubsection{Culture of human cancer cells}

The cell lines used and their respective culture media are listed in Table 3-1. The cells were cultured in $10 \mathrm{~cm}$ petri dishes under conditions of $5 \% \mathrm{CO}_{2}$ and $37^{\circ} \mathrm{C}$. Unless otherwise stated, the cell culture media was supplemented with $10 \%$ FCS, $50 \mathrm{U} / \mathrm{ml}$ Penicillin, $50 \mu \mathrm{g} / \mathrm{ml}$ Streptomycin, $200 \mu \mathrm{M}$ L-Glutamine, $10 \mu \mathrm{g} / \mathrm{ml}$ Ciprobay and $2 \mu \mathrm{g} / \mathrm{ml}$ Tetracycline. For subculture, cells were detached from the plate floor by trypsinization. Cells were subcultured 2-3 times per week at a dilution of 1:5 - 1:20, depending on the cell line. All cell culture work was performed under sterile conditions. All transfection mixes were prepared using the respective medium without antibiotics and serum.

Table 3-1: Cell lines

\begin{tabular}{lccr}
\hline Cell line & Origin & P53 status & Culture medium \\
\hline SJSA & Osteosarcoma & $\mathrm{Wt}$ & DMEM \\
U2OS & Osteosarcoma & $\mathrm{Wt}$ & DMEM \\
HCT116+/+ & Colon carcinoma & $\mathrm{Wt}$ & McCoy's without CIP \\
HCT116-/- & Colon carcinoma & null & McCoy's without CIP
\end{tabular}

\subsubsection{Cell freezing and recovery}

Cells from one $10 \mathrm{~cm}$ dish were grown to $\sim 80 \%$ confluency as described above and transferred into a $15 \mathrm{ml}$ falcon tube. Centrifugation at $800 \mathrm{rpm}$ for $7 \mathrm{~min}$ followed to pellet the cells. The supernatant was aspirated and the cells were resuspended into $1 \mathrm{ml}$ of pre-cooled freezing solution (92\% FCS, 8\% DMSO).The cells were afterwards transferred into a cryotube and placed directly on ice. After about $24 \mathrm{~h}$ in $-80^{\circ} \mathrm{C}$, the tubes were transferred in the liquid nitrogen cell storage $\left(-196^{\circ} \mathrm{C}\right)$.

For recovery of the cells after freezing, the frozen cells were directly thawn in a $10 \mathrm{~cm}$ cell culture dish with fresh complete medium. The cells were allowed to attach for one day and then their medium was replaced with fresh complete medium.

\subsubsection{Cell proliferation assay}

We used cells transfected with siRNAs for the cell proliferation assays. The transfections were done in 6-well plates as described below. Approximately 36 hours after transfection, the cells were harvested by trypsinization and seeded in a 96-well clear cell culture plate. For the assays the cells were seeded in different dilutions (1:4, 1:10, 1:20 and 1:50 of the initial cell number), and for each dilution and transfection 3 wells were seeded so that each sample was measured in triplicates and different dilutions. Two days after the transfection, when the cells were allowed to attach after seeding, the cell confluency in each well was measured using the adherent cell cytometer Celigo (Cyntellect Europe, UK - brightfield confluency measurement). The confluency of the wells was measured every day for up to 5 days after transfection, and the results were analysed and processed using Microsoft Excel. 


\subsubsection{Generation of polyclonal stable U2OS cell lines}

For generating stable U2OS cells expressing Dusp18, we initially transiently transfected U2OS cells in 2 wells of a 6-well plate, as described below, with a pIRES expression vector containing HAtagged Dusp18 cDNA or with an empty pIRES vector for generating the control pIRES empty cells. Two days after transfection, the cells were harvested by trypsinization, combined and seeded in a 10 $\mathrm{cm}$ cell culture dish, and 24 hours later the selection of stably transfected cells started. Geneticin (G418), an aminoglycoside antibiotic that acts by blocking translational elongation, was used to select for the transfected cells (selection concentration: 800ng/ml). The neoR gene (neomycin resistance) was expressed in cells that had incorporated the pIRES vector in their genome, which encodes for an aminoglycoside phosphotransferase conferring the resistance to geneticin. The cells were daily observed so they would not become confluent and their medium was changed every 2-3 days to ensure there was enough geneticin for the selection, and to remove the dead cells. Approximately 2 weeks later only the colonies of cells that were geneticin-resistant remained in the dish, and so a polyclonal stable cell line was generated. The cells were further kept and cultured in medium containing 500 $\mathrm{ng} / \mathrm{ml}$ geneticin, to ensure the survival of cells that kept the pIRES in their genome.

\subsubsection{Irradiation of human cancer cells with UVC light}

Cells were seeded and grown for at least $24 \mathrm{~h}$ prior to irradiation. Directly before exposure to UVC, the medium from each well was removed completely. The cells were irradiated with $20 \mathrm{~J} / \mathrm{m}^{2}$ UVC (unless indicated otherwise), using the BLX-254 BIO-LINK crosslinker (Itf LaborTechnik,). Control 'mock' irradiated samples were covered with aluminium foil during the exposure to UVC. For the DNA damage induction during the performance of the phosphatase siRNA screen, the cells were exposed as described above to $20 \mathrm{~J} / \mathrm{m}^{2} \mathrm{UVC} 48 \mathrm{~h}$ after siRNA transfection and left to recover for $2,5 \mathrm{~h}$ at growth conditions (with fresh medium added after irradiation) before fixation.

\subsubsection{Transfection of human cancer cells with Lipofectamine 2000}

\subsubsection{Transfection with DNA (plasmids)}

The cells were counted and seeded in plates $24 \mathrm{~h}$ prior to transfection. The number of cells seeded varied among the cell lines and was calculated such that the cells would be $\sim 80 \%$ confluent on the day of the transfection. The transfection mix was prepared according to the manufacturer's protocol using a ratio of $3 \mu 1$ of Lipofectamine 2000 for every $1 \mu \mathrm{g}$ of total DNA transfected. The amount of DNA transfected depended on the surface of cell growth and is presented in Table 3-2.

Table 3-2: Transfection of cells with DNA

\begin{tabular}{ccc}
\hline & Cell growth surface & DNA (total $\boldsymbol{\mu g})$ \\
\hline One 6-well plate well & $9,6 \mathrm{~cm}^{2}$ & 2,4 \\
One 12-well plate well & $3,9 \mathrm{~cm}^{2}$ & 1,2 \\
One 24-well plate well & $1,9 \mathrm{~cm}^{2}$ & 0,6 \\
One 96-well plate well & $34 \mathrm{~mm}^{2}$ & 0,2
\end{tabular}




\subsubsection{Transfection with siRNAs}

The reverse transfection method was used for siRNAs, meaning that the cells were seeded in the wells after the addition of the transfection mix. The number of cells seeded varied among the cell lines and was calculated such that the cells would be $50-70 \%$ confluent one day after the transfection. The transfection mix was prepared according to the manufacturer's protocol using a ratio of $2 \mu 1$ of Lipofectamine 2000 for every 50 pmol of siRNA transfected. The amount of siRNA transfected depended on the surface of cell growth and is presented in Table 3-3.

Table 3-3: Transfection of cells with siRNAs

\begin{tabular}{ccc}
\hline & Cell growth surface & siRNA (nmol) \\
\hline 10cm dish & $58 \mathrm{~cm}^{2}$ & 0,8 \\
One 6-well plate well & $9,6 \mathrm{~cm}^{2}$ & 0,1 \\
One 12-well plate well & $3,9 \mathrm{~cm}^{2}$ & 0,05 \\
One 24-well plate well & $1,9 \mathrm{~cm}^{2}$ & 0,025 \\
One 96-well plate well & $34 \mathrm{~mm}^{2}$ & 0,0045
\end{tabular}

\subsubsection{Cell harvesting}

\subsubsection{Cell harvesting and fixation for cell cycle analysis with a FACS machine}

For analysing the cell cycle distribution, cells were harvested by trypsinization for approximately $10 \mathrm{~min}$ to minimize clump formation, and all the cells (including the floating cells) were collected and pelleted by centrifugation at $1200 \mathrm{rcf}$ for $8 \mathrm{~min}\left(4^{\circ} \mathrm{C}\right)$. The cell pellet was resuspended in $500 \mu 1$ cold PBS. The cells were subsequently fixed by the addition of $1500 \mu 1100 \%$ cold ethanol, overnight at $4^{\circ} \mathrm{C}$. The next day the fixed cells were pelleted by centrifugation at $2600 \mathrm{rcf}$ and the cell pellet was washed once with cold PBS. The RNA of the cells was then digested by resuspension of the cells in $100 \mu \mathrm{l}$ RNAse A solution $\left(0,1 \mathrm{mg} / \mu \mathrm{l}\right.$ in PBS) and incubation at $37^{\circ} \mathrm{C}$ for $30 \mathrm{~min}$. An appropriate amount of PBS was subsequently added to the samples to dilute them (final cell concentration 200-500 cells/ $\mu \mathrm{l}$ ) and $200 \mu \mathrm{l}$ of each sample were placed in a FACS 96 well plate with the addition of propidium iodine (final concentration of PI: $30 \mu \mathrm{g} / \mathrm{ml}$ ) to stain the DNA of the cells. The cells were then sorted according to their size and DNA content using the Guava cell sorting system (Millipore). The FACS data were further analysed using the software ModFit (Verity Software House) to measure the percentage of cells in each cell cycle phase.

\subsubsection{Preparation of cell lysates for immunoblotting analysis}

Unless stated different in Results, $48 \mathrm{~h}$ after transfection cells were harvested by scrapping and pelleted by centrifugation at $3000 \mathrm{rpm}$ for $5 \mathrm{~min}$. For the Western blot analysis, the cells from 1 well were resuspended in 30 - 100 $\mu$ l RIPA buffer containing 3xLaemmli buffer, and lysed by vortexing. Afterwards, the samples were incubated at $95^{\circ} \mathrm{C}$ for $5 \mathrm{~min}$ for complete protein denaturation and 
cooled at $12^{\circ} \mathrm{C}$ in an eppendorf shaker for $15 \mathrm{~min}$ (shaking at $1400 \mathrm{rpm}$ ). Then, the samples were centrifuged for $1 \mathrm{~min}$ at $10.000 \mathrm{~g}$ and the supernatant was used for loading an SDS-polyacrylamide gel.

\subsubsection{Total RNA extraction}

For extraction of total RNA the cells were washed once with ice cold PBS and harvested by scrapping directly in the Trizol reagent ( $1 \mathrm{ml}$ for one 6well well) and lysed by pipetting. $200 \mu \mathrm{l}$ of chloroform for each $1 \mathrm{ml}$ of Trizol were added to the samples followed by vigorous shaking by hand for $15 \mathrm{sec}$ and incubation for 2-3 $\mathrm{min}$ at room temperature. Phase separation was done by centrifugation at $12.000 \mathrm{~g}$ for $15 \mathrm{~min}$ at $4^{\circ} \mathrm{C}$ and the water phase was transferred in a fresh eppendorf tube. Equal volume of isopropanol was added and the RNA was left to precipitate at $-20^{\circ} \mathrm{C}$ overnight. The RNA was recovered by centrifugation at $12.000 \mathrm{~g}$ for $15 \mathrm{~min}$ at $4^{\circ} \mathrm{C}$ and washed once with $70 \%$ ethanol. The RNA pellets were dried on a $37^{\circ} \mathrm{C}$ block and resuspended in $50 \mu 1$ RNAse free water. To ensure RNA purity, a further cleanup procedure was performed by addition of glycogen blue (1/50 volume, $1 \mu \mathrm{l}), 3 \mathrm{M}$ sodium acetate $(1 / 5$ volume, $5 \mu \mathrm{l})$ and ethanol $(1,25$ volume, $62,5 \mu \mathrm{l})$ and the RNA was precipitated by shock freezing in liquid nitrogen and centrifugation at $12.000 \mathrm{~g}$ for $15 \mathrm{~min}$ at $4{ }^{\circ} \mathrm{C}$. The RNA pellets were washed once with $70 \%$ ethanol, dried on a $37^{\circ} \mathrm{C}$ block and resuspended in 20 $50 \mu 1$ RNAse free water. The RNA concentration was determined using a spectrophotometer („Nanodrop ND100“, Peqlab Biotechnologie) and the RNA was stored at $-20^{\circ} \mathrm{C}$ or used directly for cDNA synthesis.

\subsection{Molecular Biology}

\subsubsection{Cloning of Dusp18}

\subsubsection{Cloning of Dusp18 cDNA in pCGN}

The coding sequence of Dusp18 was amplified from total cDNA of MOLT4 cells (an acute lymphoblastic leukemia cell line, the cDNA was kindly provided by Monika Bug), using primers designed to contain an XbaI (forward) and BamHI (reverse) restriction site (Table 2-5). To increase the amount of PCR product, the reaction was performed twice, using the first reaction as a template for the second (re-amplification). The PCR was assembled as described in Table 3-4. The cycling is shown in Table 3-5.

Table 3-4: Reaction setup for the PCR amplification of Dusp18

\begin{tabular}{cc}
\hline Reagent & Final concentration \\
\hline $\mathrm{ddH}_{2} \mathrm{O}$ & - \\
$\mathrm{MgSO}_{4}(25 \mathrm{mM})$ & $2 \mathrm{mM}$ \\
$\mathrm{dNTP} \operatorname{mix}(20 \mathrm{mM}$ each) & $0,2 \mathrm{mM}$ each \\
$10 \mathrm{x}$ Taq Buffer & $1 \mathrm{x}$ \\
primer forward & $300 \mathrm{nM}$ \\
primer reverse & $300 \mathrm{nM}$ \\
Template cDNA & $3 \mu 1$ \\
Taq polymerase & $1,25 \mathrm{u}$
\end{tabular}


Table 3-5: Cycling conditions for the PCR amplification of Dusp18 I

\begin{tabular}{ccc}
\hline Temperature & Time & Cycling \\
\hline $95^{\circ} \mathrm{C}$ & $3 \mathrm{~min}$ & $1 \mathrm{x}$ \\
\hline $95^{\circ} \mathrm{C}$ & $30 \mathrm{sec}$ & \\
$50^{\circ} \mathrm{C}$ & $30 \mathrm{sec}$ & $40 \mathrm{cycles}$ \\
$72^{\circ} \mathrm{C}$ & $50 \mathrm{sec}$ & \\
$-12^{\circ} \mathrm{C}$ & &
\end{tabular}
$12^{\circ} \mathrm{C}$

Cooling

The PCR reaction was then loaded into a $1 \%$ Agarose gel (made with TAE buffer). The product (600 bp) was cut from the gel, purified using QIAquick PCR purification kit (Qiagen), and measured on a spectrophotometer („Nanodrop ND100“, Peqlab Biotechnologie). Digestion of the purified product with BamHI and $\mathrm{XbaI}$ was performed for $2 \mathrm{~h}$ at $37^{\circ} \mathrm{C}$ (Table 3-6). The enzymes were subsequently inactivated by incubation at $65^{\circ} \mathrm{C}$ for $10 \mathrm{~min}$ and the reaction was used for the ligation.

Table 3-6: Setup of the restriction digestion reaction of the Dusp18 PCR product I

\begin{tabular}{ccc}
\hline Reagent & Final amount & Volume \\
\hline 10x Tango Buffer & $1 \mathrm{x}$ & $3,1 \mu \mathrm{l}$ \\
XbaI $(10 \mathrm{u} / \mu \mathrm{l})$ & $0,7 \mathrm{u}$ & $0,5 \mu$ of dil $1: 10$ (in water) \\
BamHI $(10 \mathrm{u} / \mu \mathrm{l})$ & $2 \mathrm{u}$ & $0,5 \mu \mathrm{l}$ of dil $1: 10$ (in water) \\
DNA & $280 \mathrm{ng}$ & $28 \mu 1$ \\
total volume & & $31 \mu \mathrm{l}$
\end{tabular}

The pCGN vector backbone containing the N-terminal HA tag sequence was obtained as a fragment from the digestion of a pCGN-HA-E1B plasmid (kindly provided by Magdalena Morawska). The pCGN plasmid was digested with $\mathrm{XbaI}$ and $\mathrm{BamHI}$ for $2 \mathrm{~h}$ at $37^{\circ} \mathrm{C}$, to create the ligation sites (Table 3-7). The digestion reaction was loaded in a $0,8 \%$ agarose gel (made with TAE buffer) and the $5,1 \mathrm{~kb}$ vector band was cut from the gel, purified using QIAquick PCR purification kit (Qiagen), and measured on a spectrophotometer (,Nanodrop ND100“, Peqlab Biotechnologie), then used for the ligation reaction.

Table 3-7: Setup of the restriction digestion reaction of the $p C G N-H A-E 1 B$ plasmid

\begin{tabular}{ccc}
\hline Reagent & Final amount & Volume \\
\hline $\mathrm{ddH}_{2} \mathrm{O}$ & $1 \mathrm{x}$ & $22,5 \mu \mathrm{l}$ \\
$10 \mathrm{x} \mathrm{Tango} \mathrm{Buffer}$ & $0,7 \mathrm{u}$ & $5 \mu \mathrm{l}$ \\
$\mathrm{XbaI}(10 \mathrm{u} / \mu \mathrm{l})$ & $2 \mathrm{u}$ & $0,7 \mu \mathrm{l}$ of dil $1: 10$ (in water) \\
$\mathrm{BamHI}(10 \mathrm{u} / \mu \mathrm{l})$ & $3 \mu \mathrm{g}$ & $0,2 \mu 1$ \\
$\mathrm{DNA}$ & & $22 \mu \mathrm{l}$ \\
total volume & & $50 \mu \mathrm{l}$
\end{tabular}

For the ligation reaction, two ratios of insert DNA to vector, as well as a negative reaction (without insert) were performed (Table 3-8) at $16^{\circ} \mathrm{C}$ overnight. E. coli chemical competent bacteria (generated from the DH-10 „Electromax“ bacteria (Invitrogen) as described in Sambrook \& Russell, 
2001) were transformed with $5 \mu 1$ of each ligation reaction (incubation of the bacteria plus DNA for 30 min on ice, heat-shock at $37^{\circ} \mathrm{C}$ for $10 \mathrm{~min}$, incubation on ice for $10 \mathrm{~min}$, addition of $200 \mu \mathrm{l}$ of $2 \mathrm{xYT}$ medium and incubation at $37^{\circ} \mathrm{C}$ for $1 \mathrm{~h}$, plating on $2 \mathrm{xYT}$ plates with $25 \mu \mathrm{g} / \mathrm{ml}$ kanamycin). 44 colonies were then screened for the insert by colony PCR (Table 3-9; cycling: $95^{\circ} \mathrm{C}, 5 \mathrm{~min} ; 30$ times $\left.\left\{95^{\circ} \mathrm{C}, 30 \mathrm{sec} ; 50^{\circ} \mathrm{C}, 30 \mathrm{sec} ; 72^{\circ} \mathrm{C}, 1 \mathrm{~min}\right\}\right)$.

Table 3-8: Setup of the ligation reaction of Dusp18 in $p C G N$

\begin{tabular}{cccccc}
\hline Reagent & Concentration & Final conc. & ratio 1:1,7 & $\mathbf{1 : 3 , 3}$ & negative \\
\hline Vector & $35 \mathrm{ng} / \mu \mathrm{l}$ & $1,75 \mathrm{or} 3,5 \mathrm{ng} / \mu \mathrm{l}$ & $2 \mu \mathrm{l}$ & $1 \mu 1$ & $2 \mu \mathrm{l}$ \\
Insert & $10 \mathrm{ng} / \mu \mathrm{l}$ & $5,75 \mathrm{ng} / \mu \mathrm{l}$ & $12 \mu \mathrm{l}$ & $12 \mu \mathrm{l}$ & - \\
T4 buffer & $10 \mathrm{x}$ & $1 \mathrm{x}$ & $2 \mu 1$ & $2 \mu 1$ & $2 \mu \mathrm{l}$ \\
T4 ligase & $1 \mathrm{u} / \mu \mathrm{l}$ & $1 \mathrm{u}$ & $1 \mu 1$ & $1 \mu 1$ & $1 \mu 1$ \\
PEG6000 & $24 \%$ & $4,6 \%$ & $4 \mu 1$ & $4 \mu 1$ & $4 \mu 1$ \\
$\mathrm{H}_{2} \mathrm{O}$ & - & - & - & - & $12 \mu 1$ \\
total & & & 21 & 20 & 20
\end{tabular}

Table 3-9: Setup of the colony PCR

\begin{tabular}{|c|c|c|}
\hline & Final Conc. & Volume \\
\hline $\mathrm{ddH}_{2} \mathrm{O}$ & - & $14,5 \mu \mathrm{l}$ \\
\hline $\mathrm{MgSO}_{4} 25 \mathrm{mM}$ & $3 \mathrm{mM}$ & $2,4 \mu \mathrm{l}$ \\
\hline dNTPs $20 \mathrm{mM}$ & $200 \mu \mathrm{M}$ & $0,2 \mu \mathrm{l}$ \\
\hline 10x Taq buffer & $1 \mathrm{x}$ & $2 \mu 1$ \\
\hline primer $\mathrm{FW} 10 \mu \mathrm{M}$ & $200 \mathrm{nM}$ & $0,4 \mu \mathrm{l}$ \\
\hline primer REV $10 \mu \mathrm{M}$ & $200 \mathrm{nM}$ & $0,4 \mu \mathrm{l}$ \\
\hline Taq polymerase LC & $1,25 \mathrm{u}$ & $0,1 \mu \mathrm{l}$ \\
\hline
\end{tabular}

A few bacteria from each colony were added using a tip

A positive clone was further amplified in a $50 \mathrm{ml}$ culture and plasmid DNA was isolated using the PureYield ${ }^{\text {TM }}$ Plasmid Midiprep System (Promega). The clone was sequenced using pCMV forward and the Dusp18 cloning forward primers (Table 2-5; reaction setup: Table 3-10), and the BigDye ${ }^{\circledR}$ Terminator v3.1 Cycle Sequencing Kit (Applied Biosystems). The polymerase chain reaction (PCR) was first developed by Mullis \& Faloona (Mullis \& Faloona, 1987). The sequencing PCR reaction was purified by ethanol precipitation (addition of $1 \mu 125 \mathrm{mM}$ EDTA, $1 \mu 13 \mathrm{M}$ sodium acetate, and $50 \mu 1$ $100 \%$ ethanol on ice, centrifugation at $16.000 \mathrm{~g}$ for $15 \mathrm{~min}$, washing once with $70 \%$ ethanol, and resuspension of the product in $15 \mu \mathrm{l}$ Hi-Dye formamide). The sequencing of the PCR product was then done in the department of developmental biochemistry (Ernst Caspari Haus, Goettingen, Germany). The sequences were analysed using the BioEdit software. 
Table 3-10: Setup of the sequencing PCR

\begin{tabular}{cc}
\hline Reagent & Final Conc. \\
\hline Plasmid & $200-400 \mathrm{ng}$ \\
Seq-buffer (kit) & $1,5 \mu \mathrm{l}$ \\
Seq-mix (kit) & $1,5 \mu 1$ \\
Primer & $8 \mathrm{pmol}$ \\
$\mathrm{ddH}_{2} \mathrm{O}$ & adjust to $10 \mu \mathrm{l}$
\end{tabular}

Cycling: $96^{\circ} \mathrm{C}, 10 \mathrm{sec} / 55^{\circ} \mathrm{C}, 15 \mathrm{sec} / 60^{\circ} \mathrm{C}, 4 \mathrm{~min}$ for 25 cycles

\subsubsection{Cloning of Dusp18 in pIRES}

The following experimental procedure was performed by Franziska Schmidt. We previously cloned Dusp18 cDNA in the pIRES vector (Invitrogen) for creating the stable U2OS cell lines. The coding region of Dusp18 was amplified by PCR (Table 3-11) using the previously generated pCGNDusp18 plasmid as a template and primers with NotI (forward) or BamHI (reverse) restriction sites. The reverse primer contained the HA tag sequence upstream of the restriction site (the primers are included in Table 2-5). The PCR fragment was purified using QIAquick® PCR Purification Kit (Qiagen). The vector and the PCR product were digested with BamHI and NotI to create the ligation sites (Table 3-12). After restriction digestion, the enzymes were inactivated by incubating the reactions at $80^{\circ} \mathrm{C}$ for $30 \mathrm{~min}$.

Table 3-11: Reaction setup for the PCR amplification of Dusp18 II

\begin{tabular}{cccc}
\hline Reagent & Stock conc. & Volume $(\boldsymbol{\mu l})$ & Final conc. \\
\hline $\mathrm{ddH}_{2} \mathrm{O}$ & & 37,5 & - \\
Pfu reaction buffer & $10 \mathrm{x}$ & 5,0 & $1 \mathrm{x}$ \\
dNTPs & $20 \mathrm{mM}$ & 0,5 & $200 \mu \mathrm{M}$ \\
DNA template & $100 \mathrm{ng} / \mu \mathrm{l}$ & 1,0 & $100 \mathrm{ng}$ \\
Primer Fwd & $5 \mu \mathrm{M}$ & 2,5 & $250 \mathrm{nM}$ \\
Primer Rev & $5 \mu \mathrm{M}$ & 2,5 & $250 \mathrm{nM}$ \\
Pfu Turbo Polymerase & $2,5 \mathrm{U} / \mu \mathrm{l}$ & 1,0 & $2,5 \mathrm{U}$ \\
\hline $\mathrm{Cycling}: 95^{\circ} \mathrm{C}, 2 \mathrm{~min} . ; 30$ times & $\left\{95^{\circ} \mathrm{C}, 30 \mathrm{sec} ; 58^{\circ} \mathrm{C}, 30 \mathrm{sec} ; 72^{\circ} \mathrm{C}, 1 \mathrm{~min}\right\} ; 72^{\circ} \mathrm{C}, 10 \mathrm{~min}$.
\end{tabular}

Table 3-12: Setup of the restriction digestion reaction for the cloning of Dusp18 in pIRES

\begin{tabular}{lcc}
\hline & insert DNA & vector \\
\hline DNA & PCR product $(10 \mu \mathrm{l})$ & $3 \mu \mathrm{g}(5,35 \mu \mathrm{l})$ \\
NotI $(10 \mathrm{U} / \mu \mathrm{l})$ & $2 \mu \mathrm{l}(20 \mathrm{U})$ & $2 \mu \mathrm{l}(20 \mathrm{U})$ \\
BamHI $(10 \mathrm{U} / \mu \mathrm{l})$ & $1 \mu \mathrm{l}(10 \mathrm{U})$ & $1 \mu \mathrm{l}(10 \mathrm{U})$ \\
$10 \mathrm{x}$ BamHI buffer & $2 \mu \mathrm{l}(1 \mathrm{x})$ & $2 \mu \mathrm{l}(1 \mathrm{x})$ \\
water & $5 \mu \mathrm{l}$ & $9,65 \mu \mathrm{l}$ \\
Final volume & $20 \mu \mathrm{l}$ & $20 \mu \mathrm{l}$ \\
\hline
\end{tabular}


The vector was subsequently dephosphorylated by incubating the reaction with 1 unit of calf intestine alkaline phosphatase (Fermentas) for $1 \mathrm{~h}$ at $37^{\circ} \mathrm{C}$. The PCR fragment and the vector were then once more purified using QIAquick® PCR Purification Kit (Qiagen), their concentrations were measured using a spectrophotometer („Nanodrop ND100“, Peqlab Biotechnologie), and then used for the ligation reaction. The ligation was performed at $15^{\circ} \mathrm{C}$ overnight using two ratios of vector to insert DNA (calculated taking into account the different sizes), as well as a negative reaction without the insert DNA (Table 3-13).

Table 3-13: Setup of the ligation reaction of Dusp 18 in pIRES

\begin{tabular}{cccc}
\hline Component & Ratio 1:3 & Ratio 1:10 & No insert DNA \\
\hline vector & $200 \mathrm{ng}$ & $200 \mathrm{ng}$ & $200 \mathrm{ng}$ \\
insert DUSP18-HA & $72 \mathrm{ng}$ & $240 \mathrm{ng}$ & - \\
ddH ${ }_{2} \mathrm{O}$ & $7,25 \mu \mathrm{l}$ & $6,75 \mu \mathrm{l}$ & $7,46 \mu \mathrm{l}$ \\
$10 \mathrm{x}$ ligase buffer & $1 \mu \mathrm{l}(1 \mathrm{x})$ & $1 \mu \mathrm{l}(1 \mathrm{x})$ & $1 \mu \mathrm{l}(1 \mathrm{x})$ \\
T4 ligase $(200 \mathrm{U} / \mu \mathrm{l})$ & $1 \mu \mathrm{l}(200 \mathrm{U})$ & $1 \mu \mathrm{l}(200 \mathrm{U})$ & $1 \mu \mathrm{l}(200 \mathrm{U})$ \\
total volume & $10 \mu \mathrm{l}$ & $10 \mu \mathrm{l}$ & $10 \mu \mathrm{l}$
\end{tabular}

The ligation was electroporated in E. coli ("Electromax" DH-10B, Invitrogen) bacteria ( $0,4 \mu 1$ of the ligation reaction were mixed with $7 \mu 1$ of bacteria and placed in an electroporation cuvette, electroporation parameters used: $1,8 \mathrm{kV}, 200 \Omega, 25 \mu \mathrm{F}$ ). The bacteria were subsequently incubated with $200 \mu \mathrm{l} 2 \mathrm{YT}$ medium for $1 \mathrm{~h}$ at $37^{\circ} \mathrm{C}$ and plated on 2YT-agar plates containing ampicillin (200 $\mu \mathrm{g} / \mathrm{ml}$ ). The colonies grown were checked with colony PCR (Table 3-9). A positive clone was further amplified in a $50 \mathrm{ml}$ culture and plasmid DNA was isolated using the PureYield ${ }^{\mathrm{TM}}$ Plasmid Midiprep System (Promega). The clone was sequenced using pCMV forward and the Dusp18 cloning forward primers (Table 2-5) as described for pCGN-HA-Dusp18.

\subsubsection{Quantitative Polymerase Chain Reaction (qPCR)}

The following experimental procedure is based on Ishiguro et al., 1995.

\subsubsection{1 cDNA synthesis from total RNA}

For cDNA synthesis, the total mRNA was reverse transcribed using a combination of poly-dT primers and random poly-dN primers. The following reagents were mixed in the first step of the reaction:

Table 3-14: Reaction setup for cDNA synthesis from total RNA part I

\begin{tabular}{cccc}
\hline & Stock conc. & $\boldsymbol{\mu l}$ per reaction & Final conc. (in 20 $\mu \mathrm{l}$ ) \\
\hline RNA & Varied & Could be up to $10 \mu \mathrm{l}$ & $1 \mu \mathrm{g}$ total RNA \\
Mixed primers & $15 \mu \mathrm{M}$ poly-dN primer & 2 & $1,5 \mu \mathrm{M}$ poly-dN primer \\
& $50 \mu \mathrm{M}$ poly-dT primer & & $5 \mu \mathrm{M}$ poly-dT primer \\
$\mathrm{dNTPs}$ & $2,5 \mathrm{mM}$ & 4 & $500 \mu \mathrm{M}$ \\
$\mathrm{H}_{2} \mathrm{O}$ & - & to $16 \mu$ l final reaction & - \\
& & volume
\end{tabular}


The mix was heated at $70^{\circ} \mathrm{C}$ for $5 \mathrm{~min}$ to resolve the secondary structures of the RNA and then briefly cooled to $12^{\circ} \mathrm{C}$ to allow primer annealing. The following reagents were added in the second step of the reaction:

Table 3-15: Reaction setup for cDNA synthesis from total RNA part II

\begin{tabular}{|c|c|c|c|}
\hline & Stock conc. & $\mu \mathrm{l}$ per reaction & Final conc. (in $20 \mu \mathrm{l})$ \\
\hline $\begin{array}{c}\text { M-MuLV RT Reaction } \\
\text { Buffer }\end{array}$ & $10 x$ & 2 & $1 \mathrm{x}$ \\
\hline RNAse Inhibitor & $40 \mathrm{U} / \mu \mathrm{l}$ & 0,25 & $10 \mathrm{U}$ \\
\hline $\begin{array}{c}\text { M-MuLV Reverse } \\
\text { Transcriptase }\end{array}$ & $200 \mathrm{U} / \mu \mathrm{l}$ & 0,125 & $25 \mathrm{U}$ \\
\hline $\mathrm{H}_{2} \mathrm{O}$ & - & 1,625 & - \\
\hline
\end{tabular}

The reverse transcription was done at $42^{\circ} \mathrm{C}$ for 1 hour and the enzyme was subsequently inactivated at $95^{\circ} \mathrm{C}$ for $5 \mathrm{~min}$. Control reactions without the reverse transcriptase were also performed to check each sample for genomic DNA contamination. Each reaction was diluted with RNAse-free water to a final volume of $50 \mu 1$ and the cDNA was stored at $-20^{\circ} \mathrm{C}$ or used directly for qPCR.

\subsubsection{Quantitative PCR}

3.2.2.2.1 Preparation of qPCR homemade mastermix:

Table 3-16: Preparation of home-made 10x PCR mix

\begin{tabular}{cccc}
\hline Component & Stock Conc. & For 10ml & Final Conc. \\
\hline Tris- $\mathrm{HCl}$ pH8.8 & $1,5 \mathrm{M}\left(\right.$ in $\left.\mathrm{H}_{2} \mathrm{O}\right)$ & $5 \mathrm{ml}$ & $750 \mathrm{mM}$ \\
$\left(\mathrm{NH}_{4}\right)_{2} \mathrm{SO}_{4}$ & $1 \mathrm{M}\left(\mathrm{in}_{2} \mathrm{O}\right)$ & $2 \mathrm{ml}$ & $200 \mathrm{mM}$ \\
Tween-20 & $10 \%\left(\right.$ in $\left.\mathrm{H}_{2} \mathrm{O}\right)$ & $100 \mu \mathrm{l}$ & $0,1 \%$ \\
$\mathrm{H}_{2} \mathrm{O}$ & & $2,9 \mathrm{ml}$ &
\end{tabular}

Table 3-17: Preparation of home-made qPCR Mastermix

\begin{tabular}{|c|c|c|c|c|}
\hline Component & Stock Conc. & $\begin{array}{c}\mu \mathrm{l} \text { for } 1 \text { sample } \\
\qquad(14 \mu \mathrm{l})\end{array}$ & $\begin{array}{c}\mu \mathrm{l} \text { for } 1000 \\
\text { samples }(14 \mathrm{ml})\end{array}$ & Final Conc. \\
\hline Home-made $10 \mathrm{x}$ & $10 \mathrm{x}$ & 2,5 & 2500 & $1 \mathrm{x}$ \\
\hline \multicolumn{5}{|l|}{ PCR mix } \\
\hline $\mathrm{MgCl}$ & $25 \mathrm{mM}$ (in $\mathrm{H}_{2} \mathrm{O}$ ) & 3 & 3000 & $3 \mathrm{mM}$ \\
\hline SyBR green & 1:800 (in DMSO) & 0,2504 & 250,4 & $1: 80.000$ \\
\hline dNTPs & $\begin{array}{c}20 \mathrm{mM} \\
\text { (each, in } \mathrm{H}_{2} \mathrm{O} \text { ) }\end{array}$ & 0,25 & 250 & $0,2 \mathrm{mM}$ \\
\hline Taq polymerase & $5 \mathrm{U} / \mu \mathrm{l}$ & 0,1 & 100 & $20 \mathrm{U} / \mathrm{ml}$ \\
\hline Triton $\mathrm{X}-100$ & $10 \%$ (in $\mathrm{H}_{2} \mathrm{O}$ ) & 0,625 & 625 & $0,25 \%$ \\
\hline Trehalose & $\begin{array}{c}1 \mathrm{M} \text { (in 10mM Tris- } \\
\mathrm{HCl} \mathrm{pH} \mathrm{8.5)}\end{array}$ & 7,5 & 7500 & $300 \mathrm{mM}$ \\
\hline
\end{tabular}


Table 3-18: Preparation of the final primer-specific qPCR mastermix

\begin{tabular}{cccc}
\hline Component & Stock Conc. & $\begin{array}{c}\text { For one reaction } \\
(\mathbf{2 4} \boldsymbol{\mu l})\end{array}$ & $\begin{array}{c}\text { Final Conc. } \\
\text { (in 25 } \boldsymbol{\mu l})\end{array}$ \\
\hline $\begin{array}{c}\text { Home-made qPCR } \\
\text { Mastermix }\end{array}$ & - & $14 \mu \mathrm{l}$ & - \\
Primer FW & $10 \mu \mathrm{M}$ & & \\
Primer REV & $10 \mu \mathrm{M}$ & $1,5 \mu \mathrm{l}$ & $600 \mathrm{nM}$ \\
$\mathrm{H}_{2} \mathrm{O}$ & - & $1,5 \mu \mathrm{l}$ & $600 \mathrm{nM}$ \\
& & $7 \mu \mathrm{l}$ & -
\end{tabular}

For the qPCR reaction, $1 \mu \mathrm{l}$ of each cDNA or water (for the water controls) was mixed with 24 $\mu 1$ of the primer-specific qPCR Mastermix in the wells of a qPCR 96-well plate. The primers used to detect each gene product are listed in Table 2-5. The amplification of the cDNAs was done using the Chromo 4 real-time PCR system (Biorad) under the following conditions: DNA denaturation at $95^{\circ} \mathrm{C}$ for $3 \mathrm{~min}$, Cycling $39 \mathrm{x}\left(15 \mathrm{sec}\right.$ at $95^{\circ} \mathrm{C}$, polymerization for $40 \mathrm{sec}-1 \mathrm{~min}$ at $60^{\circ} \mathrm{C}$ depending on the size of the product, plate reading at $60^{\circ} \mathrm{C}$, at $79^{\circ} \mathrm{C}$ and at $80^{\circ} \mathrm{C}$ to resolve possible primer dimers), followed by the melting curve of the products every $0,5^{\circ} \mathrm{C}$ from $60-95^{\circ} \mathrm{C}$ to ensure specificity of amplification. Relative quantification of the samples was done using a standard curve for the ChIP assays, or the $2^{-\Delta \Delta \mathrm{Ct}}$ method (Livak \& Schmittgen, 2001) for the mRNA quantification. The results were analyzed using the CFX Manager Software and Microsoft Excel.

\subsubsection{Chromatin Immunoprecipitation (ChIP)}

The following procedure is based on Gilmour \& Lis, 1985. For the ChIP assays, the cells were transfected in $10 \mathrm{~cm}$ dishes and fixed $48 \mathrm{~h}$ after transfection by removing the growth medium and incubating the cells with $8 \mathrm{ml}$ of 1,42\% formaldehyde (in PBS) for $15 \mathrm{~min}$ at RT. The formaldehyde was then quenched by addition of $1 \mathrm{ml} 1,25 \mathrm{M}$ glycine and incubation for $5 \mathrm{~min}$ at RT. The fixed cells were subsequently washed twice with cold PBS, harvested by scrapping in $1 \mathrm{ml}$ cold ChIP buffer with protease inhibitors (ChIP buffer ${ }^{+++}$) and lysed by pipetting. A nuclear pellet was obtained by centrifugation at $12.000 \mathrm{~g}$ for $1 \mathrm{~min}\left(4^{\circ} \mathrm{C}\right)$. The nuclei were washed once with $1 \mathrm{ml}$ cold ChIP buffer ${ }^{+++}$ and the pellet was resuspended in $300 \mu \mathrm{l}$ cold ChIP buffer $^{+++}$. The chromatin was sheared by sonification using a Bioruptor sonicator (Diagnode) 3 times for 10 min each (settings: 10sec on/off duty time, at high power) and diluted with an additional $300 \mu \mathrm{l} \mathrm{ChIP}$ buffer $^{+++}$. The samples were then pre-cleared using plain sepharose beads for $1 \mathrm{~h}$ on a rotator $\left(4^{\circ} \mathrm{C}\right)$ followed by centrifugation at $12.000 \mathrm{~g}$ for $10 \mathrm{~min}\left(4^{\circ} \mathrm{C}\right)$. The pre-cleared supernatant was subsequently aliquoted at a volume of 50 $\mu 1$ in fresh eppendorf tubes and the aliquots were snap-frozen in liquid nitrogen.

One aliquot from each sample was used as an input control in which the DNA was precipitated by the addition of $1 \mu \mathrm{l}$ GlycoBlue (glycogen) and $100 \mu \mathrm{l}$ cold $100 \%$ ethanol and incubation at $-20^{\circ} \mathrm{C}$ overnight. The DNA was pelleted by centrifugation at $12.000 \mathrm{~g}$ for $20 \mathrm{~min}\left(4^{\circ} \mathrm{C}\right)$ and washed once with $500 \mu 1$ of cold $70 \%$ ethanol. The pellet was dried and resuspended in $100 \mu 110 \%$ Chelex beads (in $\left.\mathrm{H}_{2} \mathrm{O}\right)$. 
For the immunoprecipitation of specific proteins on the chromatin, each $50 \mu$ l aliquot was diluted with ChIP buffer ${ }^{+++}$to a final volume of $500 \mu \mathrm{l}$ and incubated on a rotator overnight with $1 \mu \mathrm{g}$ of the respective antibody $\left(4^{\circ} \mathrm{C}\right)$. Protein A sepharose beads were blocked overnight in ChIP buffer containing 3,3\% BSA and 1mg of sonicated salmon sperm DNA and washed 3 times with ChIP buffer before resuspended in ChIP buffer $^{+++}$to make a 50\% slurry. $30 \mu \mathrm{l}$ of the protein A sepharose beads were then added to the antibody-antigen-chromatin complexes and incubated for $2 \mathrm{~h}$ on a rotator $\left(4^{\circ} \mathrm{C}\right)$. The ChIP immune complexes (beads) were afterwards washed 6 times with cold ChIP buffer (centrifugation at $2.000 \mathrm{~g}$ for $2 \mathrm{~min}$ at $4^{\circ} \mathrm{C}$ ) and $100 \mu \mathrm{l} 10 \%$ Chelex beads (in $\mathrm{H}_{2} \mathrm{O}$ ) were added to them.

All samples (including the inputs) were briefly vortexed and heated at $95^{\circ} \mathrm{C}$ for $10 \mathrm{~min}$. After cooling on ice, $1,5 \mu \mathrm{l}$ of protease $\mathrm{K}$ (stock $20 \mu \mathrm{g} / \mu \mathrm{l}$ ) were added in each sample and protein digestion took place at $55^{\circ} \mathrm{C}$ for $30 \mathrm{~min}$ under shaking $(1000 \mathrm{rpm})$. The protease $\mathrm{K}$ was then inactivated by heating at $95^{\circ} \mathrm{C}$ for $10 \mathrm{~min}$. The samples were centrifuged at $12.000 \mathrm{~g}$ for $1 \mathrm{~min}\left(4^{\circ} \mathrm{C}\right)$ and the supernatants were transferred in fresh eppendorf tubes and used for detection of immunoprecipitated DNA by qPCR, or stored at $-20^{\circ} \mathrm{C}$.

\subsection{Biochemistry}

\subsubsection{Immunoblotting analysis}

\subsubsection{SDS-PAGE}

For Western Blot analysis, the cells were harvested and lysed as described above. As has been previously described (Laemmli U.K., 1970), proteins can be easily separated on the basis of their mass by electrophoresis in a SDS-polyacrylamide gel under denaturing conditions. To prepare the SDSpolyacrylamide gel, the vertical gels were set in between two glass plates within a casting chamber and two spacers giving an internal thickness of $1.5 \mathrm{~mm}$ between the two plates. The gels were composed of two layers: a $10 \%$ acrylamide/bisacrylamide separating gel that separates the proteins according to size and a lower percentage (5\%) stacking gel that insures simultaneous entry of the proteins into the separating gel at the same height (Table 3-19).

Table 3-19: SDS-polyacrylamide gel preparation for protein electrophoresis

\begin{tabular}{cccc}
\hline \multicolumn{2}{c}{ Separating Gel } & \multicolumn{2}{c}{ Stacking Gel } \\
\hline Component & final conc. & Component & final conc. \\
\hline $1,5 \mathrm{M}$ Tris pH 8,8 & $0,375 \mathrm{M}$ & $1 \mathrm{M}$ Tris pH 6,8 & $0,126 \mathrm{M}$ \\
30\%Acrylamide- & $10 \%$ & $\begin{array}{c}30 \% \text { Acrylamide- } \\
\text { Bisacrylamide Solution }\end{array}$ & $5 \%$ \\
Bisacrylamide Solution & & $\mathrm{H}_{2} \mathrm{O}$ & \\
$\mathrm{H}_{2} \mathrm{O}$ & & $10 \% \mathrm{SDS}$ & $0,1 \%$ \\
$10 \% \mathrm{SDS}$ & $0,1 \%$ & $10 \% \mathrm{APS}$ & $0,1 \%$ \\
$10 \% \mathrm{APS}$ & $0,1 \%$ & TEMED & $3 \%$ \\
TEMED & $0,4 \%$ &
\end{tabular}


The separating gel was poured in between the two glass plates, leaving a space of about $1,7 \mathrm{~cm}$ and $300 \mu \mathrm{l}$ of isopropanol was then added to the surface of the gel to exclude air bubbles. After the separating gel was polymerized, the isopropanol was removed. The stacking gel was then poured on top of the separating gel, the comb inserted and the gel was allowed to polymerize. The samples were loaded into the wells of the gel and electrophoresis buffer was added last to the chamber and any air bubbles expelled. SDS-PAGE was performed using $15 \mathrm{~mA}$ through the stacking gel and $18-20 \mathrm{~mA}$ through the separating gel. The negatively charged SDS-protein complexes migrate in the direction of the anode at the bottom of the gel.

\subsubsection{Immunoblotting (Western Blotting)}

This method of protein detection was first developed by Renart et al (1979) and by Towbin et al (1979). After separating the protein samples by SDS-PAGE, they were transferred to a nitrocellulose membrane using the wet transfer apparatus (Biorad). The stacking gel and the sides of running gel were removed beyond the sample wells with a razor blade and the gel was equilibrated with wet transfer buffer. The PVDF transfer membrane was soaked in $100 \%$ methanol for one minute and equilibrated in wet transfer buffer for a few minutes. Additionally six pieces of Whatman filter paper and 3 wet transfer sponges were soaked in wet transfer buffer. Two sponges followed by three Whatman paper pieces were placed on the red part of the cassette that is then placed towards the anode. Then the transfer membrane was placed on top of filter paper stack. The gel was placed on top of the PVDF membrane. The other three pieces of filter paper and the last sponge were placed on top of the gel. A clean plastic tube was rolled on top of the stack to exclude any air bubbles. Then the black part of the cassette was placed on top of the transfer stack and the cassette was closed firmly. The transfer chamber was filled completely with wet transfer buffer and the cassette was placed with the red towards the anode. The transfer was performed at $85 \mathrm{~V}$ for $120 \mathrm{~min}$. The pre-stained molecular weight protein ladder served as an indication of successful transfer.

\subsubsection{Immunostaining}

For detection of our protein of interest on the PVDF membrane, the membrane was first blocked in freshly prepared PBS-T containing 5\% nonfat dry milk (blocking buffer) for $1 \mathrm{~h}$ at room temperature with constant agitation. The primary antibody was diluted at 1:1000 in blocking buffer and used for incubation of the membrane overnight $(12-16 \mathrm{~h})$ at $4^{\circ} \mathrm{C}$ with agitation. The membrane was then washed three times with PBS-T, each time for $10 \mathrm{~min}$. The anti-mouse peroxidaseconjugated secondary antibody was diluted in blocking buffer, added to the membrane and incubated at RT for $1 \mathrm{~h}$. The membrane was then washed briefly three times with PBS-T, and with blocking solution for 15 min twice. For the phosphor-specific antibodies, 5\% BSA was used instead of milk (due to the competing phosphates of milk casein) and TBS instead of PBS.

Finally the membranes were covered with an enhanced chemiluminescence solution containing the peroxidase substrates (SuperSignal West Dura Extended Duration Substrate, Pierce) 
and incubated for approximately $1 \mathrm{~min}$ before measuring the luminescence signal. For low intensity signals a more sensitive detection system was used (SuperSignal West Femto Maximum Sensitivity Substrate, Pierce). The chemiluminescence reaction is catalyzed by the peroxidase that is conjugated on the secondary antibody (oxidation of luminol), and leads to the emission of photons. The membrane was covered in plastic film and luminescence was detected using a chemiluminescence imaging system (INTAS). When necessary, relative quantification of the protein bands was performed using the Lab1D software (INTAS).

\subsubsection{Coimmunoprecipitation (CoIP)}

For CoIP the cells were transfected in $10 \mathrm{~cm}$ dishes. The cells were harvested by scrapping and pelleted by centrifugation at $800 \mathrm{rcf}$ for $8 \mathrm{~min}$. The cell lysis was done in $1 \mathrm{ml}$ cold CoIP buffer with protease inhibitors (CoIP buffer $\left.^{++}\right)$by homogenization using a $26 \mathrm{G}$ syringe $(0,45 \mathrm{~mm}$ diameter). The lysates were then centrifuged at $16.000 \mathrm{~g}$ for $15 \mathrm{~min}\left(4^{\circ} \mathrm{C}\right)$ to pellet the cell debris, and the supernatant was transferred in fresh eppendorf tubes and pre-cleared with $50 \mu$ of plain sepharose beads for $1 \mathrm{~h}$ on a rotator $\left(4^{\circ} \mathrm{C}\right)$. A combination of protein $\mathrm{G}$ sepharose $(10 \mu 1$ per sample) and plain sepharose beads $(40 \mu \mathrm{l})$ was combined with $1 \mu \mathrm{g}$ of each antibody and incubated for $1 \mathrm{~h}$ on a rotator $\left(4^{\circ} \mathrm{C}\right)$. After pre-clearing, $30 \mu 1$ of each sample were kept as an input control and the rest was divided among the antibody-sepharose beads complexes. The antibody-antigen reaction took place for $2 \mathrm{~h}$ on a rotator $\left(4^{\circ} \mathrm{C}\right.$ ). The complexes (beads) were subsequently washed 10 times with $800 \mu \mathrm{l} \mathrm{CoIP} \mathrm{buffer}{ }^{++}$ (the first two times) or CoIP buffer (centrifugation at $2000 \mathrm{~g}$, for 2 min each time, $4^{\circ} \mathrm{C}$ ). $25 \mu \mathrm{l}$ of 6xLaemmli solution were added in each sample followed by incubation at $95^{\circ} \mathrm{C}$ for $5 \mathrm{~min}$ for protein denaturation. The samples were stored at $-20^{\circ} \mathrm{C}$ or used directly for immunoblotting.

\subsection{Human phosphatase siRNA library screening}

\subsubsection{Transfection of U2OS cells with the phosphatase library siRNAs}

Osteosarcoma U2OS cells (wt p53) were transfected with the human phosphatase Silencer Select siRNA library (Applied Biosystems) in BD immunofluorescence 96well plates using the Biomek 3000 automation workstation (Beckmann). Each phosphatase subunit was targeted by 3 different siRNAs in separate plates. Therefore for each set of targets there were 3 plates transfected targeting the same phosphatases with different siRNAs (A, B and C), and the transfection for each set was done twice, once for mock irradiation and once for exposing to $20 \mathrm{~J} / \mathrm{m}^{2} \mathrm{UVC}$. For each well (1 siRNA per well), 4,5 pmol (in $9 \mu \mathrm{l}$ ) of each siRNA were combined with $26 \mu$ l of plain DMEM medium. For each well, 0,25 $\mu 1$ Lipofectamine 2000 were mixed with 14,75 $\mu$ l plain DMEM medium and incubated for $5 \mathrm{~min}$ at RT (prepared as a mastermix). The Lipofectamine 2000 mastermix was then aliquoted in the wells and the siRNAs were added, mixed and the transfection mix was incubated for 20 at RT. Finally, the U2OS cells were added (7.000 cells per well, in $100 \mu 1$ complete medium). The cells were incubated with the transfection mix for $48 \mathrm{~h}$ to allow for mRNA degradation and 
irradiated with UVC or mock treated (as described in §3.1.5). 2,5 h after irradiation the cells were fixed and stained as described below.

\subsubsection{Fixation and immunofluorescence staining of the U2OS cells}

For fixation, the medium was completely removed carefully from the wells and the cells were incubated in $100 \mu \mathrm{l}$ of $3,7 \%$ Formaldehyde (in $\mathrm{PBS}^{++}$) for $20 \mathrm{~min}$ (RT). After washing twice with $\mathrm{PBS}^{++}$, the cells were permeabilized with $100 \mu 1$ 0,5\% Triton-X-100 (in $\mathrm{PBS}^{++}$) for $10 \mathrm{~min}$ (RT). The Triton-X-100 solution was removed, the cells washed 4 times with $\mathrm{PBS}^{++}$and blocked with $10 \%$ FCS (in $\mathrm{PBS}^{++}$) for $10 \mathrm{~min}$ (RT). The primary antibodies solution (10\% FCS), containing the FL393 antip53 (rabbit, polyclonal, dilution: 1:300) and the anti- $\gamma \mathrm{H} 2 \mathrm{Ax}$ (phosphor-Ser139, mouse, monoclonal, dilution: 1:1850) was then added in the wells (70 $\mu \mathrm{l}$ per well). After $1 \mathrm{~h}$ incubation at RT, the cells were washed three times with $\mathrm{PBS}^{++}$(the last time for $5 \mathrm{~min}$ ) and the secondary antibodies solution (10\% FCS), containing the Alexa-488 anti-rabbit (dilution: 1:550 - green fluorescence), the Alexa-546 anti-mouse (dilution: 1:550 - red fluorescence) and Hoechst DNA dye (Molecular Probes, stock concentration: $1 \mathrm{mg} / \mathrm{ml}$, dilution: 1:5500 - blue fluorescence) was then added in the wells $(70 \mu \mathrm{l}$ per well). After $45 \mathrm{~min}$ incubation at RT in the dark, the cells were washed three times with $\mathrm{PBS}^{++}$(the last time for $5 \mathrm{~min}$ ) and fresh $\mathrm{PBS}^{++}$was added in the wells. The wells were then covered with an aluminum plate cover and the plates were stored at $4{ }^{\circ} \mathrm{C}$ or directly imaged with the BD Pathway automatic imaging system (BD Biosciences).

\subsubsection{Imaging and data analysis}

Images were collected from all the wells (each well representing a different siRNA) using the BD Pathway automatic imaging system (BD Biosciences). The images were subsequently analyzed with the BD Pathway software (BD Biosciences). Each image was first processed to identify the nuclei in the well by using the Hoechst channel to generate a well mask, which could be used to measure the fluorescence of the other two channels (p53 and $\gamma \mathrm{H} 2 \mathrm{Ax}$ ) within each nucleus in a well. Two types of data were then generated from these intensities: one was the average intensity of each signal for each well (unconstrained data) and the other was the percentage of nuclei in each well that met an intensity threshold (constrained data). The intensity threshold was defined separately for each plate. The average intensity of the whole plate was used as an intensity threshold, as we assumed a random distribution of the siRNAs in the plate that would result in an approximately equal number of up- and down-regulators of our signal readouts. The threshold was such that the percentage of nuclei meeting this constrain in the wells transfected with the control siRNAs was about $30 \%$, and this did not vary much among the different plates. Therefore this constraining of the data made the comparison of the different plates possible, as the different sets of plates were transfected and immunostained on different days, and the overall intensities moderately varied between the sets. The constrained data were used then to generate a $\mathrm{z}$-score for each targeted phosphatase subunit using the following formula: 


$$
\mathrm{z}=\frac{X-\mu}{\sigma}
$$

where $\mathrm{X}$ is the mean of $\%$ constrained nuclei of the three siRNAs (A, B and C) targeting one phosphatase subunit, $\mu$ is the mean of all the $X$ values, and $\sigma$ is the standard deviation of the $X$ values. All z-scores were then aligned in graphs for each readout, as shown in Results, and phosphatase subunits with z-scores higher than 1 or lower than -1 were considered significant hits. 


\section{Results}

\subsection{Identification of novel phosphatases as potential players in the DNA damage and p53-response}

\subsubsection{Screening of the human phosphatase siRNA library}

The proper response of cells to damaged DNA and the activation of the p53 pathway are critical to avoid transformation of cells and development of cancer. This response depends largely on phosphorylation events, and is regulated by many already known kinases (reviewed in Kastan \& Bartek, 2004). As phosphorylation is a reversible post-translational modification, the removal of phosphates must also play important roles in the DNA damage response, but only recently has this begun to be revealed. To investigate the role of phosphatases in the response to DNA damage in a high-throughput manner, we first performed an siRNA screen targeting most of the human phosphatase subunits. Three parameters were analyzed: the accumulation of p53 without DNA damage, the accumulation of p53 after UVC irradiation, and the accumulation of $\gamma \mathrm{H} 2 \mathrm{Ax}$ after UVC irradiation. The detection of $\gamma \mathrm{H} 2 \mathrm{Ax}$ without $\mathrm{UVC}$ irradiation was almost impossible (the signal to background ratio was extremely low), so that any data obtained in this manner would not be reliable.

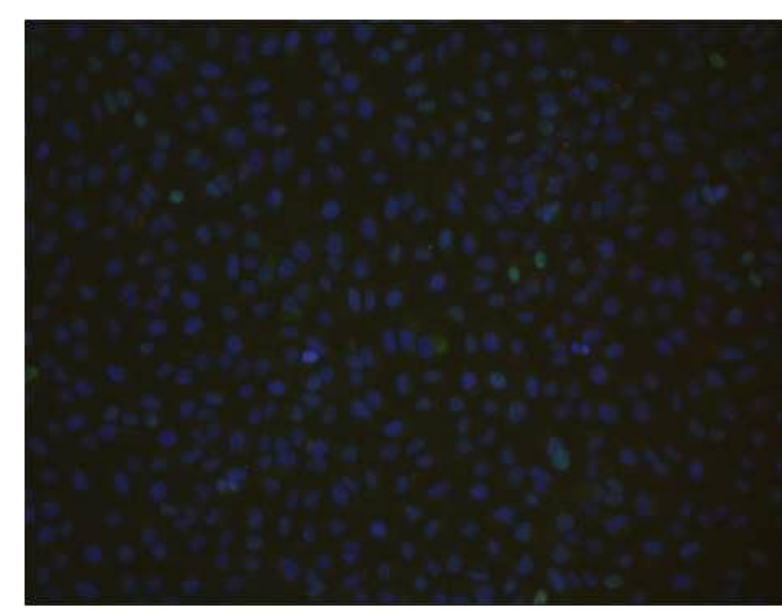

A

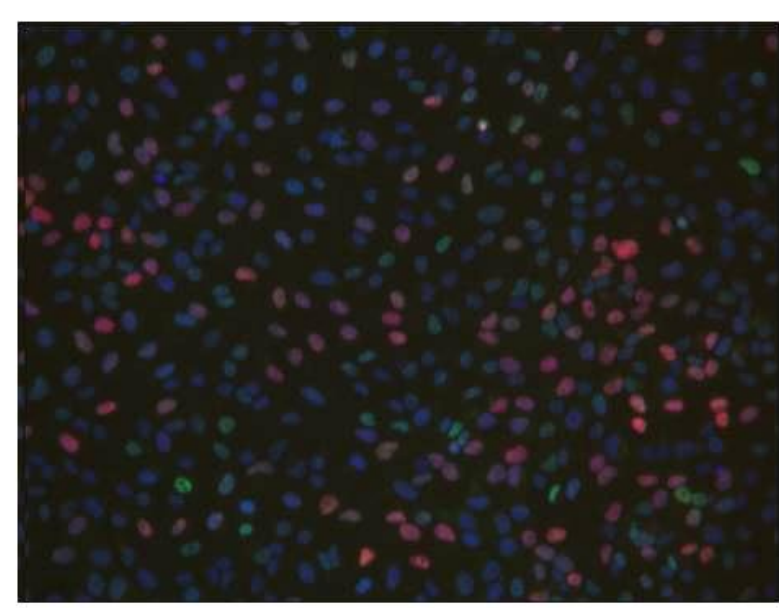

B

Figure 4-1: Immunofluorescence detection of 553 and $\gamma H 2 A x$ in UVC-exposed U2OS cells. U2OS cells were exposed to $20 \mathrm{~J} / \mathrm{m}^{2} \mathrm{UVC}$ irradiation and 2,5 h later fixed and stained for p53 (green) and $\gamma H 2 A x$ (red). The nuclei were identified by Hoechst staining (blue). The merged pictures are shown.

A: Mock irradiated cells. B: UVC irradiated cells. 
The exposure of U2OS cells to UVC irradiation induced DNA damage, which led to the accumulation of p53 as well as $\gamma \mathrm{H} 2 \mathrm{Ax}$. These parameters could be detected using immunofluorescence (Figure 4-1), and this assay served as the basis for our screen (a detailed description is provided in Methods §3.4). The data obtained were analyzed using the z-score method (as described in Methods \$3.4). A detailed overview of the targets that had a z-score more than 1 or less than -1 (this was used as a threshold to define the targets that significantly differed from the average) can be found in the Appendix (Figure 7-1). A selection of the most promising "hits", which had the highest z-scores for each parameter examined, is presented in Figure 4-2.

Using the z-score tables and the extent of consistency between the 3 different siRNAs targeting each phosphatase subunit, a selection of 39 targets was further evaluated. These phosphatases could be grouped into categories according to their known or putative function, as shown in Figure 4-3. Potential targets identified during the screen included phosphatases of the CTD domain of RNA polymerase II, subunits of the PP1 complexes, the catalytic subunits of calcineurin, protein tyrosine phosphatases, regulators of the cell cycle, PIP3 phosphatases and phosphatases that may play a role in stress signaling (e.g. regulators of JNK). To validate the effect of these 39 phosphatases, we chose one siRNA for each candidate and repeated the IF assay (see Appendix, Figure 7-2). In this way, the knockdown effect of 19 out of 39 candidates could be confirmed. An immunoblotting analysis, using one siRNA for each target in U2OS cells, was also performed. This offered us the potential to examine the effect of phosphatase knockdown on more parameters regulating the DNA damage response and the p53 network, namely Mdm2 and p21. An example of this evaluation is shown in Figure 4-4. 
A I.

p53 upregulation (Mock)

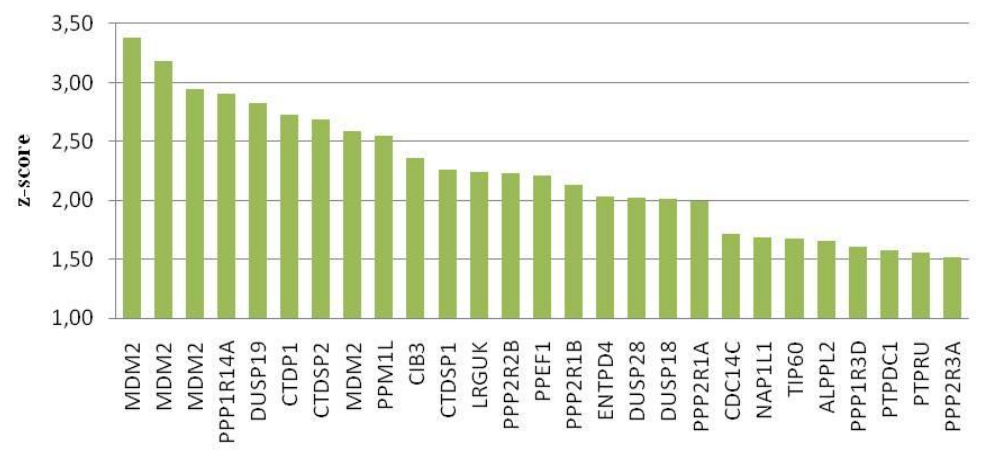

II. p53 downregulation (Mock)

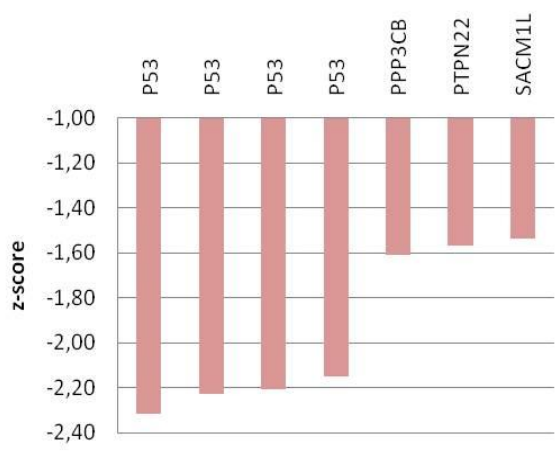

\section{B I.}

p53 upregulation (UVC)

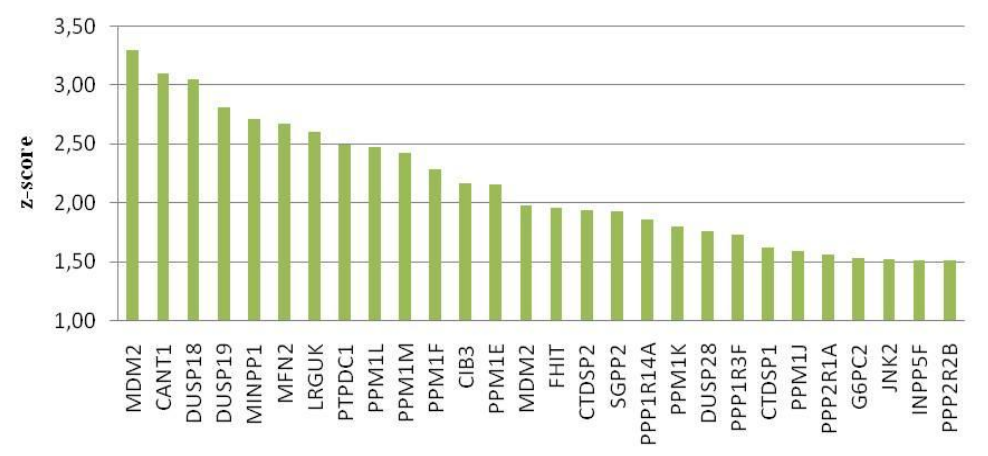

II. p53 downregulation (UVC)

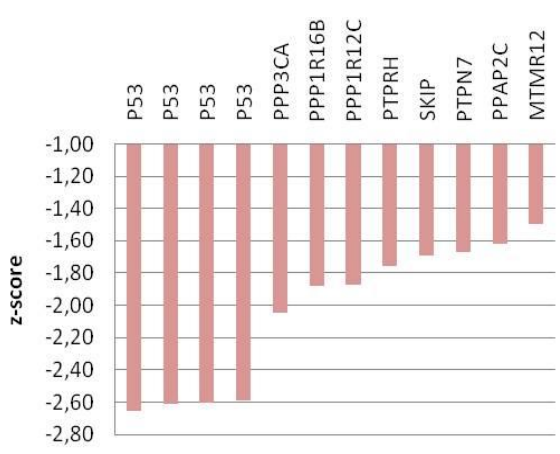

CI.

$\gamma \mathrm{H} 2 \mathrm{Ax}$ upregulation (UVC)

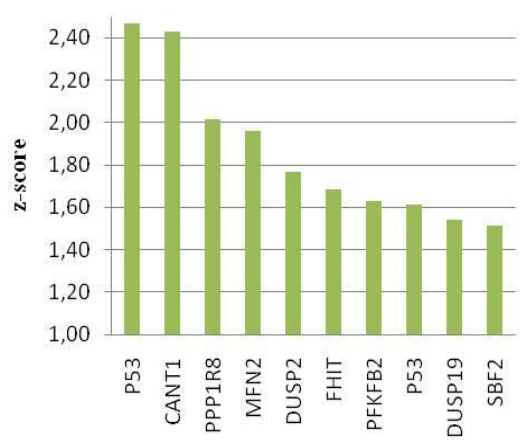

II.

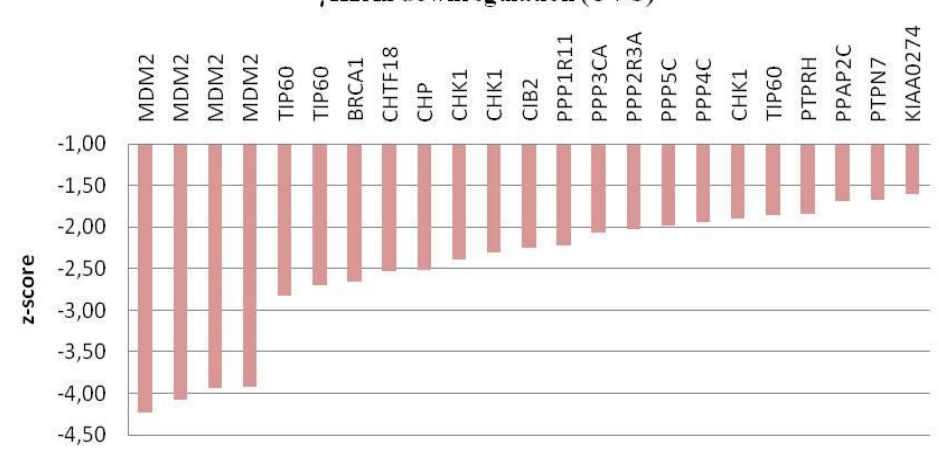

Figure 4-2: Human phosphatase siRNA library screen selected results.

The screen and the data analysis were performed as described in Methods (\$3.4). The top condidates (z-score > 1,5 or <-1,5) are displayed for upregulation (I) and downregulation (II) of each parameter measured.
A: p53 signal in non-irradiated cells
B: p53 signal in UVC-irradiated cells
C: $\gamma H 2 A x$ signal in UVC-irradiated cells 


\begin{tabular}{|c|c|c|}
\hline Group & Target & Literature \\
\hline \multirow[t]{3}{*}{ JNK/ ASK-1 signaling repressors } & DUSP18 & JNK phosphatase (Wu Q. et al., 2006) \\
\hline & DUSP19 & JNK / ASK phosphatase (Zama et al., 2002 a and b) \\
\hline & PPM1L & ASK phosphatase (Saito et al., 2007) \\
\hline \multirow[t]{3}{*}{ PIP3 phosphatases } & MINPP1 & \\
\hline & SKIP & \\
\hline & MTMR4 & \\
\hline \multirow{6}{*}{ calcineurin subunits and related proteins } & PPP3CA & \\
\hline & PPP3CB & \\
\hline & PPP3CC & \\
\hline & CHP & \\
\hline & CIB2 & DNA-PK interacting (Seki et al., 1999) \\
\hline & CIB3 & \\
\hline \multirow{4}{*}{ RNA pol II CTD phosphatases } & CTDP1/FCP1 & $\begin{array}{l}\text { FCP1 yeast mutants sensitive to DNA damage } \\
\text { (Jeonget al., 2005) }\end{array}$ \\
\hline & CTDSP2/SCP2 & \\
\hline & CTDSP1/SCP1 & \\
\hline & CTDSPL/SCP3 & \\
\hline \multirow[t]{2}{*}{ cell cycle related phosphatases } & CHTF18 & $\begin{array}{l}\text { PCNA \& DNA pol } \eta \text { interacting } \\
\text { (Shiomi et al.., 2007) }\end{array}$ \\
\hline & $\mathrm{CDC} 14 \mathrm{C}$ & \\
\hline \multirow[t]{4}{*}{ PP1 subunits } & PPP1R12C & PP1 is activated in DDR (Tang et al., 2008) \\
\hline & PPP1R16B & $\mathrm{PP} 1$ is a Chk-1 phosphatase \\
\hline & PPP1R14A & (den Elzen et al., 2004 a and b) \\
\hline & PPP1R8 & \\
\hline \multirow[t]{2}{*}{ PTK phosphatases } & PTPN22 & \\
\hline & PTPRH & expressed in cancer tissue (Matozaki et al., 1994) \\
\hline
\end{tabular}

Figure 4-3: Groups of phosphatases identified and further evaluated as potential regulators of DNA damage- and p53-response.

A phosphatase that caught our immediate interest was the dual specificity phosphatase 18 (abbreviated Dusp18 or Dusp18). The knockdown of Dusp18 induced the p53 pathway, as p53, and its targets p21 and mdm2 were accumulated in U2OS cells that were transfected with the siRNA targeting Dusp18 (Figure 4-4). 

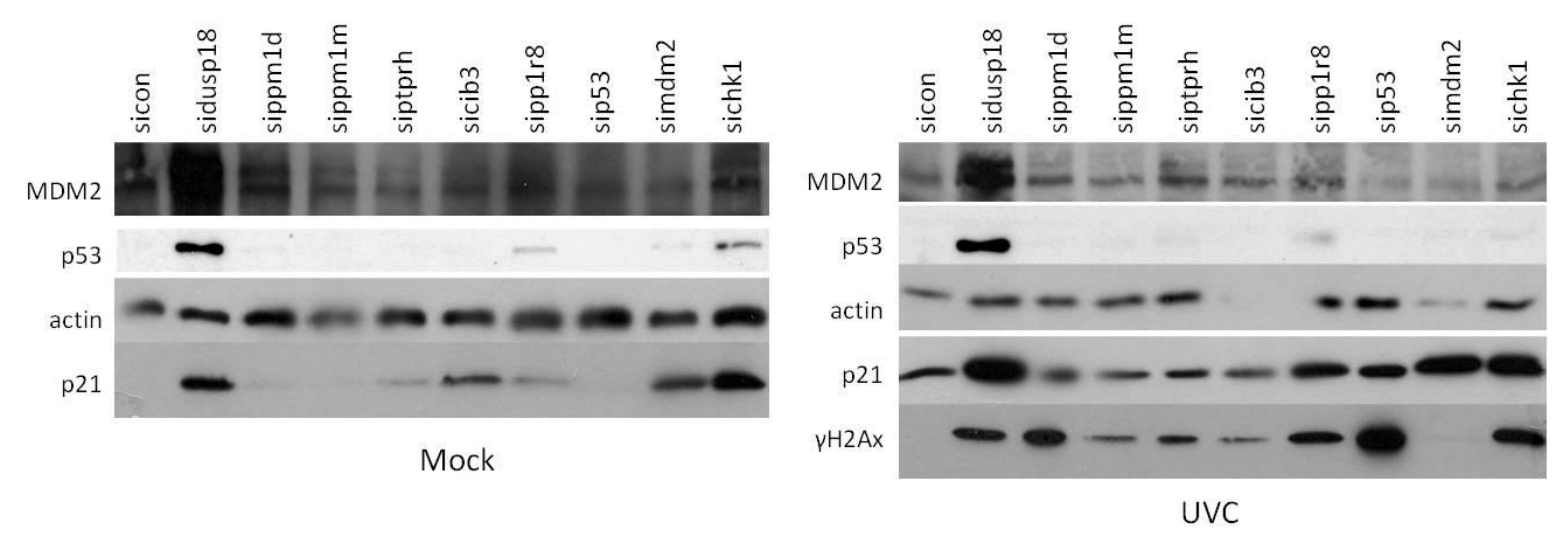

Figure 4-4: Validation of selected screen targets by immunoblotting.

U2OS cells were transfected with 1 siRNA per target from the phosphatase library and 48h later the cells were lysed. The lysates were analysed for $p 53, M d m 2, p 21$ and $\gamma H 2 A x$ protein levels. Actin was used as a loading control.

Left: Mock - irradiated cells. Right: UVC irradiated cells $\left(20 \mathrm{~J} / \mathrm{m}^{2}\right.$, harvesting 2,5h post UVC exposure).

\subsection{Investigation of Dusp18 as a novel regulator of the p53 pathway}

\subsubsection{Subcellular localization of human Dusp18}

Because of the contradictory reports available on Dusp18 localization and function, we first wanted to examine the localization of Dusp18 in our system. So far there have been two groups investigating the localization of Dusp18: Wu et al. (2006) performed overexpression experiments with an N-terminally tagged (GFP tag) human Dusp18 clone which seemed to localize uniformly in the cell (Wu et al., 2006; Figure 4-5). On the other hand, Rardin et al. (2008) performed endogenous studies using the murine and rat homologues of Dusp18 and identified it as an inner mitochondrial membrane protein, claiming that the $\mathrm{N}$-terminal tag of $\mathrm{Wu}$ et al. prevented the correct localization of the protein (notably, they made this point by using also a GFP tag, Figure 4-5; Rardin et al., 2008).

Human Dusp18 was cloned in the pCGN expression vector (with an N-terminal HA tag) and in the pIRES expression vector (with a C -terminal HA tag), as described in Methods \$3.2.1. We used these clones to conduct localization studies of Dusp18 in the cell. In our hands, HA-tagged Dusp18 localized approximately uniformly in the cytoplasm and the nucleus, and this was independent of the position of the HA tag (Figure 4-5). Furthermore, we performed a co-staining of the HA-tagged Dusp18 protein with MitoTracker (Invitrogen), which labels the mitochondria in cells. As shown in Figure 4-5, there was clearly no colocalization of the Dusp18 with the mitochondria, in our system. Finally, since the findings of Rardin and colleagues could not be confirmed, an alignment of human and murine Dusp18 was performed using Clustalw2 (European Bioinformatics Institute, EBI). The protein 
sequence between the two organisms was indeed quite conserved, with the central domain that contains the catalytic site being almost identical (Figure 4-6). However, a mitochondrial localization prediction software (Mitoprot II; Claros \& Vincens, 1996), showed a clear difference in the predicted probability of the two proteins localizing in the mitochondria: the murine homologue of Dusp18 used in the experiments of Rardin et al. had a probability of almost $90 \%$, while the human Dusp18 probability of mitochondrial localization was less than $60 \%$ (Figure 4-6). This suggested that, despite the high degree of conservation between the two homologues, their diversity might still target the proteins to different compartments in the cell.

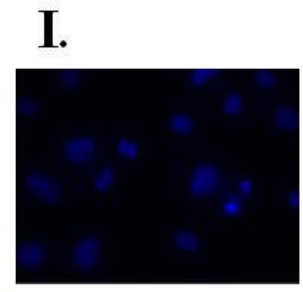

Hoechst

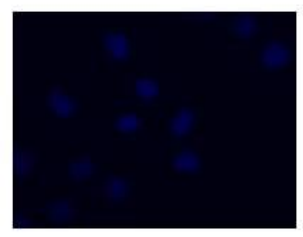

II.

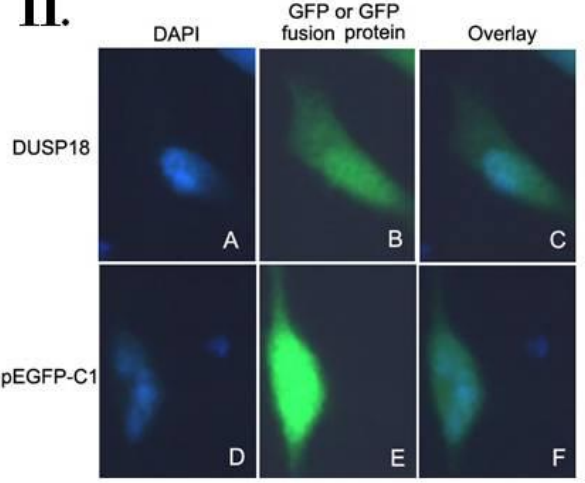

\section{.}

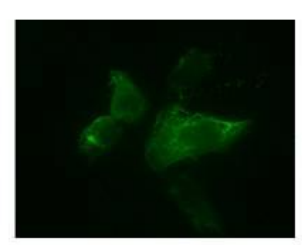

HA (dusp 18)

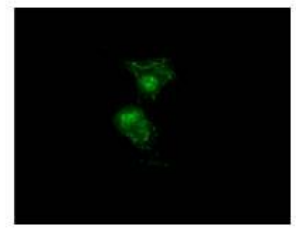

III.A.

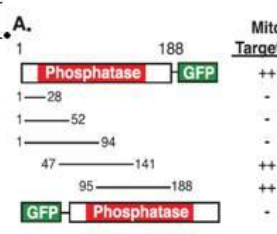

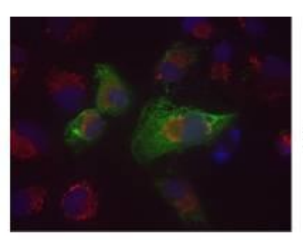

pcGN-HA-dusp 18

Merged

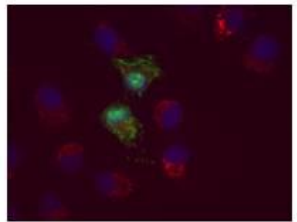

pIRES-dusp 18-HA

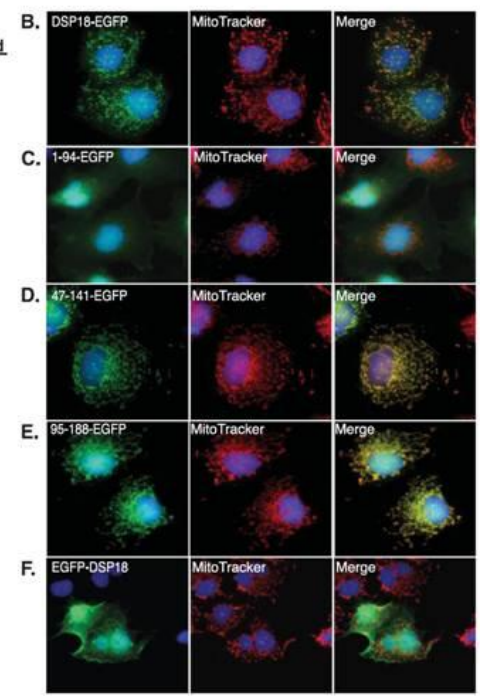

Figure 4-5: Localization of Dusp18.

I. Upper pannel: U2OS cells were transfected with the $p C G N-H A-D u s p 18$ expression plasmid and $48 \mathrm{~h}$ later the cells were fixed and immunostained for HA. Lower pannel: U2OS cells stably expressing Dusp18-HA were fixed and immunostained for HA. Hoechst: DNA staining, MitoTracker: mitochondria staining (Figure contributed by Franziska Schmidt).

II. Dusp18 localization from Wu et al., 2006.

III. Murine Dusp18 localization from Rardin et al., 2008. 


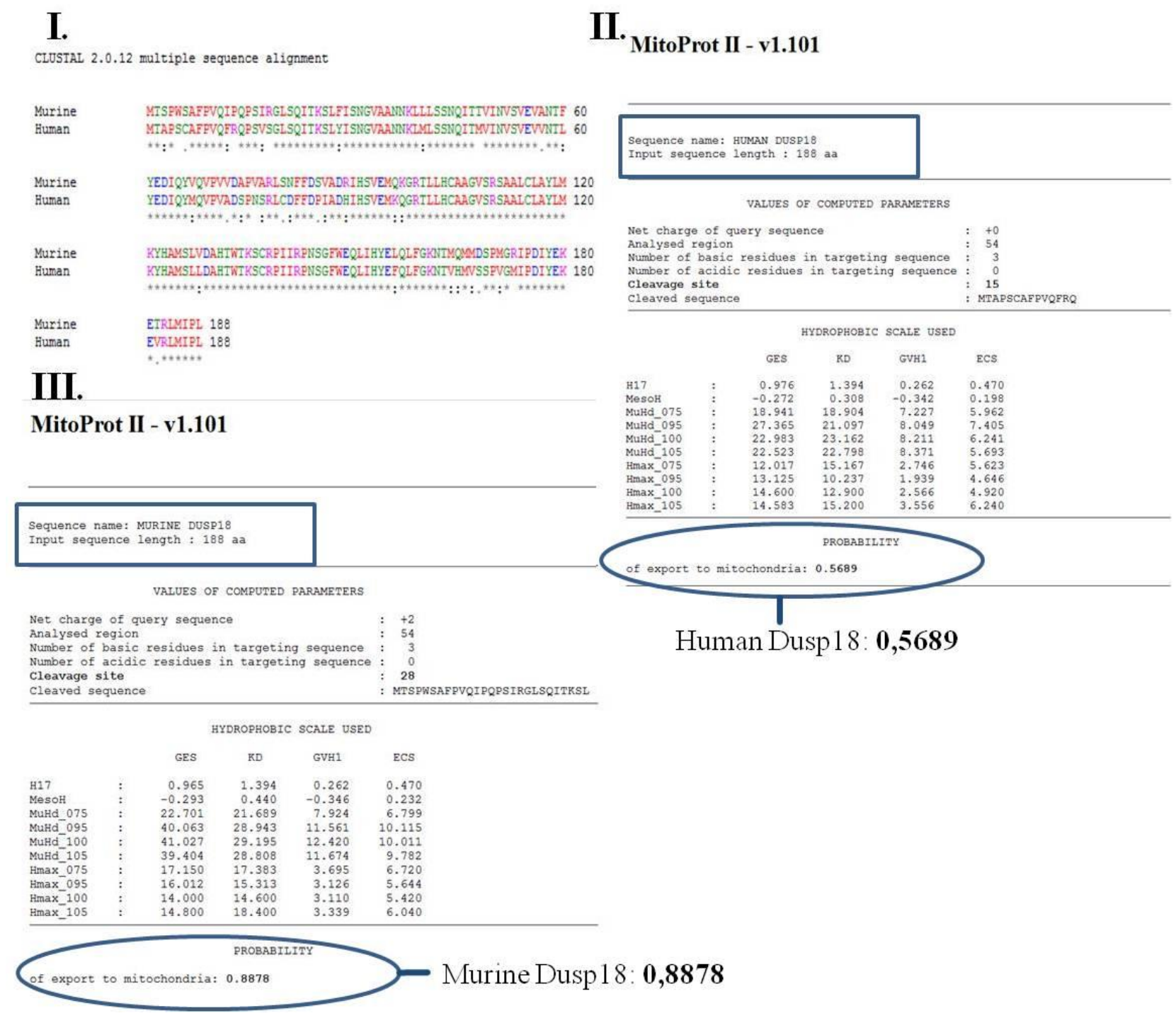

Figure 4-6: Alignment of Human and Murine Dusp18 proteins and MitoProt mitochondrial localization prediction.

I. ClustalW2 (EBI) was used to align the protein sequences of human (GI:119580319) and murine (GI:30424589) Dusp18.

II. MitoProt software (Claros \& Vincens, 1996) was used to calculate the probability of mitochondrial localization of human Dusp18 (GI:119580319).

III. MitoProt software was used to calculate the probability of mitochondrial localization of murine Dusp18 (GI:30424589).

4.2.2 The knockdown of Dusp18 induces the p53 pathway in different cell lines

The reliability of knockdown experiments performed using single siRNAs may be hindered by the possibility of observing an off-target effect. Therefore, the validation results were further evaluated by using different siRNAs against Dusp18. Four different siRNAs 
were tested, two of which were included in the siRNA library (named B and C) and 2 new siRNAs (named D and E). First, the knockdown efficiency of the siRNAs was determined using qPCR and is shown in Figure 4-7. All the siRNAs had a good knockdown efficiency on the mRNA level of Dusp18, with the siRNA B being the most efficient in HCT116 and U2OS cells. Although 2 available commercial Dusp18 antibodies were tested (Abgent, Santa Cruz see Materials), none could be used to detect endogenous Dusp18 in our system. However, we generated stable U2OS cells that express an C-terminal HA-tagged Dusp18, and in this way the efficiency of each siRNA could be evaluated also at the protein level (Figure 4-7). The result showed that in fact, at the protein level, the siRNA B was the most inefficient one, although all the siRNAs efficiently depleted the U2OS cells from Dusp18 protein. Compared to the siRNAs $\mathrm{C}$ and D, the siRNA B was also less effective in inducing the accumulation of p53 and p21 in U2OS cells (Figure 4-7), thereby correlating well with the knockdown efficiency.

\section{I. dusp18 mRNA levels in HCT116} p53+/+ cells

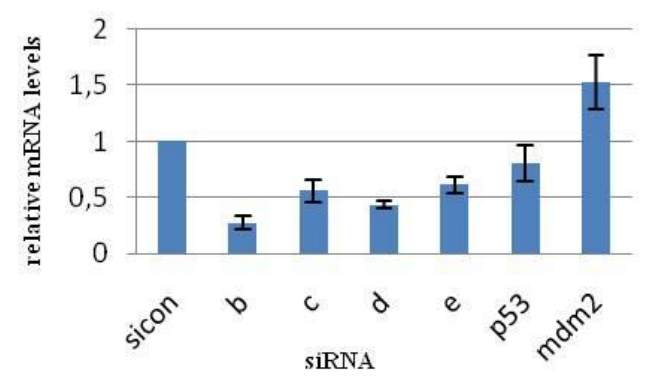

II. dusp18 mRNA levels in U2OS cells

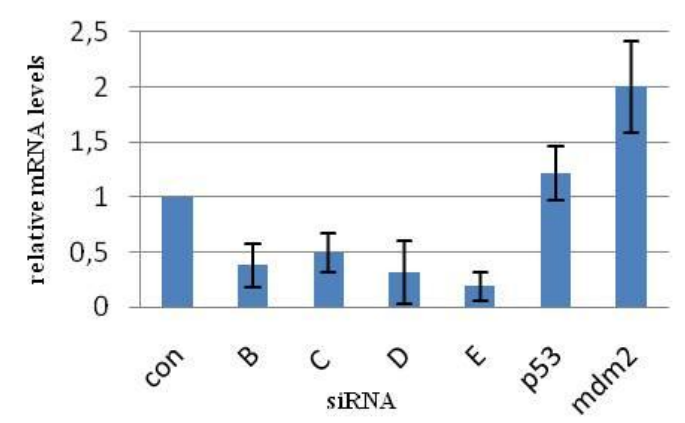

III.

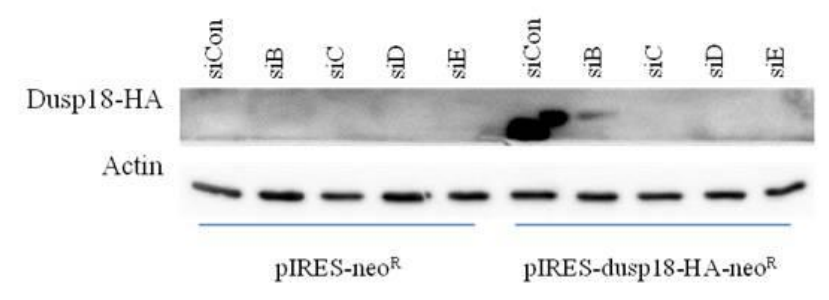

Figure 4-7: Knockdown efficiency of Dusp18 siRNAs.

I. HCT116 p53+/+ cells were transfected with siRNAs against Dusp18 and mRNA levels were quantified $48 \mathrm{~h}$ later using qPCR (quantification was relative to control siRNA mRNA levels, all $m R N A$ levels were normalized to GAPDH).

II. U2OS cells were transfected with siRNAs against Dusp18 and mRNA levels were quantified 48 later using qPCR (quantification was relative to control siRNA mRNA levels, all mRNA levels were normalized to GAPDH).

III. U2OS cells stably expressing Dusp18-HA were transfected with siRNAs against Dusp18 and Dusp18-HA protein levels were detected 48 h later using immunoblotting. 
Even though the intensity of the effect of the siRNAs on U2OS cells varied, all the siRNAs could induce p21 accumulation to a level comparable to the induction of p21 by an siRNA against mdm2 (Figure 4-8). To examine whether this was a cell-line specific effect, we knocked down Dusp18 in a tumor cell line of different origin. The colon carcinoma HCT116 cells were chosen, because genes can be relatively easily knocked out in these cells, and so a variety of isogenic HCT116 cells is available (ex. p53 -/- or p21 -/- cells). The knockdown efficiency of the siRNAs in HCT116 cells was determined using qPCR and is shown in Figure 4-7. Knockdown of Dusp18 in HCT116 cells could also induce p53, p21 and mdm2, although the intensity of the induction varied between the different siRNAs. Nevertheless, as in U2OS cells, there was a consistent and robust accumulation of p21 protein (Figure 4-8). Finally, another osteosarcoma cell line, namely the SJSA cells with an amplification of the mdm2 gene, was tested. As presented in Figure 4-8, p21 protein levels were again increased after transfection with the Dusp18 siRNAs. These results indicate that depletion of Dusp18 triggers a response in the cell that includes the accumulation of p53 and induction of its target gene $p 21$.

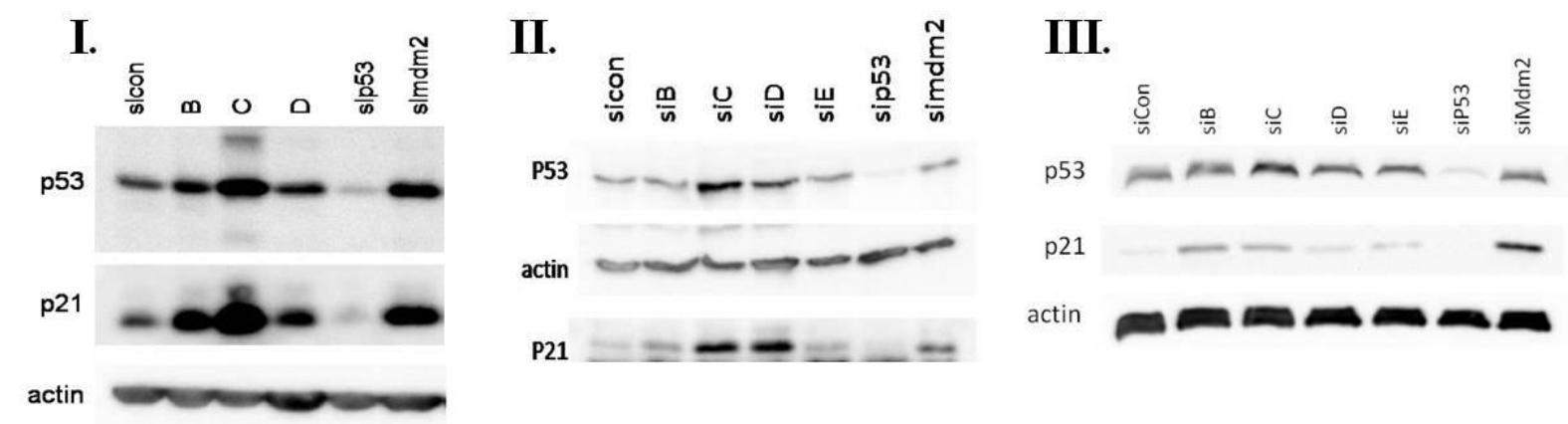

Figure 4-8: Induction of $p 53$ and $p 21$ upon Dusp18 depletion in different cell lines.

I. HCT116 p53 +/+ cells were transfected with siRNAs against Dusp18 and $48 \mathrm{~h}$ later the lysates were analysed for 553 and 21 protein levels by immunoblotting. Actin was used as a loading control.

II. U2OS cells were transfected with siRNAs against Dusp18 and 48h later the lysates were analysed for p53 and p21 protein levels by immunoblotting. Actin was used as a loading control.

III. SJSA cells were transfected with siRNAs against Dusp18 and $48 \mathrm{~h}$ later the lysates were analysed for p53 and p21 protein levels by immunoblotting. Actin was used as a loading control. 


\subsubsection{Depletion of Dusp18 does not increase the phosphorylation or acetylation of p53}

P53 is vastly regulated by post-translational modifications (Ashcroft et al., 1999; Lakin \& Jackson, 1999; Kruse \& Gu, 2009), which also include phosphorylation at several sites. The phosphorylation of p53 at its $\mathrm{N}$-terminus is believed to stabilize and activate p53 by impairing the binding of its main negative regulator, $\mathrm{Mdm} 2$, and by promoting its interaction with transcriptional coactivators (Lambert et al., 1998; Dumaz \& Meek, 1999) The acetylation of p53 at its C-terminus is known to increase the transcriptional activity of p53 (Lambert et al., 1998; Dumaz \& Meek, 1999). The acetylation of p53 at Lys382 occurs following the phosphorylation at the $\mathrm{N}$-terminus and thus can serve as an indicator of the actively modified p53 (Sakaguchi et al., 1998). Since Dusp18 is a phosphatase capable of dephosphorylating serine, threonine and tyrosine residues, we sought to examine whether the removal of Dusp18 could increase the spontaneous phosphorylation of p53. HCT116 p53 +/+ cells were transfected with the siRNAs against Dusp18 and harvestred 48 hours later (during optimization assays optimal knockdown efficiency was achieved approximately 2 days after siRNA transfection). The levels of p53 phosphorylation at Ser15, Ser46 and also at the acetylated p53 (Lys382) were detected by antibodies specific for each modification (Figure 49). Because the knockdown of Dusp18 induced the accumulation of total p53 protein, the Lab1D imaging software (Intas) was used to quantify the intensity of each signal and to normalize the phosphorylated p53 levels to the total p53 levels. As shown in Figure 4-9, the downregulation of Dusp18 did not lead to increased amount of modified p53 relatively to the total p53, when examining the Ser15 or Ser46 phosphorylation and Lys382 acetylation. We therefore considered the possibility that Dusp18 might directly or indirectly act by posttranslationally modifying p53 rather unlikely. 


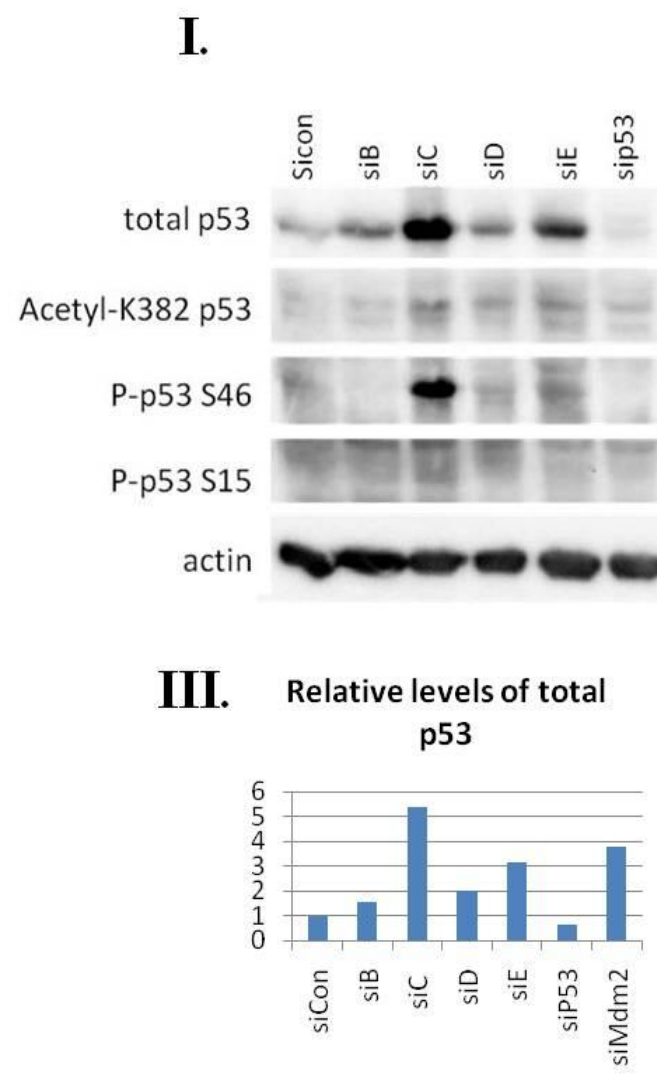

II.

Relative levels of modified p53 to total p53

in HCT116 p53 +/+ cells transfected with siRNAs against dsp18

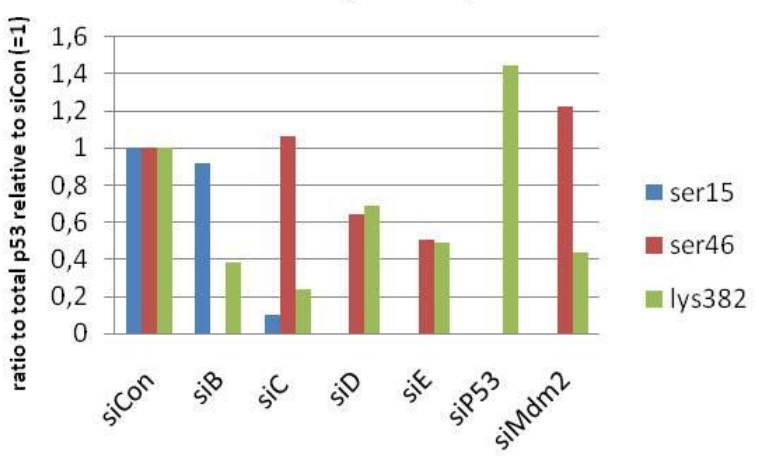

Figure 4-9: $p 53$ modification upon Dusp18 knockdown.

I. HCT116 p53 +/+ cells were transfected with siRNAs against Dusp18 and $48 \mathrm{~h}$ later the lysates were analysed for total $p 53$ and modified p53 protein levels by immunoblotting. Actin was used as a loading control.

II. Relative quantification of modified p53 levels with LabID (INTAS), normalized to total p53 levels.

III. Relative quantification of total p53 levels with LabID (INTAS).

\subsubsection{The interaction of p53 with Mdm2 was not disrupted upon Dusp18 knockdown}

The main negative regulator of p53 is the ubiquitin E3 ligase Mdm2, which binds and targets the p53 protein for proteasome-dependent degradation. Hence we hypothesized that Dusp18 knockdown might interfere with the function of $\mathrm{Mdm} 2$, and thus induce the accumulation and activation of p53. Assessing the cellular levels of Mdm2 protein after depletion of Dusp18 was complicated, because the activation of p53 can induce the transcription of $m d m 2$ (Appendix, Figure 7-3). As the binding of p53 by Mdm2 is necessary for Mdm2-dependent downregulation of $\mathrm{p} 53$, the interaction of the two proteins was investigated by Coimmunoprecipitation (CoIP). This experiment was performed using the osteosarcoma SJSA cells, because they carry an $m d m 2$ amplification, and thus have increased amounts of Mdm2 protein. P21 protein was increased by Dusp18 depletion in these cells more profoundly by the siRNAs siB and siC than with the other siRNAs (Figure 4-8), so these two 
siRNAs were used to examine the interaction of p53 with Mdm2. Although the levels of p53 were increased with Dusp18 knockdown, relative amounts of p53 coimmunoprecipitating with Mdm2 were only slightly reduced and there was still a large portion of p53 coimmunoprecipitating with Mdm2 (Figure 4-10). These findings suggest that interference with the main Mdm2 function as ubiquitin E3 ligase of p53 is unlikely the reason for p53 accumulation and activation upon Dusp18 knockdown.

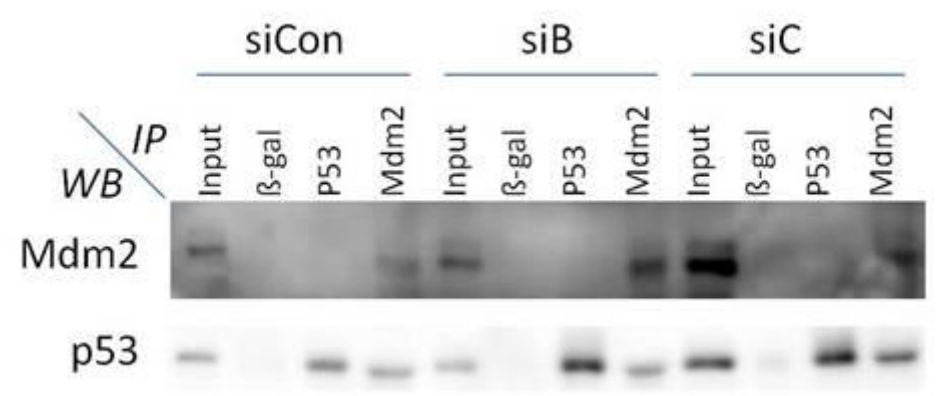

Figure 4-10: Co-immunoprecipitation of 553 and Mdm2 after Dusp18 knockdown.

SJSA cells were transfected with siRNAs against Dusp18 and 48 later, p53 (using pAb421) and Mdm2 (using 2A9) proteins were immunoprecipitated. The complexes were subsequently analysed with immunoblotting (using DO-1 for p53 detection and $2 A 9$ for Mdm2 detection). An antibody against $\beta$-gal was used to control for unspecific precipitation.

4.2.5 P53 accumulated and was activated to induce p21 transcription by depletion of Dusp18

Accumulation of p53 and p21 was observed in several cell lines depleted of Dusp18 (Figure 4-8). To confirm that the accumulation of $\mathrm{p} 21$ is a downstream effect of $\mathrm{p} 53$ transcriptional activity, a qPCR analysis of p21 mRNA levels in Dusp18-depleted HCT116 p53 +/+ cells was performed. As shown in Figure 4-11, p21 mRNA was increased upon Dusp18 knockdown. To exclude that this increase might be due to increased mRNA stability, the qPCR analysis was performed again with primers complementary to $p 21$ intronic regions, to detect the p21 pre-mRNA. The levels of p21 pre-mRNA detected by two different sets of primers (binding to intron 1 and intron 2 respectively) were also increased upon Dusp18 knockdown following a similar pattern to the total mRNA levels (Figure 4-11). The possibility of detection of genomic DNA contamination was excluded by performing control reactions without the reverse transcriptase during the cDNA synthesis (see Methods §3.2.2.1). In addition, the p21 pre-mRNA levels were dependent on the presence of p53 (Figure 4-11, 
sip53 and simdm2 samples), indicating that the p21 pre-mRNA was indeed detected. These results suggest that the increase of $\mathrm{p} 21$ protein is due to increased transcription of the $p 21$ gene.

I.

Relative p21 total mRNA levels in HCT116 $553+/+$ cells depleted of dusp18

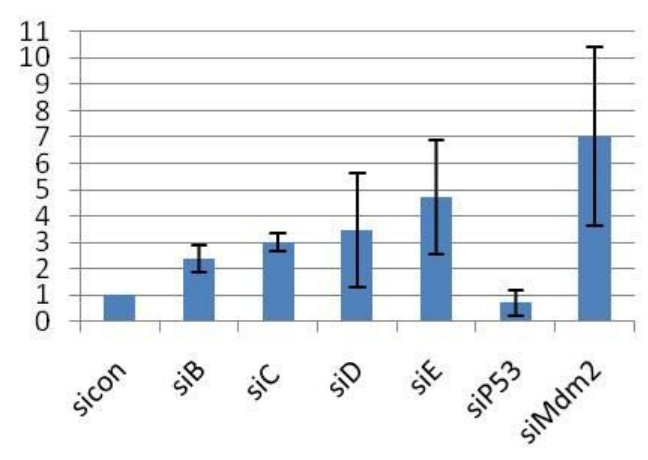

II.
Relative p21 pre-mRNA levels in HCT116 p $53+/+$ cells depleted of dusp18

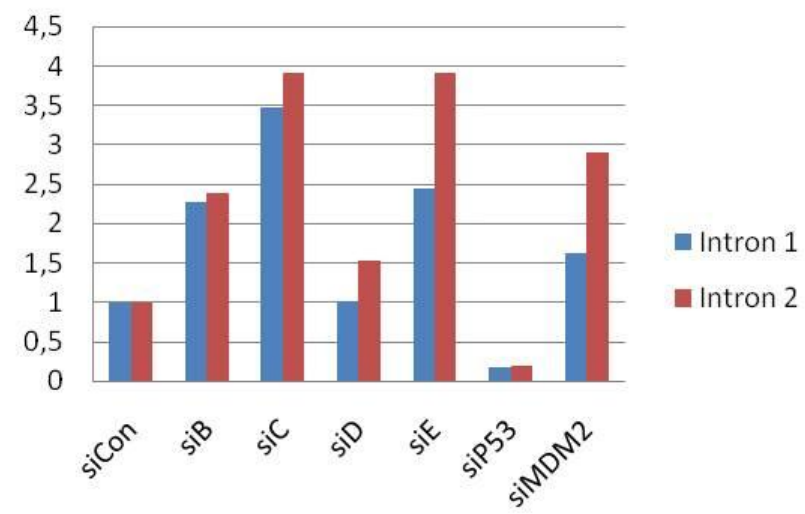

Figure 4-11: $p 21$ mRNA levels after Dusp18 knockdown.

I. HCT116 p53 +/+ cells were transfected with siRNAs against Dusp18 and 48h later p21 mRNA levels were quantified by qPCR (quantification was relative to control siRNA mRNA levels, all mRNA levels were normalized to GAPDH).

II. HCT116 p53 +/+ cells were transfected with siRNAs against Dusp18 and p21 pre-mRNA levels were quantified by qPCR using intronic primers for intron 1 and intron 2 (quantification was relative to control siRNA mRNA levels, all mRNA levels were normalized to GAPDH).

To further analyse the induction of p21 and to obtain insights into the mechanism of action of Dusp18, we performed Chromatin Immunoprecipitation experiments (ChIP) to quantify the binding of different factors on the $p 21$ gene. Several transcription factors are known to play an important role in the activation of p21 transcription, among which are $\mathrm{p} 53$ and Specific Protein 1 (SP1). Thus Dusp18 knockdown could increase the amount of any of these proteins bound to the $p 21$ promoter. The level of RNA polymerase bound to the transcription start site and at several positions downstream of it, in the $p 21$ gene, was also investigated. No significant changes in RNA polymerase or SP1 levels at any site in the $p 21$ locus could be detected (Appendix, Figure 7-4), but an increase of p53 bound to the distant p53 responsive element of the $p 21$ promoter (-2283 bp) was observed, as presented in Figure 4-12. In addition, no comparable increase of p21 mRNA or protein could be detected in HCT116 p53 -/- cells (negative data not shown). These results suggest that the increase of p21 mRNA is a consequence of increased p53 levels and transcriptional activity. 


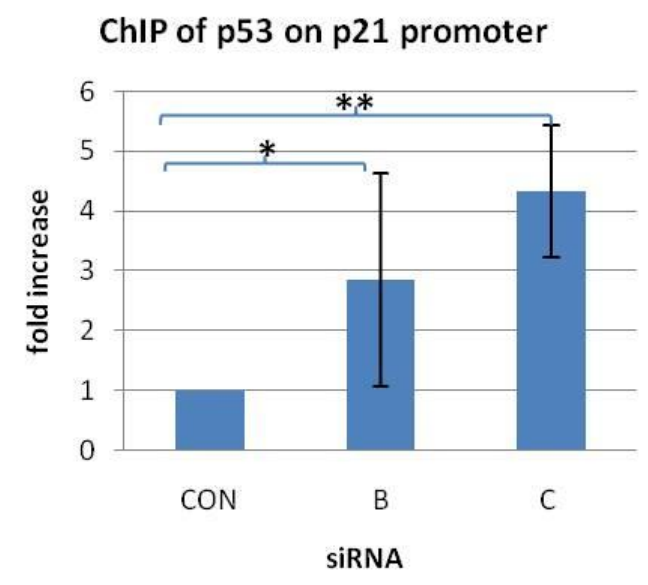

Figure 4-12: Binding of 553 on $p 21$ promoter upon Dusp18 knockdown.

Chromatin immunoprecipitation of p53 on the distal p53 binding site of the p21 promoter (-2283 bp) in HCT116 p53 +/+ cells, $48 \mathrm{~h}$ after depletion of Dusp18. Error bars represent standard deviation from 7 independent experiments. * $p>0,1 ; * * p>0,005$

Another possible mechanism of Dusp18 action could be its interference with the cofactors of $\mathrm{p} 53$ that contribute to $p 21$ transcription. SP1 is known to be a p53-coactivator for the transcription of some p53 targets, such as p21 and puma (Moustakas \& Kardassis, 1998; Koutsodontis \& Kardassis, 2004). To investigate whether the induction of p21 is dependent on SP1, we performed a double knockdown of SP1 and Dusp18. As shown in Figure 4-13, SP1 is needed for the induction of p21 at least by the siRNAs siB, siD and siE. For the siC siRNA there was a massive accumulation of $\mathrm{p} 21$, which was not reduced if SP1 is depleted from the cells, possibly because of the very robust p53 induction caused by this siRNA that might compensate for the reduced SP1 levels in the cell (Figure 4-13). 


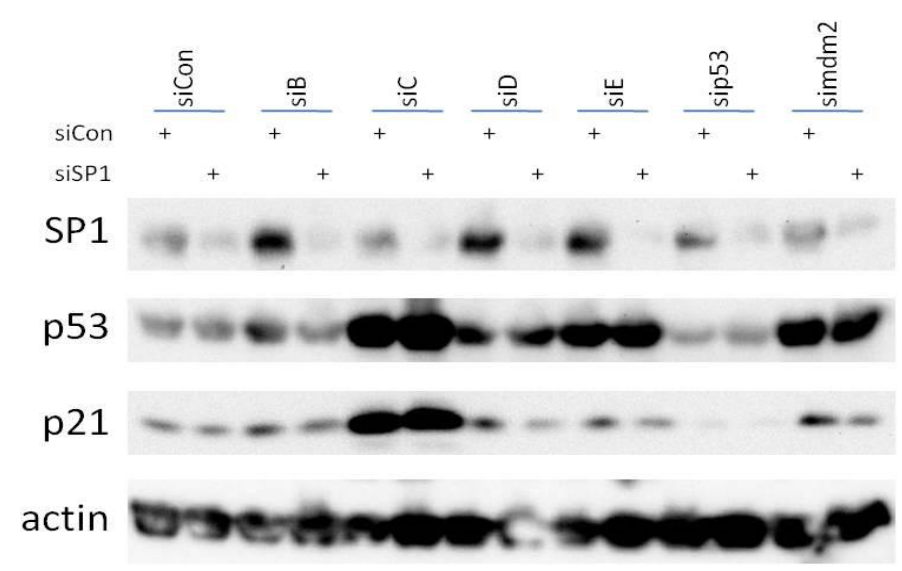

Figure 4-13: Combined knockdown of Dusp18 and SP1 in HCT116 p53 +/+ cells.

HCT116 p53 +/+ cells were transfected with siRNAs against Dusp18 together with an SP1 or control siRNA, and $48 h$ later the cell lysates were analysed for p53 and p21 protein levels by immunoblotting. Actin was used as a loading control.

\subsection{Dusp18 is necessary for cell survival and proper cell cycle progression}

\subsubsection{Cells depleted of Dusp18 undergo spontaneous apoptosis}

The physiological consequences of Dusp18 knockdown were subsequently investigated. HCT116 p53 +/+ cells transfected with siRNAs against Dusp18 underwent apoptosis without any further DNA damage or treatment, as demonstrated by the cleavage of PARP-1 and caspase 3 (Figure 4-14). Furthermore, FACS (Fluorescence Activated Cell Sorting) cell cycle analysis of the cells 3 days after transfection with the siRNAs showed an increased subG1 fraction in HCT116 p53 +/+ cells, indicating cell death (Figure 4-14). The same experiments performed with HCT116 p53 -/- cells suggest that this apoptosis induction is largely p53-dependent, as PARP-1 and caspase 3 cleavage and an increase of the subG1 fraction was also observed in the absence of p53 (Figure 4-14), but not to the same extent as in the p53 +/+ cells. Hence, these results indicate that Dusp18 is needed for the survival of cancer cells under normal growth conditions. 


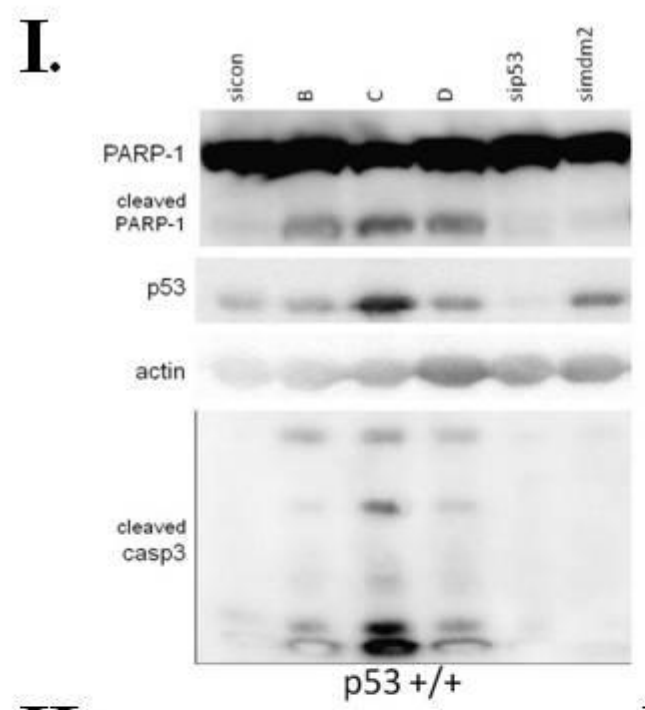

IIa.

\section{IIIb.

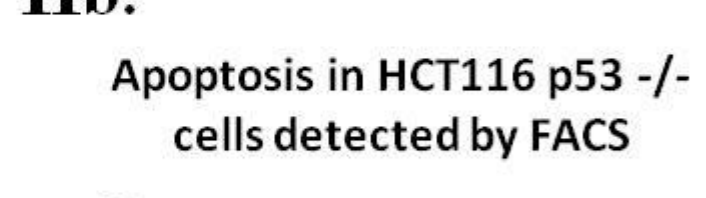

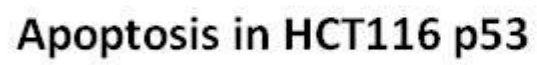
$+/+$ cells detected by FACS
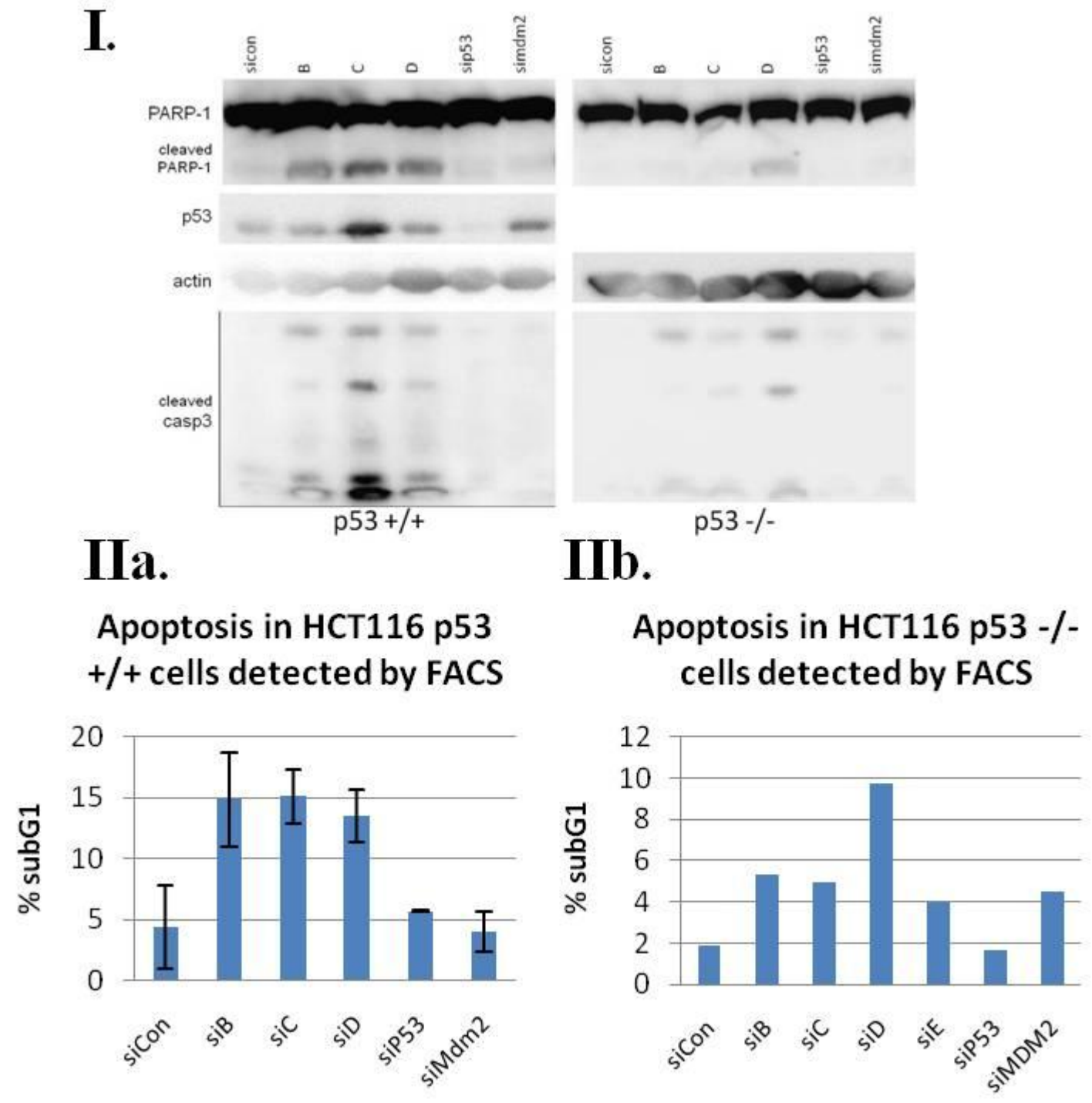

Figure 4-14: Apoptosis detection in HCT116 cells after Dusp18 knockdown.

I. HCT116 cells were transfected with siRNAs against Dusp18 and the cell lysates were subjected to immunoblotting analysis for apoptosis markers.

II. HCT116 cells were transfected with siRNAs against Dusp18 and the cell cycle distribution was analysed by FACS. The subG1 percentage is shown for p53 +/+ (IIa) and p53-/- (IIb) cells. Error bars represent standard deviation from 2 independent epxeriments.

\subsubsection{Depletion of Dusp18 induced DNA damage response}

P53 accumulation and activation, as well as the induction of apoptosis can occur as a downstream result of the activation of the DNA damage response cascade. Thus HCT116 cells were transfected with siRNAs against Dusp18 to examine whether Dusp18 knockdown could induce the accumulation or modification (activation) of DNA damage responsive proteins. One of the primary events in response to damaged DNA is the phosphorylation of 
the histone variant $\mathrm{H} 2 \mathrm{Ax}$ (the phosphorylated form is then called $\gamma \mathrm{H} 2 \mathrm{Ax}$ ). The DNA damage marker $\gamma \mathrm{H} 2 \mathrm{Ax}$ was increased upon Dusp18 depletion (Figure 4-15). An increase of phosphorylated checkpoint kinase 2 (pChk2) was also detected (Figure 4-15), consistent with a DNA damage response induction. However, the levels of phospho-p38 and p-chk-1 (Figure 4-15) remained unchanged. These results indicate that cells depleted of Dusp18 show an induction of the DNA damage response cascade, possibly preferably via the Chk2 pathway, and that the increase of $\mathrm{p} 53$ and p21 could be a downstream effect of this activation.

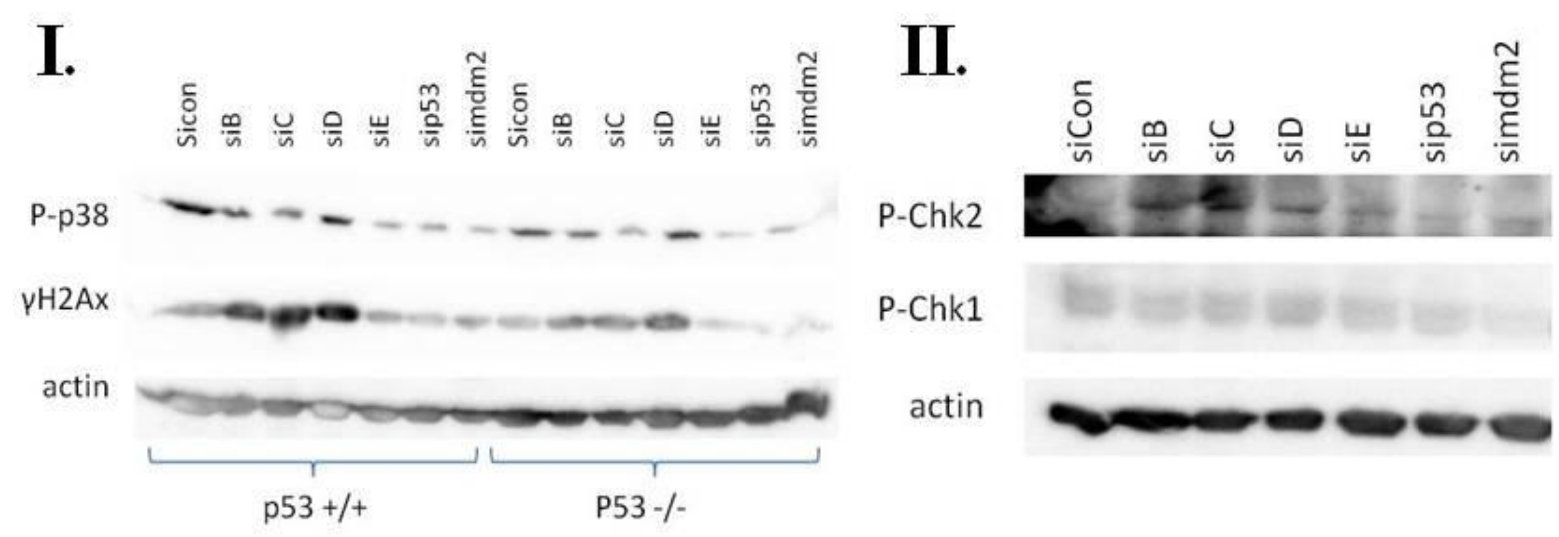

Figure 4-15: Stress response in HCT116 cells depleted of Dusp18.

I. HCT116 cells were transfected with siRNAs against Dusp18 and 48h later the cell lysates were subjected to immunoblotting analysis for $p-p 38$ and $\gamma H 2 A x$. Actin was used as a loading control.

II. HCT116 p53 +/+ cells were transfected with siRNAs against Dusp18 and $48 \mathrm{~h}$ later the cell lysates were subjected to immunoblotting analysis for p-Chk2 and p-Chk1. Actin was used as a loading control.

Finally, the localization of nucleophosmine (NPM) in Dusp18 depleted cells was also examined. Nucleophosmine is normally localized in the nucleoli and is dispersed in the nucleus upon several types of stress (Kurki et al., 2004), including some DNA damaging agents, like treatment with doxorubicin (Figure 4-16). The dispersion of NPM in the nucleoplasm is, under certain conditions, accompanied by the inhibition of Mdm2 and induction of p53 (Kurki et al., 2004). The localization of nucleophosmine was unaffected by the depletion of Dusp18 (Figure 4-16). This suggests that Dusp18 knockdown does not activate p53 via the NPM pathway. 


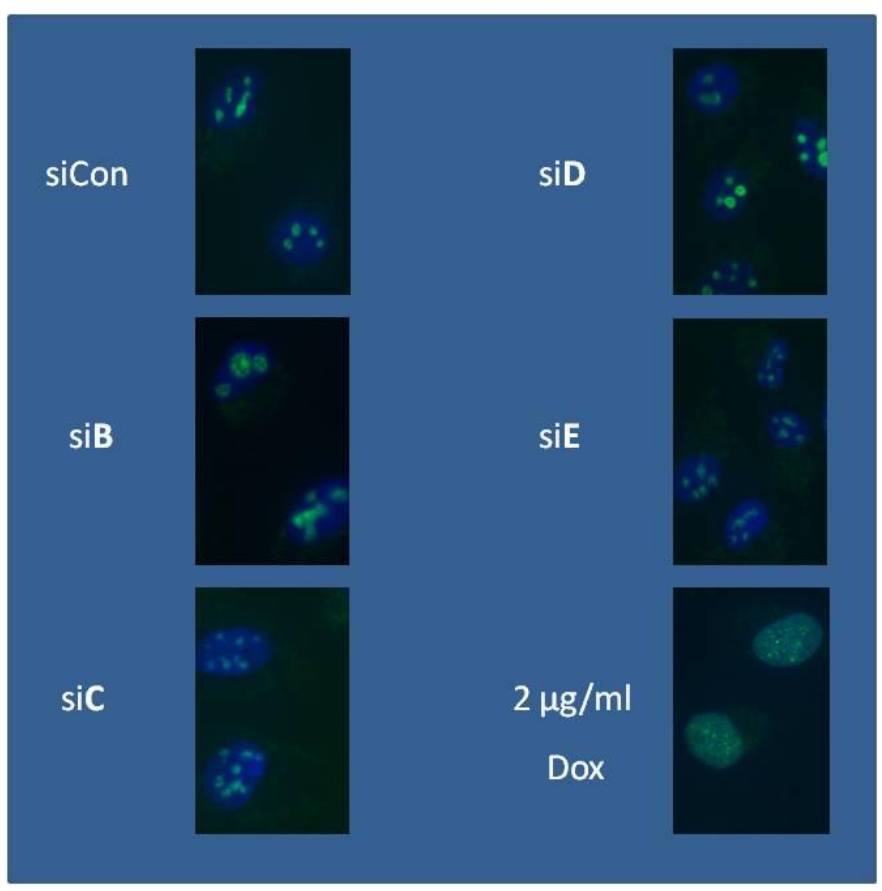

Figure 4-16: Nucleophosmin localization in U2OS cells depleted of Dusp18.

U2OS cells were transfected with siRNAs against Dusp18 and $48 h$ later fixed and stained for nucleophosmin. Cells treated with $2 \mu \mathrm{g} / \mathrm{ml}$ doxorubicin were used as a positive control for nucleophosmin nuclear dispersion (Figure contributed by Franziska Schmidt).

4.3.3 Removal of Dusp18 caused an accumulation of cells in S phase which correlated with reduced cell proliferation.

The choice of pathways to be activated as well as the intensity of the response to genotoxic stress depends, among other parameters, on the cell cycle phase at the time of exposure. The accumulation of $\gamma \mathrm{H} 2 \mathrm{Ax}$ in nuclei is most intense when the damage occurs during DNA replication (Suzuki et al., 2006). FACS analysis of HCT116 p53 +/+ cells 3 days after transfection with siRNAs against Dusp18 showed an increased percentage of cells in S phase, although the extent of the effect varied among the different siRNAs (Figure 4-17). The increased $S$ phase was accompanied by a reduction of the G1 fraction, as shown in Figure 417 (ratio of cells in S phase to cells in G1 phase). This effect was more intense for siRNAs $\mathrm{siC}$ and siD. The same experiment performed in U2OS cells (wild-type p53) showed an even more profound accumulation of cells in $S$ phase, as presented in Figure 4-18. The original FACS data are presented in Figure 4-19, showing that all siRNAs induced an $\mathrm{S}$ phase accumulation except the siD, which induced a G1 arrest. To examine whether this effect of Dusp18 knockdown on the cell cycle distribution was p53-dependent, the FACS analysis was repeated in HCT116 p53 -/- cells depleted of Dusp18. In these cells, the siRNAs siC and siD induced an accumulation of G2- and S phase cells respectively (Figure 4-20). 
I.

Cell cycle distribution of HCT116 p $53+/+$ cells

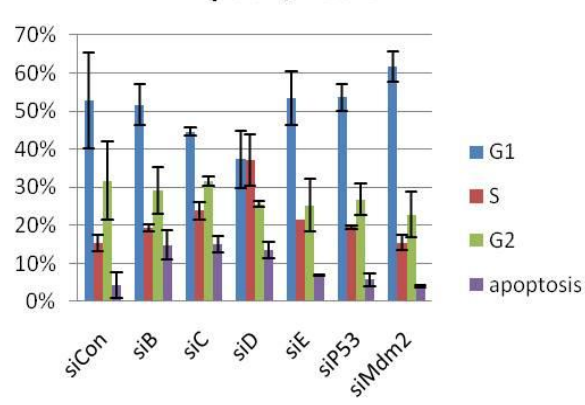

Cell cycle distribution of

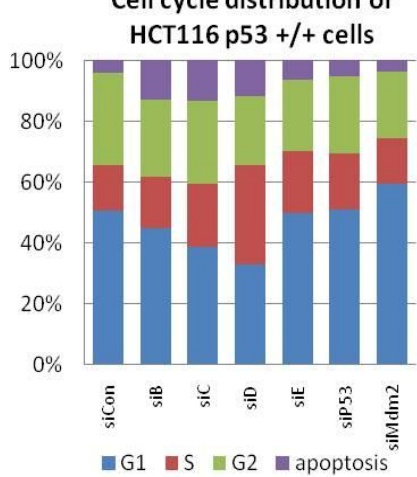

II.

Ratio of \% cells in S-phase to \% of cells in G1 phase

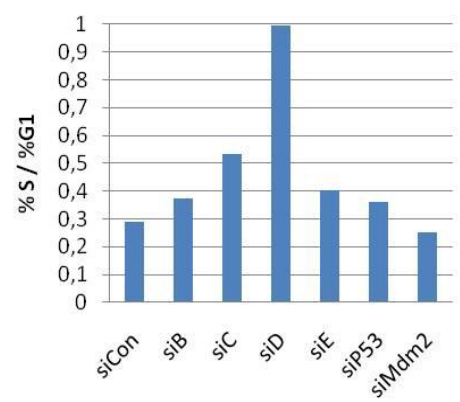

Figure 4-17: Cell cycle distribution of HCT116 p53+/+ cells depleted of Dusp18.

HCT116 p53 +/+ cells were transfected with siRNAs against Dusp18 and $72 \mathrm{~h}$ later fixed and subjected to FACS. The histograms obtained were analysed with the ModFit software to measure the percentage of cells in each phase.

I. Cell cycle distribution. Error bars represent standard deviation from 2 independent experiments.

II. Ratio of percentage of cells in S phase to percentage of cells in G1 phase.

I.

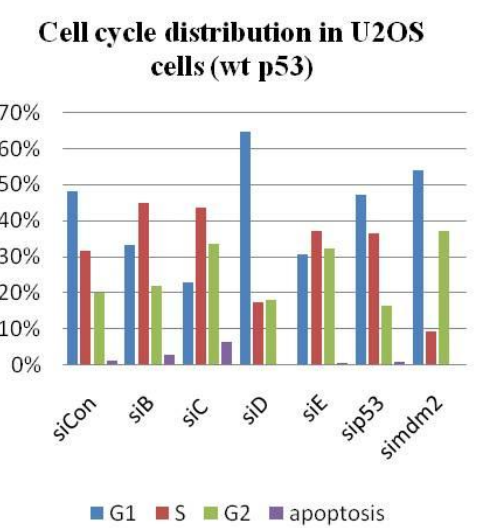

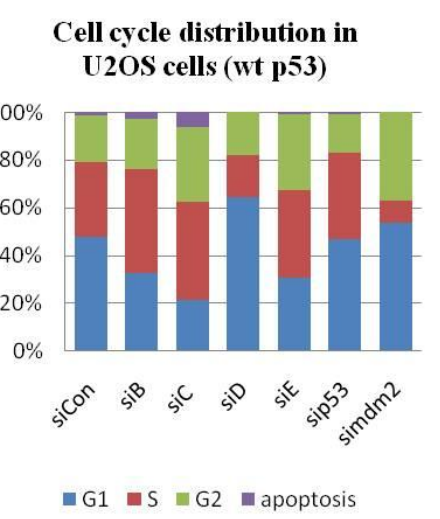

II.

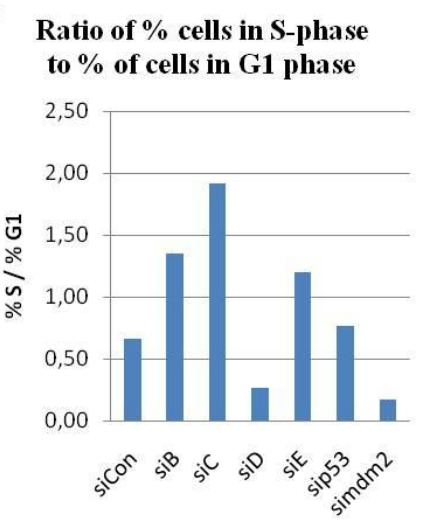

Figure 4-18: Cell cycle distribution of U2OS (wt p53) cells depleted of Dusp18.

U2OS cells were transfected with siRNAs against Dusp18 and $72 \mathrm{~h}$ later fixed and subjected to FACS. The histograms obtained were analysed with the ModFit software to measure the percentage of cells in each phase.

I. Cell cycle distribution.

II. Ratio of percentage of cells in S phase to percentage of cells in G1 phase. 

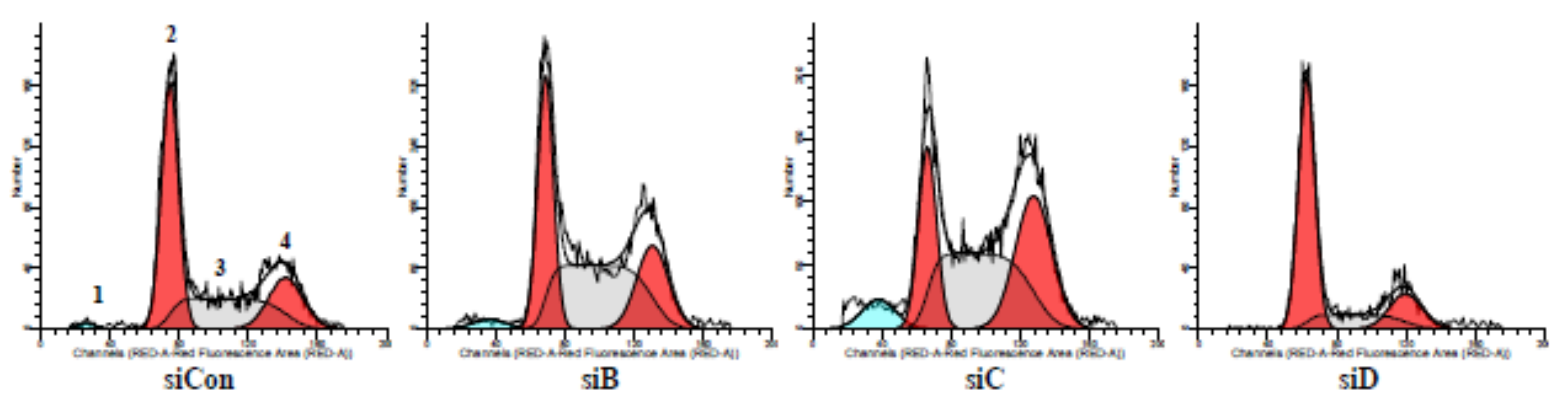

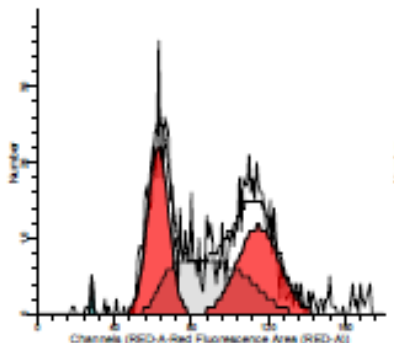

siE

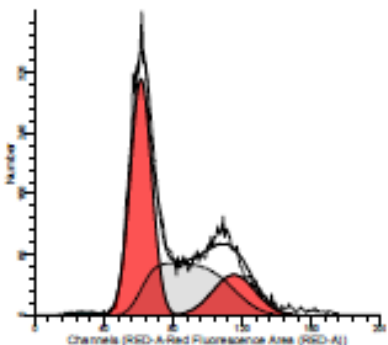

$\operatorname{sip} 53$

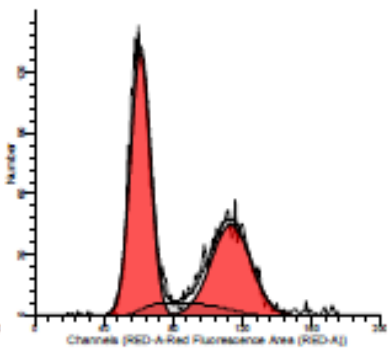

simdm2

Figure 4-19: Cell cycle distribution of U2OS (wt p53) cells depleted of Dusp18 (ModFit analysis). U2OS cells were transfected with siRNAs against Dusp18 and $72 \mathrm{~h}$ later fixed and subjected to FACS. The histograms obtained were analysed with the ModFit software to identify and quantify the different cell cycle phases:

1: Apoptotic cells (subG1); 2: G1; 3: S; 4: G2.

\section{I.}

Cell cycle distribution in

HCT 116 p53 -/- cells

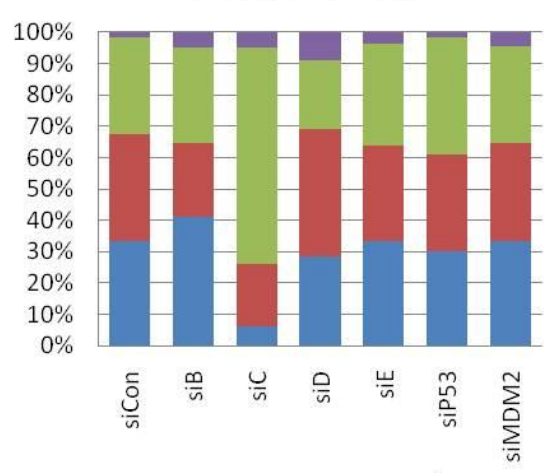

II. Ratio of \% cells in S-phase to \% of cells in $\mathrm{G} 1$ phase

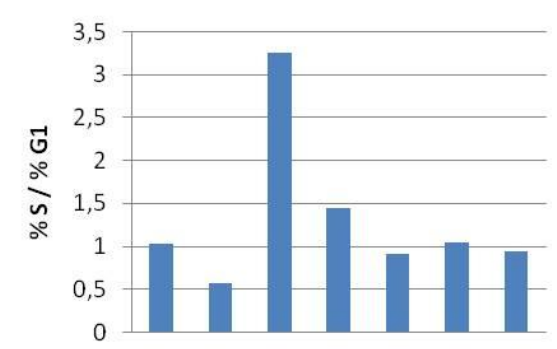

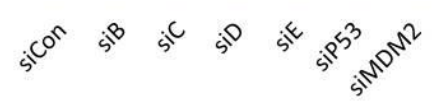

$\mathrm{G} 1 \mathrm{G} 1 \mathrm{~S}=\mathrm{G} 2$ mapoptosis

Figure 4-20: Cell cycle distribution of HCT116 p53 -/- cells depleted of Dusp18.

HCT116 p53-/-cells were transfected with siRNAs against Dusp18 and $72 \mathrm{~h}$ later fixed and subjected to FACS. The histograms obtained were analysed with the ModFit software to measure the percentage of cells in each phase.

I. Cell cycle distribution.

II. Ratio of percentage of cells in S phase to percentage of cells in G1 phase. 
This accumulation of cells in the $S$ phase could result from an increase of the G1 to $S$ transition, or alternatively because the depletion of Dusp18 caused a delay in the S phase. To distinguish between these two possibilities, a proliferation assay was performed. HCT116 p53 +/+ or p53 -/- cells were transfected with the siRNAs against Dusp18 and starting 2 days post transfection (marked as $48 \mathrm{~h}$ ) the increase in the cell confluency over a period of 4 days was monitored. As shown in Figure 4-21 and Figure 7-6 (Appendix), the proliferation rate of both cell lines, as measured by the increase of confluency over time, was reduced by the siRNAs $\mathrm{siC}$ and siD. This correlates with the accumulation of cells in S phase (FACS data, Figures 418 and 4-20), and suggests that this increase of the percentage of cells replicating their DNA is caused by a delay in S phase, and not by an increased G1 to S transition. Although the cell proliferation was measured for up to 5 days post transfection of the siRNAs, the effect of Dusp18 depletion on the cell confluency was observed only during the first $72 \mathrm{~h}$. This could be attributed to a rapid decrease in the efficiency of the siRNAs 4 days after cell transfection (as is most common with transient siRNA transfections).

I.
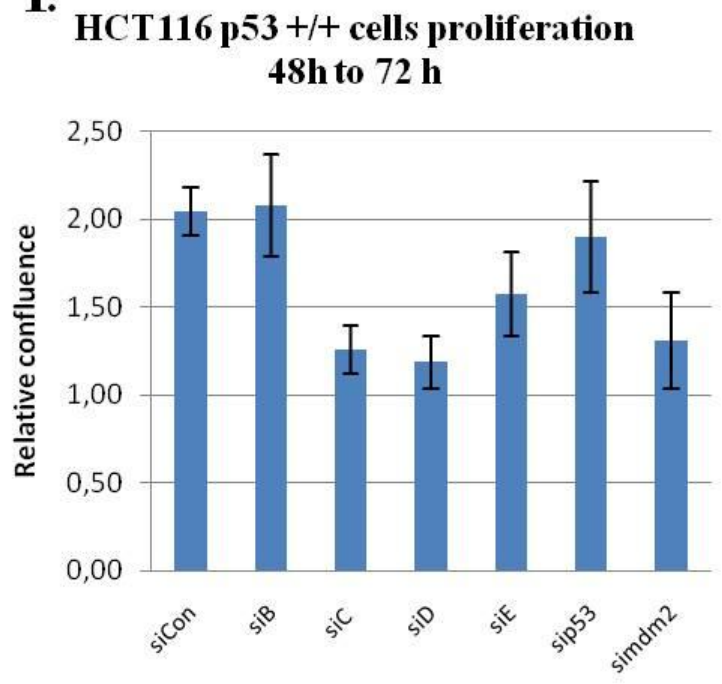

II.

HCT 116 p53 -/- cells proliferation $48 \mathrm{~h}$ to $72 \mathrm{~h}$

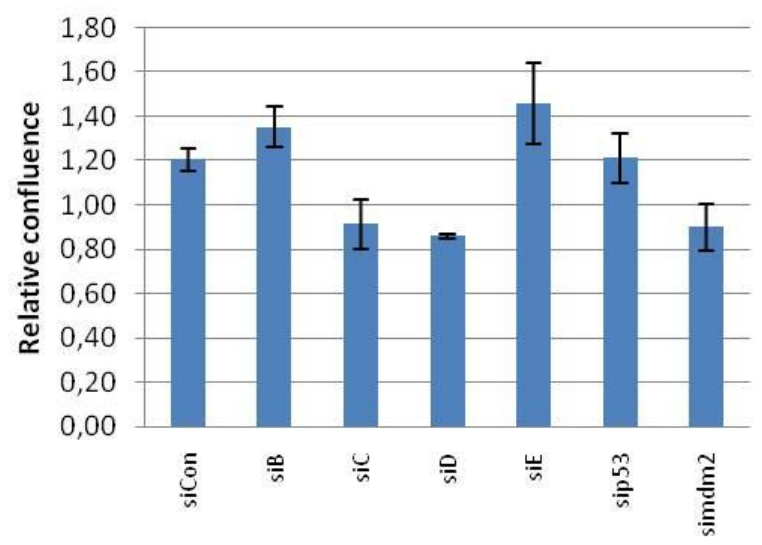

Figure 4-21: Proliferation of HCT116 cells depleted of Dusp18.

HCT116 p53 +/+ (I) and p53 -/-(II) cells were transfected with siRNAs against Dusp18 and their confluence was measured $48 \mathrm{~h}$ and $72 \mathrm{~h}$ after transfection. The increase in confluence within that time is represented in the graphs. Error bars indicate standard deviation from 4 different dilutions of cells (see Methods \$3.1.3). 


\subsubsection{Dusp18 is needed for proper cell cycle progression}

To confirm that the cells progress slower through the cell cycle or arrest without Dusp18, the FACS analysis of Dusp18-depleted cells was combined with a nocodazole trap. HCT116 p53 +/+ cells and U2OS cells were transfected with siRNAs against Dusp18, and were treated with nocodazole to induce an arrest in G2/M phase (nocodazole prevents polymerization of microtubules that normally occurs during the spindle formation, and the cell division stops during the prometaphase of mitosis because of the activation of the spindle assembly checkpoint; Nüsse \& Egner, 1984). As shown in Figures 4-22, 4-23 and 4-24 the vast majority of cells transfected with the control siRNA were indeed arrested in G2/M phase after nocodazole treatment. However, the cells that were transfected with the siRNA against Mdm2 were only partially arrested in G2/M, and approximately one third of them were still in G1. This result was expected, as Mdm2 is the main negative regulator of p53 and its inhibition or depletion induces p21 (by p53 activation). P21 is an inhibitor of cyclindependent kinases and induces a cell cycle arrest in G1 (el-Deiry et al., 1994). In both cell lines tested, the cells that were transfected with the siRNAs against Dusp18 showed an overall slower progression of the cell cycle, indicated by the clear reduction of the G2/M fragment after the nocodazole trap. Many of the Dusp18-depleted cells were still in G1 or S phase, suggesting that these cells had problems reaching mitosis at all (Figures 4-22, 4-23 and 4-24). These results, together with the proliferation assay, the FACS analysis and the apoptosis induction in Dusp18-depleted cells, suggest that Dusp18 plays an important role in the proper cell cycle progression as well as the survival of the cells. 

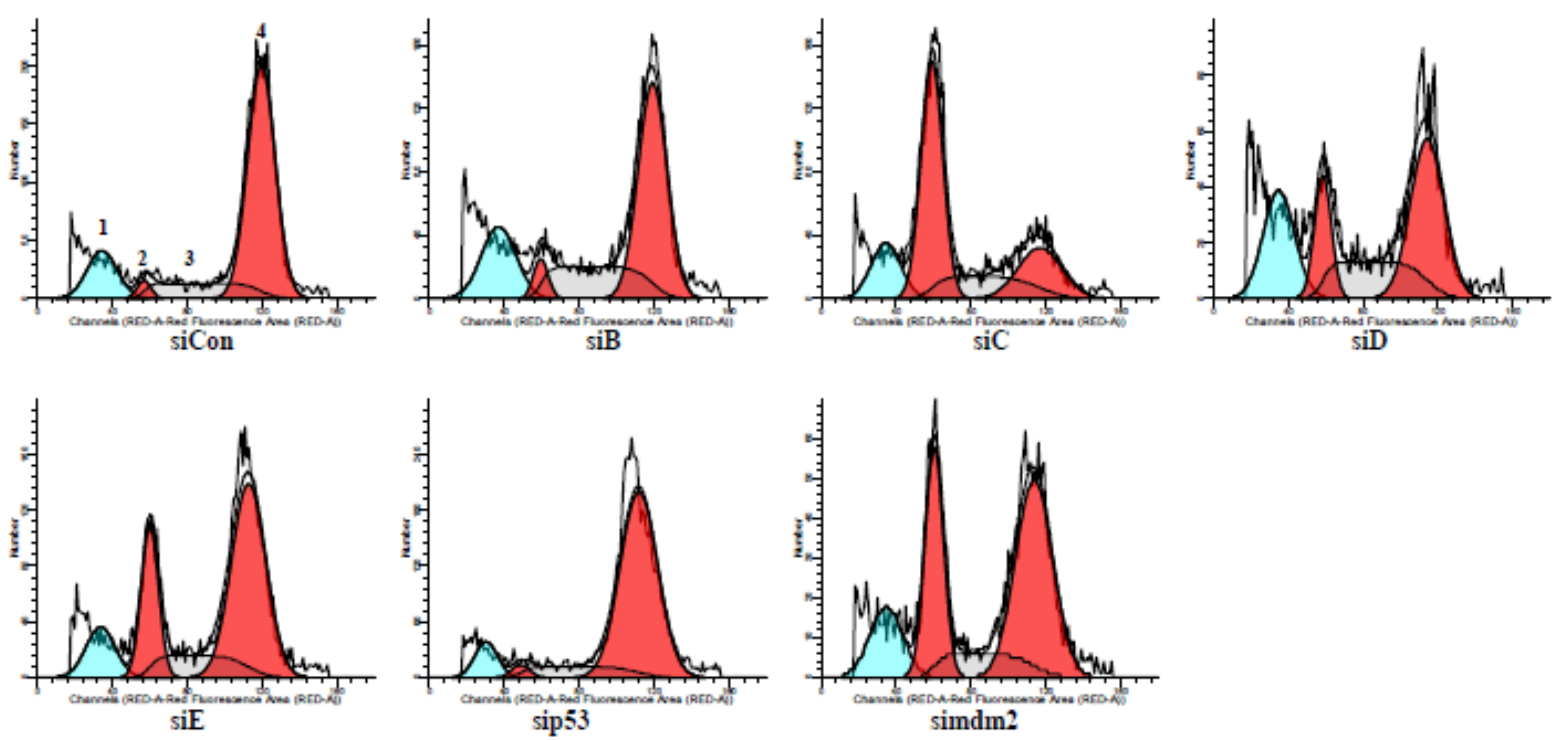

Figure 4-22: Cell cycle distribution of HCT116 p53+/+cells depleted of Dusp18 and trapped in G2/M with Nocodazole (ModFit analysis).

HCT116 p53 +/+ cells were transfected with siRNAs against Dusp18 and $48 \mathrm{~h}$ later treated with $100 \mathrm{ng} / \mathrm{ml}$ nocodazole for additionally 20h, then fixed and subjected to FACS. The histograms obtained were analysed with the ModFit software to identify the different cell cycle phases:

1: Apoptotic cells (subG1); 2: G1; 3: $S ; 4: G 2$.

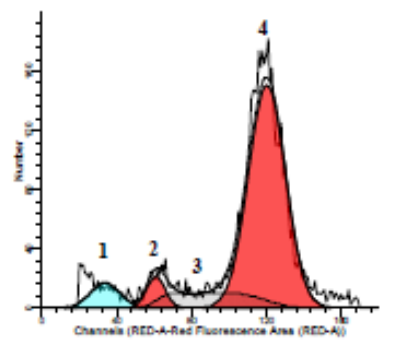

siCon
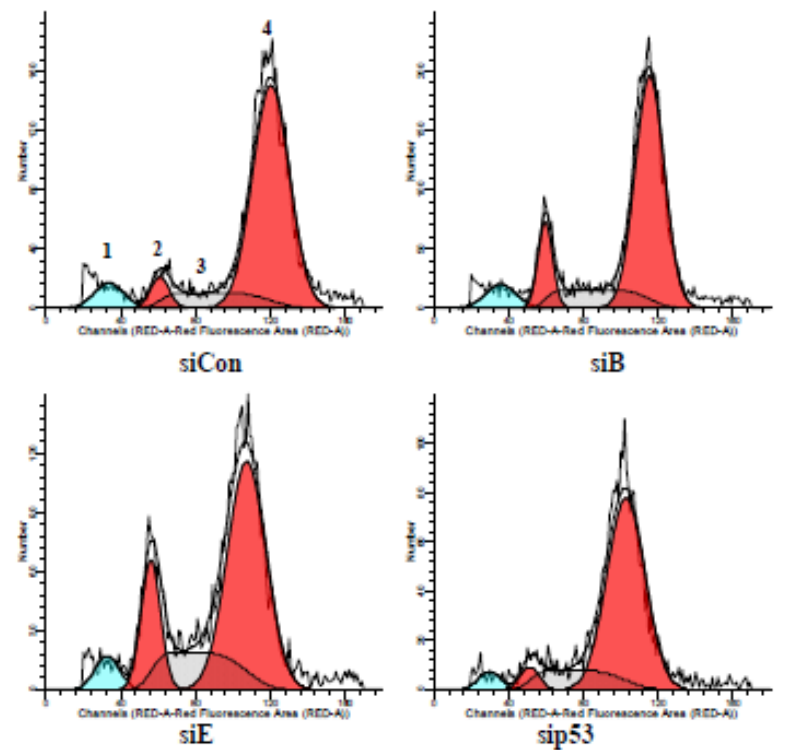

siB

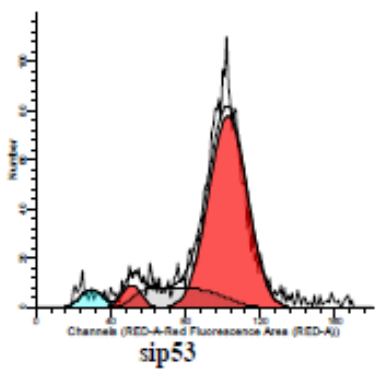

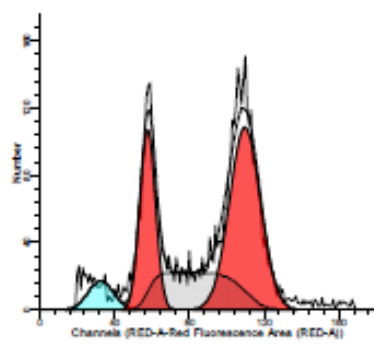

$\mathrm{siC}$

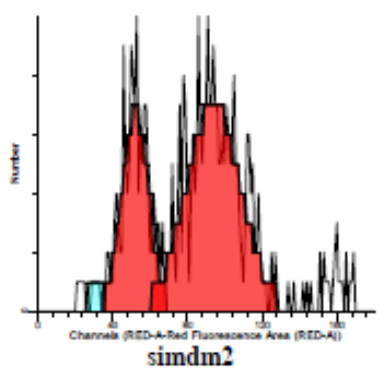

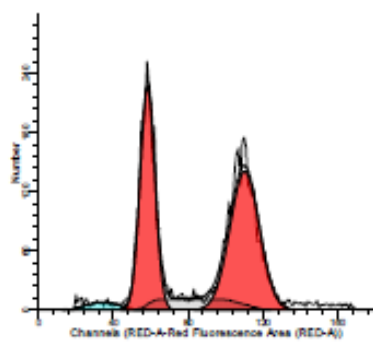

siD

Figure 4-23: Cell cycle distribution of U2OS cells depleted of Dusp18 and trapped in G2/M with Nocodazole (ModFit analysis).

U2OS cells were transfected with siRNAs against Dusp18 and 48h later treated with $100 \mathrm{ng} / \mathrm{ml}$ nocodazole for additionally 20h, then fixed and subjected to FACS. The histograms obtained were analysed with the ModFit software to identify the different cell cycle phases:

1: Apoptotic cells (subG1); 2: G1; 3: S; 4: G2. 
A

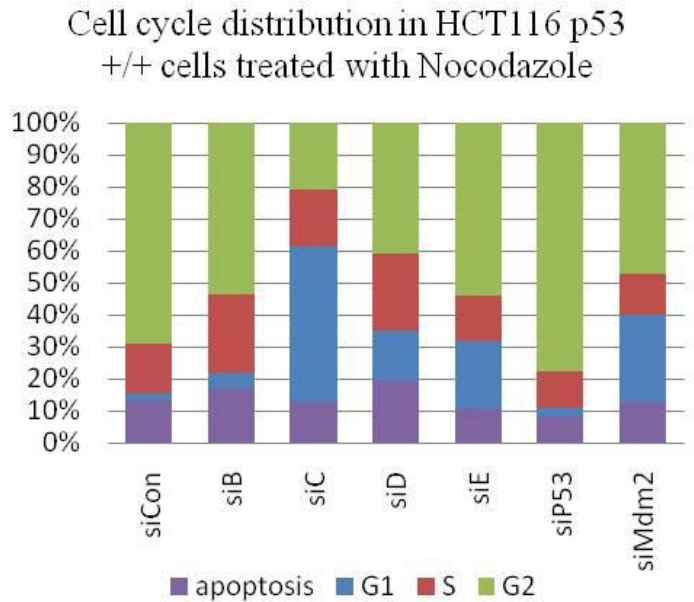

B

Cell cycle distribution in U2OS cells treated with Nocodazole

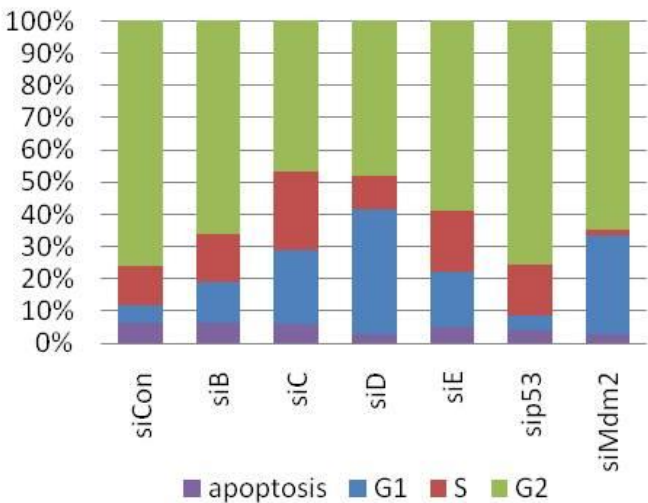

Figure 4-24: Cell cycle distribution of HCT116 p53 +/+ and U2OS cells depleted of Dusp18 trapped in G2 with Nocodazole.

HCT116 p53+/+ (A) or U2OS (B) cells were transfected with siRNAs against Dusp18 and 48h later treated with $100 \mathrm{ng} / \mathrm{ml}$ nocodazole for additionally $20 \mathrm{~h}$, then fixed and subjected to FACS. The histograms obtained were analysed with the ModFit software to measure the percentage of cells in each phase.

\subsubsection{Dusp18 knockdown sensitized HCT116 p53 +/+ cells to gemcitabine}

Since the Dusp18 depleted cells accumulated in $\mathrm{S}$ phase and showed an increase of $\gamma \mathrm{H} 2 \mathrm{Ax}$, we sought to examine if the knockdown of Dusp18 could sensitize the cells to a damaging drug that is effective while the DNA is replicating. SiRNA transfected cells were therefore treated with gemcitabine. Gemcitabine is a cytosine nucleotide analogue that induces DNA damage and accumulation of $\gamma \mathrm{H} 2 \mathrm{Ax}$ in S phase cells. After combining Dusp18 knockdown with gemcitabine treatment, the accumulation of $\gamma \mathrm{H} 2 \mathrm{Ax}$ was even higher than in cells treated with gemcitabine and transfected with the negative control siRNA (Figure 4-25). Interestingly, the induction of p53 by mdm2 knockdown had a protective effect on the cells, as it inhibited the accumulation of $\gamma \mathrm{H} 2 \mathrm{Ax}$ (in agreement with previously published data; Kranz et al., 2008). This further strengthens the hypothesis that, although the knockdown of Dusp18 induces p53 and p21, this induction is likely a secondary effect of the DNA damage response, and, in fact, the depletion of Dusp18 somehow triggers the DNA damage responsive cascade, leading first to the accumulation of $\gamma \mathrm{H} 2 \mathrm{Ax}$ and subsequently activating the $\mathrm{p} 53$ pathway. 


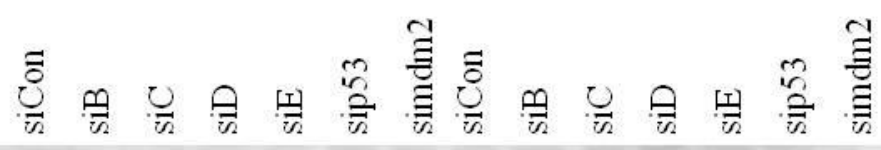

$\gamma \mathrm{H} 2 \mathrm{Ax}$

Actin

water

gemcitabine

Figure 4-25: $\alpha H 2 A x$ in HCT116 p53 +/+ cells depleted of Dusp 18 after treatment with gemcitabine. HCT116 p53 +/+ cells were transfected with siRNAs against Dusp18 and 36h later were treated with 100nM gemcitabine for $15 \mathrm{~h}$ additionally. Total cell lysates were subsequently used for immunoblotting analysis and detection of $\gamma H 2 A x$. 


\section{Discussion}

\subsection{Identification of novel phosphatases that modulate the DNA damage response and the p53 pathway}

Persistent damage to hereditary material leads to genomic instability, a major cause of cancer development. Thus organisms have developed ways to maintain genomic stability, as well as to recognize, repair or eliminate cells with damaged DNA to the benefit of the body. The aim of this study was to contribute to the elucidation of the mechanisms that control the response of cells to DNA damage, with a particular interest in the early DNA damage response and the p53 pathway.

In contrast to kinases, the role of phosphatases in the DNA damage response is not well established. The particular cellular response to genotoxic stress depends on the balanced network of several signaling pathways that are activated, inactivated and undergo crosstalk to determine cellular fate. Phosphatases are expected to take part in the regulation of the phosphorylation cascades that constitute the core of these signaling pathways. They may regulate the output of this network by shifting the balance between pathways, either by deactivating dephosphorylation of signaling kinases, activating phosphorylation or by ceasing a constant dephosphorylation action upon signaling. As discussed in the Introduction, several phosphatases have already been identified as "players" in the modulation of these cascades. We believe that this is only a small portion of the role of phosphatases in the DNA damage response, and to address the matter efficiently, we first performed a high throughput siRNA screen to identify novel phosphatases that regulate the response to genotoxic stress.

We focused our efforts on one particular phosphatase, namely DUSP18, as the knockdown of this phosphatase induced the accumulation of p53. However, several of our screen "hits" were also investigated by other researchers. For example, the phosphatase PPM1D, was initially identified as a negative regulator of p53 ( $\mathrm{Lu}$ et al., 2005), but its depletion caused a $\gamma \mathrm{H} 2 \mathrm{Ax}$ accumulation in our screen (Appendix, Figures 7-1 and 7-2) and in the further validation experiments (Figure 4-4, compare lane 3 to lane 1 for $\gamma \mathrm{H} 2 \mathrm{Ax}$ ). Indeed, two independent groups recently identified PPM1D as a $\gamma \mathrm{H} 2 \mathrm{Ax}$ phosphatase (Macůrek et al., 2010; Moon et al. 2010), confirming our findings and enhancing the reliability of our screen results. In addition, the catalytic subunits of calcineurin PPP3CA and PPP3CB were identified as positive regulators of p53 (Appendix, Figure 7-1, p53 downregulation upon calcineurin knockdown independently of UVC). This is in agreement with a recent report from Wu X. et al. showing that calcineurin inhibition counteracts p53-induced cellular senescence to promote cancer formation (Wu et al., 2010). These examples indicate that, with our screen, 
we could indeed identify new phosphatases that can regulate the response to DNA damage and the p53 pathway.

\subsection{The depletion of Dusp18 induced the p53 pathway}

During our screen and the hit validation experiments, an siRNA against Dusp18 massively induced the accumulation of p53 in osteosarcoma U2OS cells, as well as the activation of $\mathrm{p} 53$ as shown by the induction of its target genes $p 21$ and $m d m 2$. We therefore chose to further investigate this new potential negative regulator of the p53 pathway, as its inhibition seemed to activate p53 in cancer cells and hence it could become a novel anticancer drug target.

\subsubsection{Human Dusp18 was not localized in mitochondria in our system}

The background knowledge on this phosphatase is limited to 6 publications, of which 2 have described the cloning of Duspl8 and the in vitro characterization of its enzymatic activity (Hood et al., 2002; Wu et al., 2003). The structure of the protein has also been solved by Jeong and colleagues (Jeong et al., 2006). However, the in vivo function of Dusp18 is still unclear, as the 2 groups that investigated this aspect have published contradictory results (Wu et al., 2006; Rardin et al, 2008). The research of Wu Q. et al. was based on overexpression studies of the human Dusp18, which revealed a role for Dusp18 in the regulation of JNK signaling. More specifically, the authors claimed that Dusp18 can directly interact and dephosphorylate the p54SAPKbeta protein, but not p38 or p44ERK1 (Wu et al., 2006). In contrast to that, Rardin et al. performed experiments with the murine homologue of Dusp18. Using both overexpression and the endogenous protein in rat cells, the group showed that the murine Dusp18 is localized in the periphery of the inner mitochondrial membrane, facing the intermembrane space. As JNK is not localized in the mitochondria, the authors rejected a role for Dusp18 as a JNK phosphatase (Rardin et al., 2008). The targeting of proteins to the mitochondria depends, in most cases, on a sequence located at the $\mathrm{N}$-terminus of the protein, which contains positively charged as well as hydrophobic amino acids that can form amphiphilic $\alpha$-helices in a suitable environment (Claros \& Vincens, 1996). Wu et al. also performed localization experiments with overexpressed human Dusp18 (N-terminally tagged with GFP), and found it ubiquitously expressed both in the cytoplasm and the nucleus of cells (Wu et al., 2006; Figure 4-5). Rardin et al. suggested that the N-terminal bulky GFP tag mislocalized the protein and inhibited its targeting to the mitochondria. However, their deletion experiments showed that the region necessary and sufficient to target Dusp18 to the mitochondria is in fact found in the C-terminal half of the protein (amino acids 95-188), and that the N-terminal half is dispensable for localization (Wu et al., 2006). 
We wanted to examine the localization of Dusp18 in our system. For this we cloned the human Dusp18 open reading frame in expression vectors with either an $\mathrm{N}$ - or a C-terminal HA tag. Notably, the HA tag consists only of 7 amino acids, and is therefore much smaller than a GFP tag $(\sim 20 \mathrm{kDa})$. Both clones were expressed in U2OS osteosarcoma cells and localized in the cytoplasm and nucleus independently of the position of the HA tag. When we marked the mitochondria of the cells expressing HA-tagged Dusp18, we could not observe any colocalization between them and the Dusp18 (Figure 4-5). Hence, at least in our system, human Dusp18 was not localized in the mitochondria. Because Rardin et al. used the murine homologue of Dusp18 for their experiments, we aligned the human and murine sequences to examine the extent of their similarity. Furthermore we used a mitochondrial targeting prediction program to calculate the probability of mitochondrial localization for the two homologues. Although the protein sequence of Dusp18 is well conserved between human and mouse, there are differences in the amino acid sequences mostly at the $\mathrm{N}$ - and C-termini. Only the middle parts of the proteins that contain the dual specificity phosphatase catalytic domain are identical (Figure 4-6). In addition, the prediction program for mitochondrial targeting predicted the localization of the murine protein to the mitochondria with a probability close to $90 \%$, while the probability for the human homologue was less than $60 \%$ (Figure 4-6). These results raise the possibility that the mitochondrial localization of Dusp18 might be specific for the mouse homologue, and the human protein is actually localized in the cytoplasm and nucleus as previously shown by Hood et al. and Wu Q. et al. (Hood et al., 2002; Wu et al., 2006). However, at this point we cannot exclude the possibilities that overexpressed Dusp18 is mislocalized in the cells, perhaps due to lack of a modification or an interaction partner needed for its localization to mitochondria, although this does not correlate with the widely accepted model of mitochondrial targeting of proteins.

\subsubsection{The depletion of Dusp18 induced p53 and p21 accumulation in several cell lines}

Several siRNAs against Dusp18 were tested for their ability to induce p53 and its target genes in different tumor cell lines. Although the intensity of the effect varied depending on the siRNA and the cell line used, all the siRNAs showed the same tendency of inducing the p53 target p21. Other gene targets of p53 were also induced by the knockdown of Dusp18, including proapoptotic genes such as puma (data not shown), but only the induction of $p 21$ was consistent between the different siRNAs and independent of the cell line we used. Our first hypothesis was that, since Dusp18 is a phosphatase, it could directly or indirectly affect the modification of p53, and therefore its stability and activity. We used phospho- and acetylp53 specific antibodies to test whether Dusp18 depletion would induce the spontaneous 
modification of p53, indicating that in a healthy cell Dusp18 might act to control basal levels and activity of p53. No such spontaneous phosphorylation of serines 15 and 46 was detected. Although there is a plethora of phosphorylation sites on p53, all of which we could not test, we also looked at the acetylation of lysine 382. This residue is located in the inhibitory domain of p53. Its acetylation follows p53 multiple phosphorylation, and thus is indicative of a heavily modified and transcriptionally active p53 (Sakaguchi et al., 1998). We could not observe any spontaneous K382 acetylation induced by the knockdown of Dusp18. These results suggest that the induction of p53 by the depletion of Dusp18 is likely not a direct consequence of p53 hyperphosphorylation due to the removal of a phosphorylationcounteracting molecule.

In agreement to that, the interaction of p53 with its negative regulator Mdm2 was not significantly affected by the depletion of Dusp18 (Figure 4-10). The efficiency of complex formation of the two proteins is largely regulated by post-translational modifications on both polypeptides. Thus, should the accumulation and activation of $\mathrm{p} 53$ be a result of increased phosphorylation of either itself or Mdm2, we would expect the inhibition, to a great extent, of their interaction. The accumulation and activation of p53 by a mechanism different than the direct inhibition of the Mdm2 function would result in the reduction but not complete abrogation of the complex formation. Hence, the small reduction in the amount of p53 coprecipitated with Mdm2 that we observed is likely a secondary effect and not the initial reason for the activation of $\mathrm{p} 53$.

The induction of $\mathrm{p} 21$ by the depletion of Dusp18 occurred in the cells as a consequence of p53 activation, as shown by the increase in p21 pre-mRNA levels and by the increased binding of $\mathrm{p} 53$ to the $p 21$ promoter. Despite that, we could not detect an increase of the RNA polymerase bound to any sites of the $p 21$ gene tested. It is known that the p21 mRNA production is regulated at the level of transcription elongation rather than the loading of RNA polymerase II on the promoter (Mattia et al., 2007; Donner et al., 2007; Beckerman et al., 2009). In addition, the amount of RNA polymerase bound along the coding region of the gene does not strikingly increase. Instead, the C-terminal transcription domain (CTD) of RNA polymerase molecules is phosphorylated to create the elongating form of the enzyme, and this changes dramatically upon induction of p21 (Donner et al., 2007). Thus, the lack of increased RNA polymerase binding to the $p 21$ locus can be explained by the phosphorylation of existing molecules on the gene, and by an increased transcription speed, which would not necessarily increase the number of bound molecules. Rather, this would allow them to go faster through the gene, therefore producing more mRNA in a given amount of time. The 
chromatin immunoprecipitation of RNA polymerase II phosphorylated at the Ser2 of its CTD heptapeptides (which represents the elongating form of the enzyme) could provide support to this hypothesis.

Another possible mechanism of Dusp18 action could be the inhibition of p53 transcriptional activity by the modulation of one of its transcription partners. A good candidate was the general transcription factor SP1 (Specificity Protein 1), as it is also needed for the activation of the $p 21$ promoter, and its activity is regulated by phosphorylation. Therefore Dusp18 might partially act on SP1 to inhibit its binding to the promoter of $p 21$. We tested this hypothesis by investigating the amounts of SP1 bound to the $p 21$ promoter when the cells were depleted of Dusp18, but did not observe a significant increase of chromatin immunoprecipitated SP1 (Figure 7-4). However, we did observe that the accumulation of p21 protein was dependent on the presence of SP1; in the combined knockdown of SP1 and Dusp18 the p21 protein amount failed to increase to the levels of the Dusp18 knockdown alone for 3 out of 4 siRNAs (Figure 4-13). The accumulation of p53 with the siRNA C was so robust that it could have perhaps overcome the necessity of abundant SP1, and thus this siRNA seemed to induce p21 independently of SP1 levels. A further observation of this experiment was that SP1 protein levels were also increased upon depletion of Dusp18; yet this effect was not confirmed upon repetition of the experiment (data not shown).

In conclusion, Dusp18 depletion led to the accumulation of p21 mRNA and protein in several tumor cell lines, as a result of the activation of the p53 pathway. The amount of p53 bound to the responsive element on the $p 21$ promoter was augmented, and the p $21 \mathrm{mRNA}$ induction was a result of increased transcription, but not increased transcription initiation as the binding of RNA polymerase II to the $p 21$ gene remained the same. Finally, the induction of p21 is at least partially dependent on the p53 cofactor SP1.

\subsection{The survival of tumor cells depends on Dusp18}

Tumor cells transfected with siRNAs against Dusp18 showed signs of apoptosis induction, starting at 48 hours after transfection. HCT116 cells depleted of Dusp18 showed cleavage of the apoptotic markers PARP-1 and caspase 3 at 48 hours after siRNA transfection. Additionally, FACS analysis revealed an increase in the subG1 fraction of cells sorted 72 hours after siRNA transfection. These events were augmented in p53 +/+ relatively to the p53 -/- cells, indicating that the apoptosis induction was largely p53 dependent, or that simply the presence of p53 in the cells sensitized them to the depletion of Dusp18.

The accumulation of $\mathrm{p} 21$ (i.e. resulting from $\mathrm{Mdm} 2$ depletion) typically induces a prolonged arrest of the cell cycle at the border of G1 and S phases (el-Deiry et al., 1994). 
Despite the induction of p21 by Dusp18 knockdown, the cell cycle sorting analysis of siRNAtransfected HCT116 and U2OS cells indicated that there was an increase in the fragment of cells in S phase upon Dusp18 depletion. This effect could have been the result of increased entry of the cells into $\mathrm{S}$ phase, or the activation of the intra-S phase checkpoint. Monitoring of the proliferation of Dusp18-depleted HCT116 cells showed that the absence of our favorite phosphatase induced a proliferation defect, indicated by the low rate of confluency increase over time. Therefore siRNA targeting of Dusp18 must result in a slow progression of the cells through the cell cycle.

To confirm this hypothesis, we performed the FACS analysis again using nocodazole to arrest the cells in the G2/M phase, after depleting them of Dusp18. This should allow the cells to proceed to the end of the G2 phase, and then stop there, unless there is an arrest already earlier in the cell cycle. Indeed, the control siRNA transfected cells almost completely accumulated at the border of G2/M phase (Figure 4-22, 4-23 and 4-24). Instead, the Dusp18 depleted cells clearly showed a slower progression of the cell cycle, and, in addition to the G2/M peak, there was a large amount of cells still in G1 and S phases. HCT116 p53 +/+ and U2OS (p53 wild type) cells depleted of Mdm2 arrested as expected in G1 phase, due to the accumulation of $\mathrm{p} 21$ by the induction of p53. However, in Mdm2 siRNA transfected cells there was a reduction in the percentage of the $S$ phase cells, in contrast to the Dusp18 siRNAs. In addition, there was no increase in apoptotic cells observed with the depletion of Mdm2, while in Dusp18 depleted cells the subG1 fragment of cells was augmented indicating cell death. Therefore the cell cycle profile and the arrest of Dusp18 depleted cells in G1 and S phase is not identical to the profile resulting from direct p53 induction by the Mdm2 siRNA.

These results lend further support the hypothesis that, instead of acting by directly inhibiting the accumulation and activation of p53, Dusp18 probably suppresses the activation of another pathway, which in turn activates p53 and its target p21.

\subsection{Dusp18 depletion induces $\gamma \mathrm{H} 2 \mathrm{Ax}$ and initiates the DNA damage response cascade}

P53 is activated in response to cellular stress. Therefore the influence of Dusp18 knockdown on different factors regulating or responding to different kinds of stress was examined. We were particularly interested in DNA damage responsive proteins, as the involved signaling cascades can also lead to the cell cycle arrest and apoptosis we observed. Of the proteins investigated, the most prominent relevant consequence of Dusp18 knockdown was the accumulation of $\gamma \mathrm{H} 2 \mathrm{Ax}$.

There are two possible hypotheses that can explain the accumulation of $\gamma \mathrm{H} 2 \mathrm{Ax}$. The first and more straightforward way to explain the phosphorylation of $\mathrm{H} 2 \mathrm{Ax}$ in the absence of 
Dusp18 is that the latter is a novel $\gamma \mathrm{H} 2 \mathrm{Ax}$ phosphatase (Figure 5-1 (1)). Thus the depletion of Dusp18 would allow the accumulation of spontaneously phosphorylated histone molecules, by shifting the balance of phosphorylation versus dephosphorylation events. So far several other phosphatases have been implicated in the dephosphorylation of $\gamma \mathrm{H} 2 \mathrm{Ax}$, including the protein phosphatases PP4, PP6 and PP2A. This indicates that this dephosphorylation event is not performed specifically in the cells by one phosphatase, and that different enzymes might cooperate or take over this task under diverse conditions. Hence it might be possible that other, undiscovered yet phosphatases may contribute to $\gamma \mathrm{H} 2 \mathrm{Ax}$ dephosphorylation. However, an accumulation of $\gamma \mathrm{H} 2 \mathrm{Ax}$ was observed in cells depleted of Dusp18 without any further genotoxic stress (Figure 4-15), although this accumulation was augmented by the addition of gemcitabine (Figure 4-25). In contrast, the depletion of already identified $\gamma \mathrm{H} 2 \mathrm{Ax}$ phosphatases has not resulted in any detectable $\gamma \mathrm{H} 2 \mathrm{Ax}$ accumulation without further cellular stress in previously published results (Chowdhury et al., 2005; Nakada et al., 2008; Moon et al., 2010; Douglas et al., 2010). Instead, the depletion of these phosphatases has led to prolonged or more profound $\gamma \mathrm{H} 2 \mathrm{Ax}$ signal after DNA damage, or has interfered with the restoration of the damage and the re-entry in the cell cycle. This difference makes the assumption that Dusp18 might be a novel direct $\gamma \mathrm{H} 2 \mathrm{Ax}$ phosphatase rather unlikely.

The second hypothesis that can explain the accumulation of $\gamma \mathrm{H} 2 \mathrm{Ax}$ is that the depletion of Dusp18 induces the activation of the DNA damage response cascade in the cells (Figure 5-1 (2)). This assumption is in agreement with the activation of other DNA damage responsive proteins (such as the phosphorylation of Chk2, Figure 4-15), and the physiological consequences of cell cycle arrest and apoptosis induction, that occur in part as a result of p53 activation. As $\gamma \mathrm{H} 2 \mathrm{Ax}$ is one of the earliest events of DNA damage response, Dusp18 might act as a repressor at one or more of the first steps of the cascade activation. For example, Dusp18 might be a negative regulator of the ATM/ATR kinases, such that siRNAs against Dusp18 may induce the activation of these proteins, and initiate the DNA damage response. A simultaneous knockdown of Dusp18 and ATM/ATR could further elucidate this hypothesis. Little is known so far about the connection between the actual damage of DNA and the activation of ATM and ATR, but certainly Dusp18 could also act upstream of these kinases, by negatively regulating one of these intermediate steps. For instance, the serine/threonine kinase Cdk5 has been shown to phosphorylate ATM on Ser794, a modification that precedes and is required for the activating autophosphorylation of ATM on Ser1981. Tian et al. recently showed that, in post-mitotic neurons, DNA damage activates ATM via Cdk5 and leads to $\gamma \mathrm{H} 2 \mathrm{Ax}$ accumulation and $\mathrm{p} 53$ activation. This is accompanied by an induction of 
Cdks 2 and 6, forcing these normally non-dividing cells to re-enter the cell cycle. The re-entry into the cell cycle requires ATM activity and leads to apoptotic neuronal death. This pathway of aberrant cell cycle progression that leads to apoptosis may not be restricted only to neuronal cells, as both ATM and Cdk5 are widely expressed (Tian et al., 2009). A hypothetical mode of action for Dusp18 could be an inhibitory role on Cdk5 or its activators p25 and p35. The detection of Ser794-phosphorylated ATM in Dusp18-depleted cells and/or a double knockdown experiment of Dusp18 with Cdk5 might provide further insight into this possibility. Furthermore, Ayoub and colleagues (Ayoub et al., 2008) discovered that DNA breaks result in an altered chromatin structure, which allows for the weakening of hydrogen bonds between Heterochromatin Protein 1 (HP1) and Lys9-methylated H3. They showed that the dissociation of HP1 from the damaged DNA occurs in a CK2 dependent manner (phosphorylation of HP1 at Thr15) and promotes the conversion of $\mathrm{H} 2 \mathrm{Ax}$ into $\gamma \mathrm{H} 2 \mathrm{Ax}$ at damaged DNA sites (Ayoub et al., 2008). Dusp18 could suppress one or more of these events, and thus the depletion of this phosphatase could favor the accumulation of $\gamma \mathrm{H} 2 \mathrm{Ax}$ resulting either from spontaneous DNA damage or from faulty activation of the CK2/HP1 pathway. The use of a CK2 inhibitor in combination with Dusp18 depletion, or the detection of HP1 localization upon Dusp18 knockdown by immunofluorescence may help to support or contradict this hypothesis.

The activity of Dusp18 upstream of the activation of the DNA damage response is also possible (Figure 5-1 (3)); Dusp18 could be necessary for a vital cellular process, or for the maintenance of a survival pathway in the cell. A very interesting aspect we have not yet addressed is whether Dusp18 knockdown leads to the induction of actual damage to DNA, or just to the activation of the DNA damage response cascade. The detection of DNA ends (for example by TUNEL or comet assay) would provide an answer to this question. In this way, we could discern between the possibility that Dusp18 acts by directly inhibiting the initiation of the DNA damage response cascade, or by maintaining a process necessary for survival and proliferation. For example, the PI3K/AKT survival pathway regulates many cellular procedures implicated in survival and proliferation (Osaki et al., 2004). Saito et al. found that inhibition of this pathway in colorectal cells, by overexpression of its negative regulator PTEN (phosphatase and tensin homologue deleted in chromosome 10), induced a G2/M arrest and suppressed their proliferation. Combination of PTEN overexpression with the ATM/ATR inhibitor caffeine abrogated the cell cycle arrest and instead led to apoptotic death (Saito et al., 2003). Dusp18 might be necessary for the sustained activation of such a pathway in tumor cells, and thus its depletion might decrease the activity of this pathway, hence inducing cell 
cycle arrest and apoptosis. Investigation of the phosphorylated levels of AKT targets, such as GSK3ß or the FOXO transcription factor could provide further evidence regarding this hypothesis.

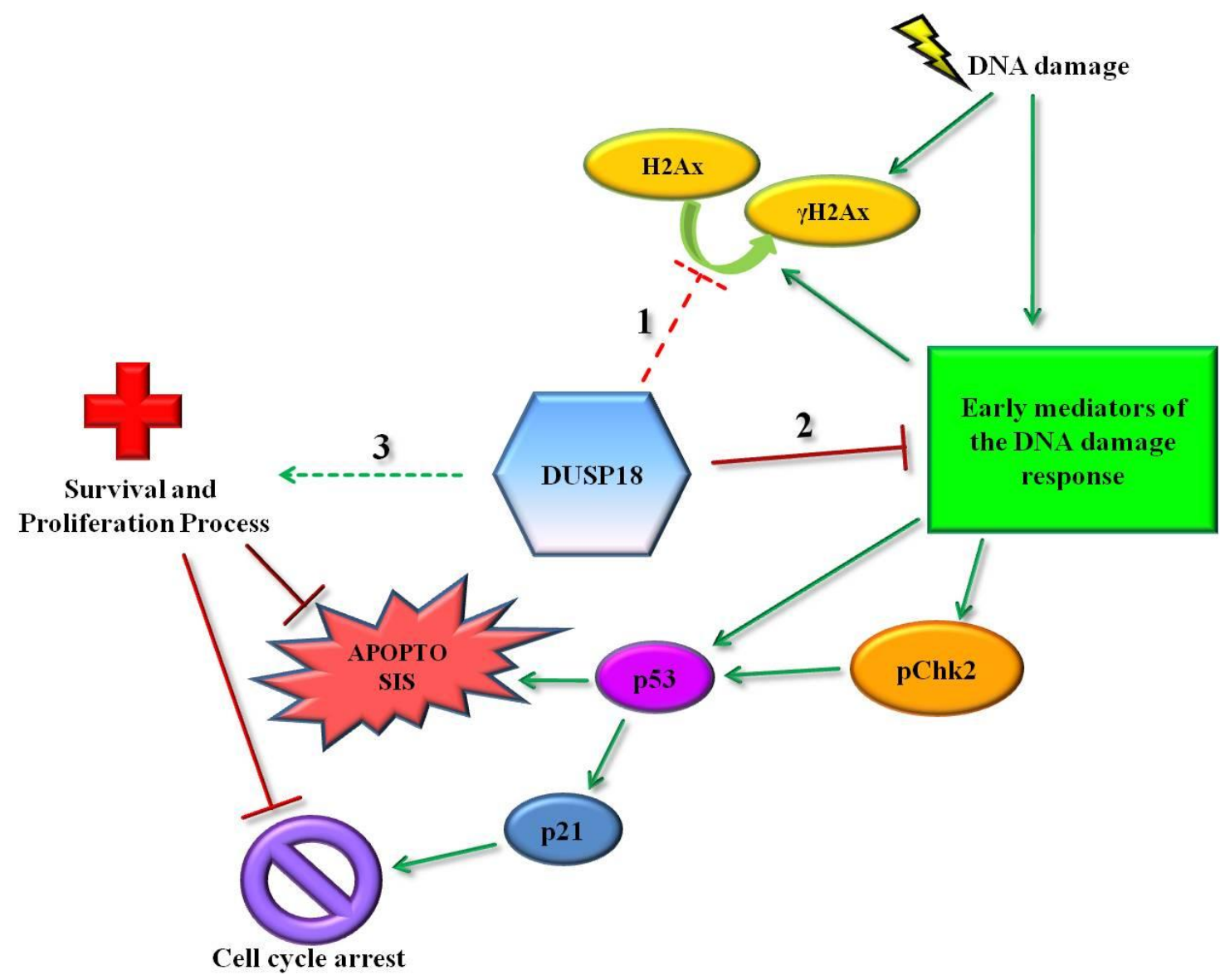

Figure 5-1: Possible mechanisms of Dusp18 action.

1: Dusp 18 could directly dephosphorylate $\gamma H 2 A x$. However, spontaneous $\gamma H 2 A x$ accumulation was not observed in the absence of other known $\gamma H 2 A x$ phosphatases.

2: Dusp18 could suppress the activity of one or more of the early DNA damage response mediators. The results of this work favor this hypothesis.

3: Dusp18 could be necessary for a vital cellular process. This hypothesis does not explain $\gamma H 2 A x$ accumulation.

In conclusion, the aim of this work was to identify new phosphatases that regulate the DNA damage response and/or the p53 pathway. We identified the dual specificity phosphatase 18, Dusp18, as a novel modulator of both these pathways. Dusp18 did not seem to exert its function by directly interfering with the p53 pathway. Rather, the depletion of Dusp18 activated the DNA damage response cascade in tumor cells, which in turn induced p53 and p21 accumulation. The physiological effects of Dusp18 depletion in cancer cell lines 
included a prolonged delay of cell cycle progression both in G1 and S phase, and an increased rate of apoptosis. Both these effects took place in the absence of any further exogenous cellular stress, i.e. genotoxic drugs. However, the accumulation of the characteristic marker of DNA damage response activation, $\gamma \mathrm{H} 2 \mathrm{Ax}$, was augmented when Dusp18-depleted cells were further treated with the $\mathrm{S}$ phase targeting DNA damaging drug gemcitabine. Our data suggest that Dusp18 might play an essential role in moderating the activity levels of the early DNA damage responsive kinases, hence its absence could allow their uncontrolled activation. Another equally possible model would place Dusp18 in charge of maintaining the activity of a pathway promoting the survival and proliferation of cells. Tumor cells often have a higher dependence on pathways such as the PI3K/AKT than their respective normal tissue cells (Roy et al., 2010 and references therein). Further investigation is necessary to gain insight into the details of Dusp18 action. Nevertheless, we have identified a novel protein, whose depletion leads, without any further exogenous damage, to the arrest of proliferation and apoptotic death of tumor cells. As most enzymes, Dusp18 could provide a novel drug target. Finally, the cell death-inducing effect of Dusp18 knockdown could be enhanced by suppressing the cell cycle arrest, for instance by the parallel inhibition of checkpoint kinases, or other so called caretaker genes (synergistic lethality). Hence, the targeted inhibition of Dusp18 alone or in combination with kinase inhibitors in tumors could provide the grounds for the development of novel therapeutic drugs, adding to our hopes of discovering new approaches to combat cancer. 


\section{SUMmary ANd CONCLUSIONS}

From bacteria to mammals, organisms have developed mechanisms to maintain the stability of their genome. Environmental factors, such as UV light and cellular processes, like genomic replication and recombination, constantly induce point mutations and breaks on the DNA. If this damage is not promptly and properly repaired, it can lead to impaired gene expression, inactivate the protective effects of tumor suppressors, and induce oncogenes, thus promoting the malignant transformation of the cell. Therefore, persistent DNA damage can prove catastrophic for the organism. One of the major tumor suppressors is the so-called "guardian of the genome" p53. The main functions of p53 are to facilitate DNA repair, to induce cell cycle arrest (by augmenting the expression of the Cdk/cyclin inhibitor p21) and to initiate the induction of apoptosis in severely damaged cells.

The phosphorylation of proteins is a rapid, specific and reversible modification; this makes it ideal for the regulation of signal transduction pathways. The response to genotoxic stress largely depends on a series of phosphorylations, and on the activity of several known kinases. The phosphorylation state of the proteins that constitute the DNA damage response cascade is regulated by the balanced activities of kinases and phosphatases. The role of kinases in this pathway is quite well established; however, the contribution of phosphatases in the regulation of the DNA damage response has only recently begun to be revealed.

The aim of this study was to identify new phosphatases regulating the response to genotoxic stress and the p53 network. To address this in a high-throughput manner, an siRNA screen targeting most known human phosphatase subunits was performed. Briefly, U2OS cells (an osteosarcoma-derived cell line) were transfected with the siRNA library (3 different siRNAs were used per targeted phosphatase subunit). Subsequently, the cells were exposed to UVC irradiation to induce DNA damage, or mock treated. Then, the cells were fixed and labeled with fluorescent antibodies against the tumor suppressor $\mathrm{p} 53$, and $\gamma \mathrm{H} 2 \mathrm{Ax} . \gamma \mathrm{H} 2 \mathrm{Ax}$ is the Ser139 phosphorylated form of the histone variant H2Ax. This modification occurs within a few minutes after inducing DNA damage, marks the sites of damaged chromatin and plays a key role in the amplification and transduction of the DNA damage signal. The phosphatase siRNA library screening resulted in the identification of 39 potential novel modulators of p53 and of the DNA damage response. Several of these were identified and confirmed by other groups during the course of this study, thereby enhancing the reliability of our screen data. Our efforts were focused on understanding the function of the dual specificity phosphatase 18 (Dusp18), which emerged from our screen as a promising new p53 modulator. 
The transfection of several cell lines with siRNAs against Dusp18 activated the p53 pathway, as detected by the accumulation of p53 and its target gene product p21. The induction of p21 was robust and particularly consistent among the different cell lines and siRNAs used. The depletion of Dusp18 in cells lacking p53 did not result in a similar induction of p21. Quantitative PCR analysis revealed that the depletion of Dusp18 led to the increase of p21 mRNA and pre-mRNA levels. In addition, the siRNAs against Dusp18 augmented the amount of p53 that was bound to the $p 21$ promoter. Furthermore, combined depletion of Dusp18 and a p53 transcriptional cofactor, SP1, reduced the observed accumulation of $\mathrm{p} 21$ protein. These results suggest that the induction of $\mathrm{p} 21$ is a consequence of the increased transcriptional activity of p53.

The p53 protein stability and activity are regulated by a variety of post-translational modifications. However, no detectable increase in the phosphorylation or acetylation of p53 was observed after depletion of Dusp18. Furthermore, the interaction of p53 with its negative regulator, Mdm2, was not disrupted upon Dusp18 knockdown. These results suggest that Dusp18 might not act directly on p53 to suppress the p53 pathway.

The depletion of Dusp18 induced apoptosis in tumor cells. Although to a lesser extent, this apoptosis induction was also observed in cells lacking p53. An accumulation of $\gamma \mathrm{H} 2 \mathrm{Ax}$ also occurred upon Dusp18 knockdown, independently of p53. In addition, an increase in pChk2, but not pChk1 levels, was detected. The cell cycle analysis of cells depleted of Dusp18 showed a delayed progression through the $\mathrm{S}$ phase, which was accompanied by a reduced proliferation rate. A nocodazole trap in $\mathrm{G} 2 / \mathrm{M}$ phase revealed that the siRNAs against Dusp18 induced an arrest in G1 and in S phase, as the cells depleted of Dusp18 failed to synchronize in G2/M. This led us to assume that the $S$ phase arrest could sensitize the tumor cells to cancer therapeutic drugs that target DNA replication, such as gemcitabine. Indeed, cells depleted of Dusp18 showed an increased response to this drug, as detected by an augmented accumulation of $\gamma \mathrm{H} 2 \mathrm{Ax}$. These findings indicate a role for Dusp18 in tumor cell survival and proliferation, and thus introduce Dusp18 as a potential novel cancer drug target.

In conclusion, Dusp18 was identified as a novel phosphatase modulating the tumor suppressor p53 and the DNA damage response. Our results suggest that the depletion of Dusp18 can lead to proliferation defects and the apoptotic death of tumor cells. Furthermore, Dusp18 knockdown can synergistically potentiate the cytotoxic effect of cancer drugs. Hence, Dusp18 may represent a potential new therapeutic target for cancer. 


\section{APPENDIX}

\begin{tabular}{|c|c|}
\hline \multicolumn{2}{|c|}{ p53 control downregulation } \\
\hline Target & $\boldsymbol{z}$-score \\
\hline P53 & -2.32 \\
\hline P53 & -2.23 \\
\hline P53 & -2.21 \\
\hline P53 & -2.15 \\
\hline PPP3CB & -1.61 \\
\hline PTPN22 & -1.57 \\
\hline SACM1L & -1.54 \\
\hline PPP3CA & -1.49 \\
\hline PTPN11 & -1.47 \\
\hline HDHD1A & -1.44 \\
\hline TNS3 & -1.38 \\
\hline PTPN12 & -1.37 \\
\hline MTMR14 & -1.36 \\
\hline PTPRA & -1.35 \\
\hline PTPN7 & -1.35 \\
\hline CON1 & -1.34 \\
\hline ACP6 & -1.30 \\
\hline PPP1R16B & -1.27 \\
\hline PTPRH & -1.22 \\
\hline RP11-35N61 & -1.21 \\
\hline ENOPH1 & -1.21 \\
\hline LPPR4 & -1.21 \\
\hline EPM2A & -1.20 \\
\hline PTPN1 & -1.19 \\
\hline TPTE & -1.19 \\
\hline DUSP13 & -1.19 \\
\hline PTPRC & -1.16 \\
\hline PPAP2C & -1.12 \\
\hline MTMR9 & -1.11 \\
\hline CDC14A & -1.10 \\
\hline ANP32A & -1.10 \\
\hline PPAPDC1B & -1.09 \\
\hline ALPI & -1.08 \\
\hline KIAA1274 & -1.08 \\
\hline PPP1R11 & -1.06 \\
\hline PPP2R3B & -1.06 \\
\hline ALPP & -1.06 \\
\hline DTPN9 & -1.01 \\
\hline & -1.01 \\
\hline
\end{tabular}

\begin{tabular}{|c|c|}
\hline \multicolumn{2}{|c|}{ p53 control upregulation } \\
\hline Target & z-score \\
\hline MWM2 & 3.38 \\
\hline MDM2 & 3.18 \\
\hline MDM2 & 2.94 \\
\hline PPP1R14A & 2.91 \\
\hline DUSP19 & 2.83 \\
\hline CTDP1 & 2.73 \\
\hline CTDSP2 & 2.69 \\
\hline MDM2 & 2.59 \\
\hline PPM1L & 2.54 \\
\hline CIB3 & 2.36 \\
\hline CTDSP1 & 2.26 \\
\hline LRGUK & 2.24 \\
\hline PPP2R2B & 2.23 \\
\hline PPEF1 & 2.21 \\
\hline PPP2R1B & 2.13 \\
\hline ENTPD4 & 2.03 \\
\hline DUSP28 & 2.02 \\
\hline DUSP18 & 2.01 \\
\hline PPP2R1A & 1.99 \\
\hline $\mathrm{CDC} 14 \mathrm{C}$ & 1.72 \\
\hline NAP1L1 & 1.68 \\
\hline TIP60 & 1.68 \\
\hline ALPPL2 & 1.65 \\
\hline PPP1R3D & 1.61 \\
\hline PTPDC1 & 1.57 \\
\hline PTPRU & 1.56 \\
\hline PPP2R3A & 1.52 \\
\hline PPM1B & 1.49 \\
\hline MTMR4 & 1.48 \\
\hline PPM1M & 1.45 \\
\hline G6PC3 & 1.43 \\
\hline NUDT14 & 1.42 \\
\hline PPAPDC1A & 1.39 \\
\hline $\mathrm{ACPT}$ & 1.37 \\
\hline DUSP2 & 1.37 \\
\hline PPA1 & 1.32 \\
\hline MINPP1 & 1.30 \\
\hline ATP6V0E1 & 1.29 \\
\hline RWDD2 & 1.27 \\
\hline PPP1R12B & 1.26 \\
\hline PPM1F & 1.26 \\
\hline LHPP & 1.21 \\
\hline PPP1R7 & 1.20 \\
\hline PPEF2 & 1.19 \\
\hline NAP1L5 & 1.09 \\
\hline PPP2R2C & 1.05 \\
\hline CANT1 & 1.04 \\
\hline ASNA1 & 1.02 \\
\hline PPP1R3F & 1.01 \\
\hline
\end{tabular}

\begin{tabular}{|c|c|}
\hline \multicolumn{2}{|c|}{ p53 UVC downregulation } \\
\hline Target & $\boldsymbol{z}$-score \\
\hline P53 & -2.65 \\
\hline P53 & -2.61 \\
\hline P53 & -2.60 \\
\hline P53 & -2.59 \\
\hline PPP3CA & -2.04 \\
\hline PPP1R16B & -1.88 \\
\hline PPP1R12C & -1.87 \\
\hline PTPRH & -1.75 \\
\hline SKIP & -1.69 \\
\hline PTPN7 & -1.67 \\
\hline PPAP2C & -1.62 \\
\hline MTMR12 & -1.50 \\
\hline PDXP & -1.47 \\
\hline PPP1R11 & -1.45 \\
\hline PTPN11 & -1.44 \\
\hline PTPN20B & -1.41 \\
\hline PPP1R14D & -1.39 \\
\hline PPP3CB & -1.39 \\
\hline SSH1 & -1.39 \\
\hline PTPN22 & -1.35 \\
\hline ANP32A & -1.34 \\
\hline PTPN9 & -1.30 \\
\hline MTMR14 & -1.30 \\
\hline MTMR7 & -1.26 \\
\hline DUSP13 & -1.25 \\
\hline ALPI & -1.24 \\
\hline PPP1R14B & -1.23 \\
\hline PPA2 & -1.21 \\
\hline ALPL & -1.20 \\
\hline PPM1G & -1.18 \\
\hline PTPRK & -1.17 \\
\hline ACPP & -1.16 \\
\hline PPTC7 & -1.14 \\
\hline PTPN18 & -1.13 \\
\hline PTPN2 & -1.13 \\
\hline CHTF18 & -1.12 \\
\hline FBP1 & -1.11 \\
\hline PTPN13 & -1.07 \\
\hline ACP5 & -1.05 \\
\hline ALPP & -1.04 \\
\hline PPP6C & -1.01 \\
\hline & -1.01 \\
\hline
\end{tabular}




\begin{tabular}{|c|c|}
\hline \multicolumn{2}{|c|}{ p53 UVC upregulation } \\
\hline Target & z-score \\
\hline MWM2 & 3.30 \\
\hline CANT1 & 3.10 \\
\hline DUSP18 & 3.05 \\
\hline DUSP19 & 2.81 \\
\hline MINPP1 & 2.71 \\
\hline MFN2 & 2.67 \\
\hline LRGUK & 2.60 \\
\hline PTPDC1 & 2.49 \\
\hline PPM1L & 2.48 \\
\hline PPM1M & 2.43 \\
\hline PPM1F & 2.29 \\
\hline CIB3 & 2.17 \\
\hline PPM1E & 2.16 \\
\hline MDM2 & 1.98 \\
\hline FHIT & 1.96 \\
\hline CTDSP2 & 1.94 \\
\hline SGPP2 & 1.93 \\
\hline PPP1R14A & 1.86 \\
\hline PPM1K & 1.80 \\
\hline DUSP2 8 & 1.76 \\
\hline PPP1R3F & 1.73 \\
\hline CTDSP1 & 1.62 \\
\hline PPM1J & 1.59 \\
\hline PPP2R1A & 1.56 \\
\hline G6PC2 & 1.53 \\
\hline JNK2 & 1.52 \\
\hline INPP5F & 1.52 \\
\hline PPP2R2B & 1.51 \\
\hline HDDC3 & 1.46 \\
\hline NAP1L5 & 1.44 \\
\hline DUSP14 & 1.43 \\
\hline MDM2 & 1.43 \\
\hline ANP32D & 1.36 \\
\hline PPP1R12A & 1.35 \\
\hline SET & 1.32 \\
\hline MTMR4 & 1.27 \\
\hline PHACTR4 & 1.25 \\
\hline PPM1B & 1.25 \\
\hline PTP4A3 & 1.25 \\
\hline NT5C2 & 1.22 \\
\hline CTDP1 & 1.22 \\
\hline MDM2 & 1.13 \\
\hline SAPS1 & 1.11 \\
\hline PTPN20A & 1.08 \\
\hline DUSP3 & 1.02 \\
\hline
\end{tabular}

\begin{tabular}{|c|c|}
\hline \multicolumn{2}{|c|}{$\gamma \mathrm{H} 2 \mathrm{Ax}$ UVC downregulatior } \\
\hline Target & z-score \\
\hline MDM2 & -4.23 \\
\hline MDM2 & -4.08 \\
\hline MIM2 & -3.94 \\
\hline MDM2 & -3.92 \\
\hline TIP60 & -2.82 \\
\hline TIP60 & -2.70 \\
\hline BRCA1 & -2.65 \\
\hline CHTF18 & -2.53 \\
\hline CHP & -2.51 \\
\hline CHK1 & -2.39 \\
\hline CHK1 & -2.30 \\
\hline CIB2 & -2.25 \\
\hline PPP1R11 & -2.22 \\
\hline PPP3CA & -2.06 \\
\hline PPP2R3A & -2.02 \\
\hline PPP5C & -1.98 \\
\hline PPP4C & -1.94 \\
\hline CHK1 & -1.90 \\
\hline TIP60 & -1.86 \\
\hline PTPRH & -1.84 \\
\hline PPAP2C & -1.69 \\
\hline PTPN7 & -1.67 \\
\hline KIAA0274 & -1.60 \\
\hline PPP3CC & -1.49 \\
\hline PPP2CA & -1.46 \\
\hline DUSP10 & -1.46 \\
\hline RNGTT & -1.30 \\
\hline MTMR7 & -1.27 \\
\hline PTPRN2 & -1.25 \\
\hline PPP2R5B & -1.24 \\
\hline CHK1 & -1.24 \\
\hline PTPN18 & -1.23 \\
\hline TPTE & -1.10 \\
\hline PPP2R2C & -1.09 \\
\hline $\mathrm{ANP32C}$ & -1.07 \\
\hline TIP60 & -1.05 \\
\hline ALPI & -1.05 \\
\hline DUPD1 & -1.05 \\
\hline PPM1A & -1.03 \\
\hline INPP5E & -1.01 \\
\hline
\end{tabular}

\begin{tabular}{|c|c|}
\hline \multicolumn{2}{|c|}{$\gamma$ H2Ax UVC upregulation } \\
\hline Target & $\boldsymbol{z}$-score \\
\hline P53 & 2.47 \\
\hline CANT1 & 2.43 \\
\hline PPP1R8 & 2.01 \\
\hline MFN2 & 1.96 \\
\hline DUSP2 & 1.77 \\
\hline FHIT & 1.69 \\
\hline PFKFB2 & 1.63 \\
\hline P53 & 1.61 \\
\hline DUSP19 & 1.54 \\
\hline SBF2 & 1.51 \\
\hline P53 & 1.45 \\
\hline DUSP11 & 1.38 \\
\hline NUDT4 & 1.34 \\
\hline PPM1K & 1.33 \\
\hline P53 & 1.31 \\
\hline G6PC2 & 1.31 \\
\hline PPP1R7 & 1.29 \\
\hline PPP1R14C & 1.27 \\
\hline ENTPD4 & 1.26 \\
\hline PPEF1 & 1.26 \\
\hline PPM1M & 1.24 \\
\hline SGPP2 & 1.16 \\
\hline NUDT10 & 1.15 \\
\hline PPM1B & 1.14 \\
\hline INPP5D & 1.14 \\
\hline MTMR10 & 1.12 \\
\hline DUSP3 & 1.11 \\
\hline DUSP21 & 1.11 \\
\hline CIB3 & 1.07 \\
\hline LOC283871 & 1.06 \\
\hline PPP1R16A & 1.06 \\
\hline PPM1D & 1.05 \\
\hline LRGUK & 1.05 \\
\hline PTPRR & 1.04 \\
\hline NUDT8 & 1.04 \\
\hline LOC389217 & 1.02 \\
\hline DUPP1 & 1.02 \\
\hline & 1.02 \\
\hline
\end{tabular}

Figure 7-1: Human phosphatase siRNA library screen results.

Phosphatase subunits with a z-score >1 (upregulation) or $<-1$ (downregulation) are listed (blue script) for the different parameters measured. The z-scores of several control siRNAs used are included (black script). 


\begin{tabular}{|c|c|c|c|c|c|c|}
\hline & screen & validation & screen & validation & screen & validation \\
\hline TARGET & p53 UVC & & p53 Con & & $\mathrm{gH} 2 \mathrm{Ax}$ & \\
\hline CANT2 & up & $25 \times n$ & & up & up & 0 \\
\hline DUSP18 & up & up & up & up & & down \\
\hline DUSPI9 & up & & up & 0 & up & up \\
\hline MINPPI & up & $\overline{u p}$ & up & 0 & & $\overline{0}$ \\
\hline$M F N 2$ & up & up & & up & up & up \\
\hline$P P M / L$ & up & up & up & up & & 0 \\
\hline$P P M L M$ & up & up & up & up & & $\overline{0}$ \\
\hline LRGUK & up & up & up & 0 & & 0 \\
\hline PPM D & & up & & 0 & up & $\overline{u p}$ \\
\hline CTDSPl & up & up & & up & & down \\
\hline CTDSP2 & up & up & up & up & & 0 \\
\hline CTDSPL & & up & & up & & 0 \\
\hline CTDPl & & up & up & up & & up \\
\hline$P P P 3 C A$ & down & 0 & down & up & down & $\overline{0}$ \\
\hline$P P P 3 C B$ & down & up & down & up & & 0 \\
\hline PPP3CC & & up & & up & down & 0 \\
\hline$A N P 32 A$ & down & 0 & & up & & up \\
\hline ANP32D & up & up & & up & & $\overline{0}$ \\
\hline PTPN22 & down & 110 & down & up & & 0 \\
\hline$S K Z P$ & down & 0 & & up & & 0 \\
\hline PTPRH & down & 0 & & down & & 0 \\
\hline PPPIRI GB & down & 0 & & down & & 0 \\
\hline PPPIRI2C & down & ap & & 0 & & up \\
\hline PPPIRI $4 A$ & up & up & up & 0 & & 0 \\
\hline PPPIR8 & & up & & up & up & up \\
\hline$C I B 2$ & & up & & 0 & down & 0 \\
\hline$C I B 3$ & up & up & & 0 & & 0 \\
\hline CHP & & up & & 0 & down & 0 \\
\hline CHTF18 & & 0 & & down & down & 0 \\
\hline FHIT & up & up & & 0 & up & 0 \\
\hline MTMR4 & up & 0 & & up & & up \\
\hline NUDT4 & & up & & up & up & up \\
\hline ENTPD4 & & 0 & & 0 & up & up \\
\hline DUSP2 & & up & & up & up & 0 \\
\hline DUSP 12 & & up & & up & up & up \\
\hline$P T P D C l$ & up & up & up & up & & 0 \\
\hline
\end{tabular}

Figure 7-2: Validation of selected screen results using immunofluorescence.

The screening experimental procedure was repeated in U2OS cells using 1 siRNA per target from the siRNA library for a selection of phosphatase subunits. The confirmed results are marked in green boxes; the inverted results are marked in red boxes. 


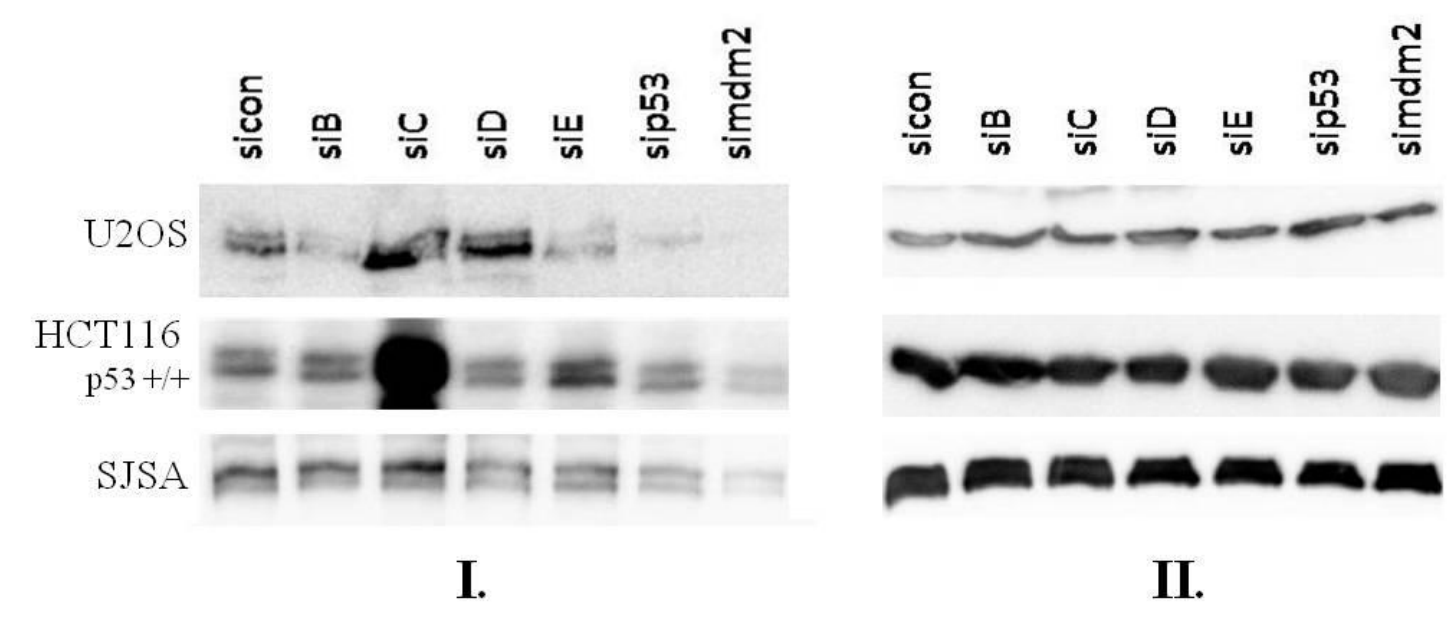

Figure 7-3: Mdm2 protein levels in cells depleted of Dusp18.

Each cell line shown was transfected with siRNAs against Dusp18 and 48h later the cell lysates were subjected to immunoblotting analysis to detect Mdm2 protein (I). Actin was used as a loading control (II). 
SP1 binding on p21 promoter (SP1 site -282bp)

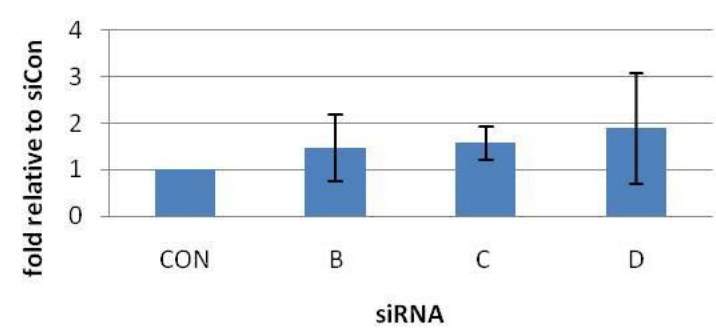

RNA pol II binding on the p21 promoter (transcription start site)

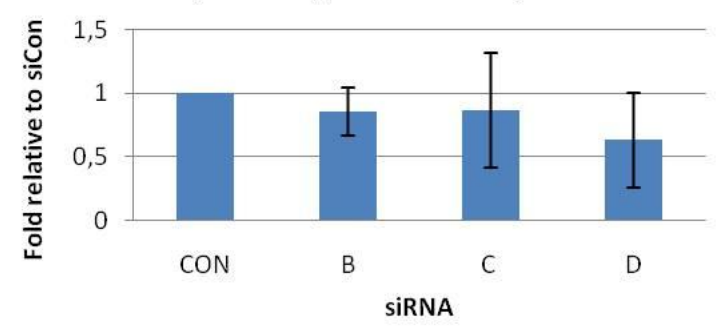

RNA pol II binding on p21 gene (position +6000 bp)

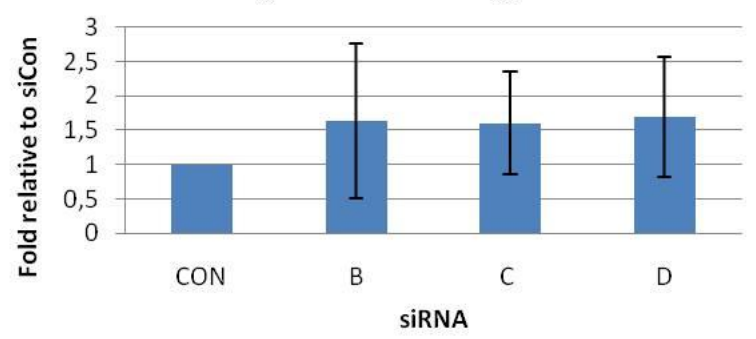

B.

A. SP1 binding on p21 promoter (SP1 site -30bp)

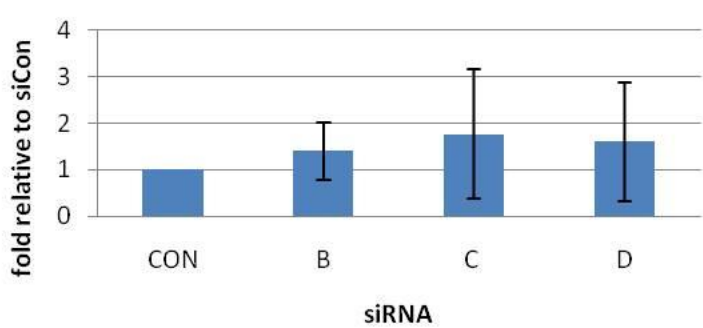

SiRNA

RNA pol II binding on the p21 gene (position+1500 bp)

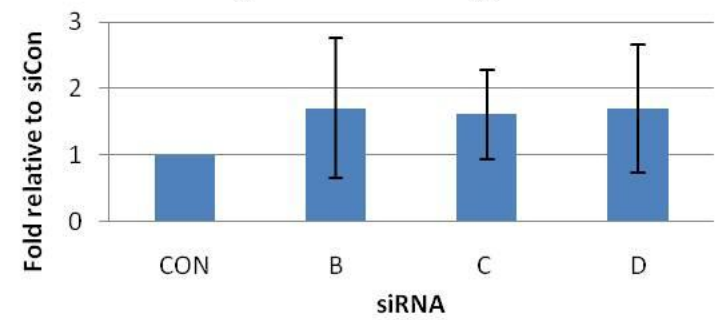

Figure 7-4: Binding of SP1 and RNA pol II along the p21 gene upon Dusp18 knockdown.

Chromatin immunoprecipitation of SPI (A) and RNA polymerase II $(\boldsymbol{B})$ on the p21 gene in HCT116 p53 +/+ cells depleted of Dusp18. Error bars represent standard deviation from 7 independent experiments. 


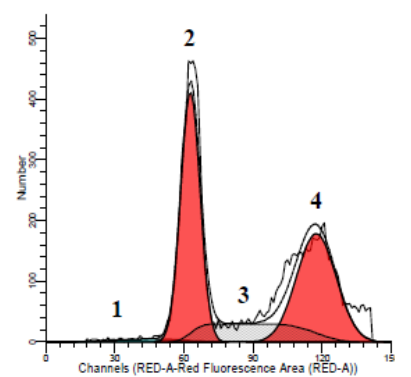

siCon

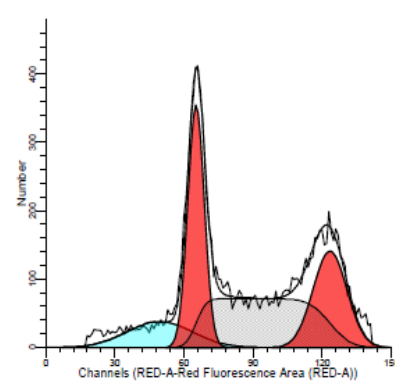

siD

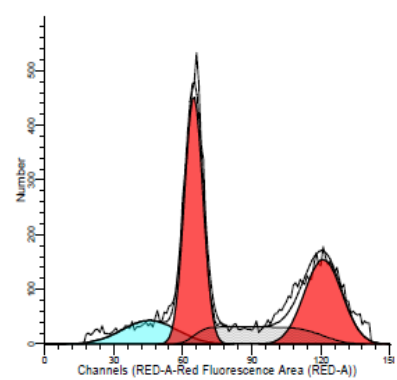

siB

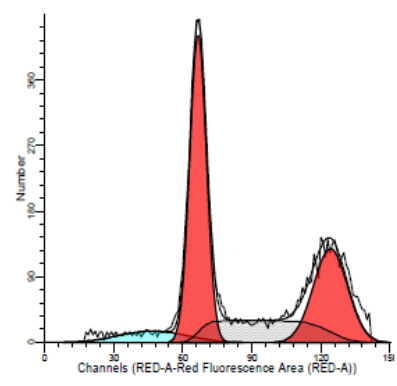

siE

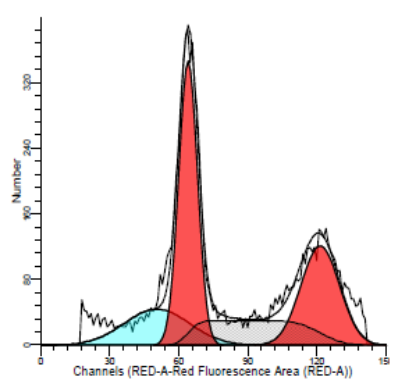

siC

Figure 7-5: Cell cycle distribution of HCT116 p53 +/+ cells depleted of Dusp18.

HCT116 p53 +/+ cells were transfected with siRNAs against Dusp18 and $72 \mathrm{~h}$ later fixed and subjected to FACS. The histograms obtained were analysed with the ModFit software to identify the different cell cycle phases:

1: Apoptotic cells (subG1); 2: G1; 3: S; 4: G2.

I.

Proliferation of HCT116 p53 +/+ cells transfected with dsp18 siRNAs

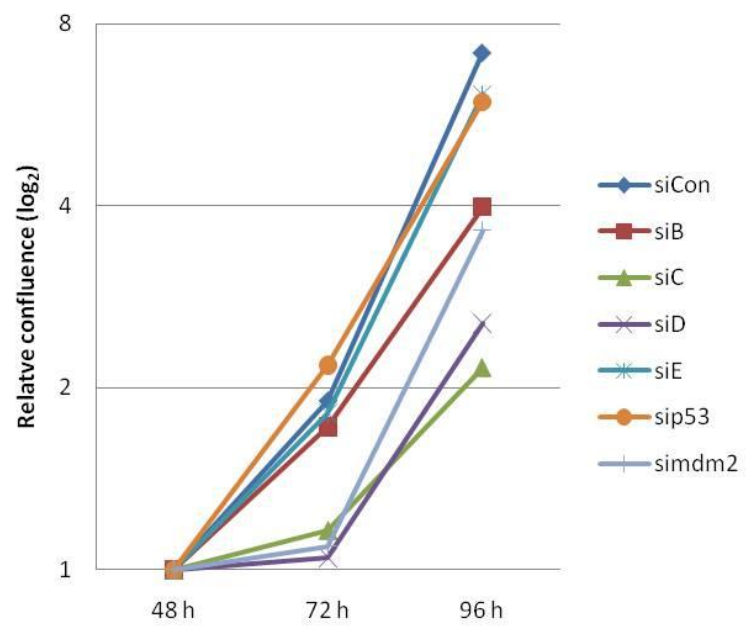

II.

Proliferation of HCT116 p53 -/- cells transfected with dsp18 siRNAs

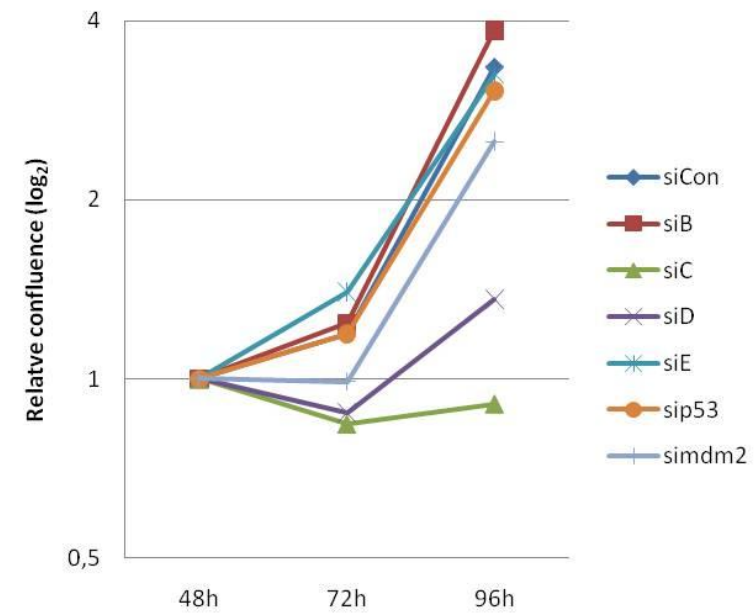

Figure 7-6: Proliferation of HCT116 cells depleted of Dusp18.

HCT116 p53 +/+ (I) and p53-/-(II) cells were transfected with siRNAs against Dusp18 and their confluence was measured 48,72 and $96 \mathrm{~h}$ after transfection. The increase in confluence ( $\log _{2}$ scale) within that time is presented in the graphs. 


\section{Cell cycle distribution in}

HCT 116 p21 -/- cells

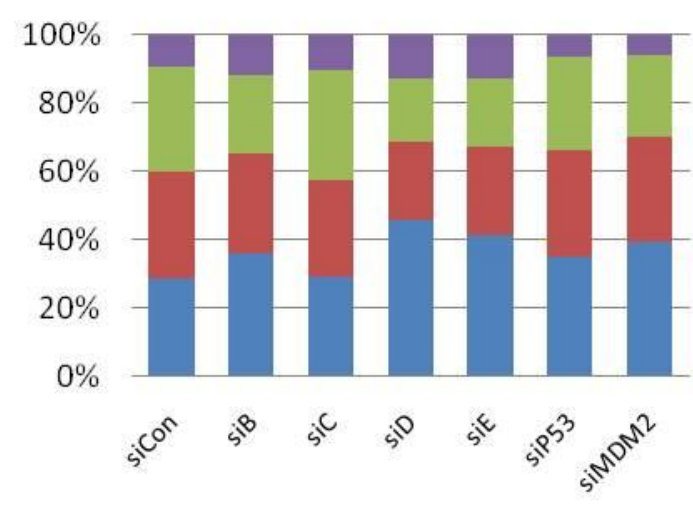

G1 $=\mathrm{S}$ - $\mathrm{G} 2$ apoptosis

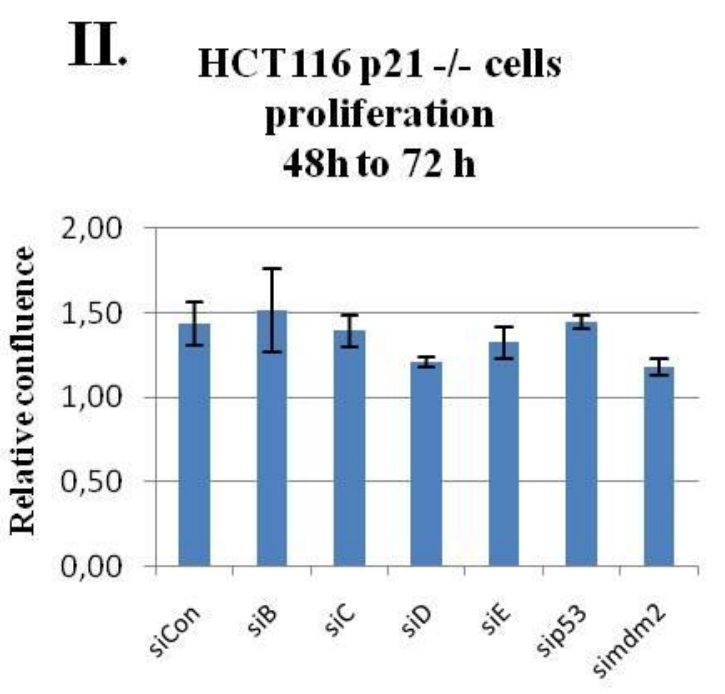

\section{Proliferation of HCT 116 p $21-/-$ cells transfected with dsp18 siRNAs}

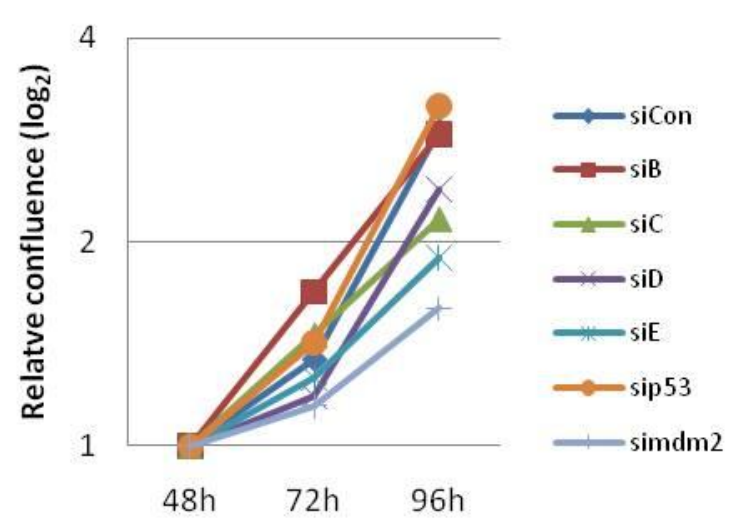

Figure 7-7: Proliferation of HCT116 21 -/- cells depleted of Dusp18.

I. HCT116 p21 -/- cells were transfected with siRNAs against Dusp18 and $72 \mathrm{~h}$ later fixed and subjected to FACS. The histograms obtained were analysed with ModfFit to measure the percentage of cells in each cell cycle phase.

II. HCT116 p21 -/- cells were transfected with siRNAs against Dusp18 and their confluence was measured $48 \mathrm{~h}$ and $72 \mathrm{~h}$ after transfection. The increase in confluence within that time is represented in the graphs. Error bars indicate standard deviation from 4 different dilutions of cells (see Methods \$3.1.3).

III. HCT116 p21 -/- cells were transfected with siRNAs against Dusp18 and their confluence was measured 48, 72 and $96 \mathrm{~h}$ after transfection. The increase in confluence ( $\log _{2}$ scale) within that time is represented in the graph. 


\section{REFERENCES}

\section{Ashcroft M, Kubbutat MH, Vousden KH.}

"Regulation of p53 function and stability by phosphorylation."

Mol Cell Biol. 1999 Mar;19(3):1751-8.

Ayoub N, Jeyasekharan AD, Bernal JA, Venkitaraman AR.

"HP1-beta mobilization promotes chromatin changes that initiate the DNA damage response."

Nature. 2008 May 29;453(7195):682-6.

\section{Barak Y, Juven T, Haffner R, Oren M.}

"mdm2 expression is induced by wild type 53 activity."

EMBO J. 1993 Feb;12(2):461-8.

Beckerman R, Donner AJ, Mattia M, Peart MJ, Manley JL, Espinosa JM, Prives C.

"A role for Chk1 in blocking transcriptional elongation of p21 RNA during the S-phase checkpoint." Genes Dev. 2009 Jun 1;23(11):1364-77.

Bendjennat M, Boulaire J, Jascur T, Brickner H, Barbier V, Sarasin A, Fotedar A, Fotedar R. "UV irradiation triggers ubiquitin-dependent degradation of p21(WAF1) to promote DNA repair." Cell. 2003 Sep 5;114(5):599-610.

Blattner C, Tobiasch E, Litfen M, Rahmsdorf HJ, Herrlich P.

"DNA damage induced p53 stabilization: no indication for an involvement of p53 phosphorylation." Oncogene. 1999 Mar 4;18(9):1723-32.

Chao C, Hergenhahn M, Kaeser MD, Wu Z, Saito S, Iggo R, Hollstein M, Appella E, Xu Y. "Cell type- and promoter-specific roles of Ser 18 phosphorylation in regulating p53 responses."

J Biol Chem. 2003 Oct 17;278(42):41028-33.

Chen D, Kon N, Li M, Zhang W, Qin J, Gu W.

"ARF-BPI/Mule is a critical mediator of the ARF tumor suppressor."

Cell. 2005 Jul 1;121(7):1071-83.

Cheng Q, Chen L, Li Z, Lane WS, Chen J.

"ATM activates p53 by regulating MDM2 oligomerization and E3 processivity."

EMBO J. 2009 Dec 16;28(24):3857-67.

Chowdhury D, Keogh MC, Ishii H, Peterson CL, Buratowski S, Lieberman J.

"gamma-H2AX dephosphorylation by protein phosphatase $2 A$ facilitates DNA double-strand break repair."

Mol Cell. 2005 Dec 9;20(5):801-9.

Claros MG, Vincens P.

"Computational method to predict mitochondrially imported proteins and their targeting sequences." Eur J Biochem. 1996 Nov 1;241(3):779-86. 


\section{Cohen PT.}

"Protein phosphatase 1--targeted in many directions."

J Cell Sci. 2002 Jan 15;115(Pt 2):241-56.

Colombo E, Bonetti P, Lazzerini Denchi E, Martinelli P, Zamponi R, Marine JC, Helin K, Falini B, Pelicci PG.

"Nucleophosmin is required for DNA integrity and p19Arf protein stability."

Mol Cell Biol. 2005 Oct;25(20):8874-86.

Costanzo V, Shechter D, Lupardus PJ, Cimprich KA, Gottesman M, Gautier J.

"An ATR-and Cdc7-dependent DNA damage checkpoint that inhibits initiation of DNA replication." Mol Cell. 2003 Jan;11(1):203-13.

Damrot J, Helbig L, Roos WP, Barrantes SQ, Kaina B, Fritz G.

"DNA replication arrest in response to genotoxic stress provokes early activation of stress-activated protein kinases (SAPK/JNK)."

J Mol Biol. 2009 Feb 6;385(5):1409-21.

Das S, Boswell SA, Aaronson SA, Lee SW.

"P53 promoter selection: choosing between life and death."

Cell Cycle. 2008 Jan 15;7(2):154-7.

de Rozieres S, Maya R, Oren M, Lozano G.

"The loss of mdm2 induces p53-mediated apoptosis."

Oncogene. 2000 Mar 23;19(13):1691-7.

den Elzen N, Kosoy A, Christopoulos H, O'Connell MJ.

"Resisting arrest: recovery from checkpoint arrest through dephosphorylation of Chk1 by PP1."

Cell Cycle. 2004 May;3(5):529-33.

den Elzen NR, O'Connell MJ.

"Recovery from DNA damage checkpoint arrest by PP1-mediated inhibition of Chk1."

EMBO J. 2004 Feb 25;23(4):908-18.

Dhanasekaran DN, Johnson GL.

"MAPKs: function, regulation, role in cancer and therapeutic targeting."

Oncogene. 2007 May 14;26(22):3097-9.

Donner AJ, Hoover JM, Szostek SA, Espinosa JM.

"Stimulus-specific transcriptional regulation within the p53 network."

Cell Cycle. 2007 Nov 1;6(21):2594-8.

Donner AJ, Szostek S, Hoover JM, Espinosa JM.

"CDK8 is a stimulus-specific positive coregulator of p53 target genes."

Mol Cell. 2007 Jul 6;27(1):121-33. 
Dornan D, Wertz I, Shimizu H, Arnott D, Frantz GD, Dowd P, O'Rourke K, Koeppen H, Dixit VM

"The ubiquitin ligase COP1 is a critical negative regulator of $p 53 . "$

Nature. 2004 May 6;429(6987):86-92.

Douglas P, Zhong J, Ye R, Moorhead GB, Xu X, Lees-Miller SP.

"Protein phosphatase 6 interacts with the DNA-dependent protein kinase catalytic subunit and dephosphorylates gamma-H2AX."

Mol Cell Biol. 2010 Mar;30(6):1368-81.

Dumaz N, Meek DW.

"Serine15 phosphorylation stimulates p53 transactivation but does not directly influence interaction with HDM2."

EMBO J. 1999 Dec 15;18(24):7002-10.

el-Deiry WS, Harper JW, O'Connor PM, Velculescu VE, Canman CE, Jackman J, Pietenpol JA, Burrell M, Hill DE, Wang Y, et al.

"WAF1/CIP1 is induced in p53-mediated G1 arrest and apoptosis."

Cancer Res. 1994 Mar 1;54(5):1169-74.

Eymin B, Karayan L, Séité P, Brambilla C, Brambilla E, Larsen CJ, Gazzéri S.

"Human ARF binds E2F1 and inhibits its transcriptional activity."

Oncogene. 2001 Mar 1;20(9):1033-41.

Feng J, Wakeman T, Yong S, Wu X, Kornbluth S, Wang XF.

"Protein phosphatase 2A-dependent dephosphorylation of replication protein A is required for the repair

of DNA breaks induced by replication stress."

Mol Cell Biol. 2009 Nov;29(21):5696-709.

Feng L, Hollstein M, Xu Y.

"Ser46 phosphorylation regulates p53-dependent apoptosis and replicative senescence."

Cell Cycle. 2006 Dec;5(23):2812-9.

\section{Gilmour DS, Lis JT.}

"In vivo interactions of RNA polymerase II with genes of Drosophila melanogaster."

Mol Cell Biol. 1985 Aug;5(8):2009-18.

Goodarzi AA, Jonnalagadda JC, Douglas P, Young D, Ye R, Moorhead GB, Lees-Miller SP, Khanna KK.

"Autophosphorylation of ataxia-telangiectasia mutated is regulated by protein phosphatase $2 \mathrm{A."}$ EMBO J. 2004 Nov 10;23(22):4451-61.

Gui CY, Ngo L, Xu WS, Richon VM, Marks PA.

"Histone deacetylase (HDAC) inhibitor activation of p21WAF1 involves changes in promoterassociated proteins, including HDAC1."

Proc Natl Acad Sci U S A. 2004 Feb 3;101(5):1241-6. 


\section{Hainaut P, Hollstein M.}

"p53 and human cancer: the first ten thousand mutations."

Adv Cancer Res. 2000;77:81-137

Harper JW, Adami GR, Wei N, Keyomarsi K, Elledge SJ.

"The p21 Cdk-interacting protein Cip1 is a potent inhibitor of G1 cyclin-dependent kinases."

Cell. 1993 Nov 19;75(4):805-16.

Haupt Y, Maya R, Kazaz A, Oren M.

"Mdm2 promotes the rapid degradation of $553 . "$

Nature. 1997 May 15;387(6630):296-9.

Hood KL, Tobin JF, Yoon C.

"Identification and characterization of two novel low-molecular-weight dual specificity

phosphatases."

Biochem Biophys Res Commun. 2002 Nov 8;298(4):545-51.

Hu MC, Qiu WR, Wang YP.

"JNK1, JNK2 and JNK3 are p53 N-terminal serine 34 kinases."

Oncogene. 1997 Nov 6;15(19):2277-87.

Ishiguro T, Saitoh J, Yawata H, Yamagishi H, Iwasaki S, Mitoma Y.

"Homogeneous quantitative assay of hepatitis $C$ virus $R N A$ by polymerase chain reaction in the presence of a fluorescent intercalater."

Anal Biochem. 1995 Aug 10;229(2):207-13.

Jang YJ, Ji JH, Choi YC, Ryu CJ, Ko SY.

"Regulation of Polo-like kinase 1 by DNA damage in mitosis. Inhibition of mitotic PLK-1 by protein phosphatase $2 A . "$

J Biol Chem. 2007 Jan 26;282(4):2473-82.

\section{Jentsch S, Siepe D.}

"Pin1, a novel switch in the ubiquitin pathway."

Cell Cycle. 2009 Dec;8(23):3800-1.

\section{Jeong DG, Cho YH, Yoon TS, Kim JH, Son JH, Ryu SE, Kim SJ.}

"Structure of human DSP18, a member of the dual-specificity protein tyrosine phosphatase family." Acta Crystallogr D Biol Crystallogr. 2006 Jun;62(Pt 6):582-8.

\section{Jeong SJ, Kim HJ, Yang YJ, Seol JH, Jung B Y, Han JW, Lee HW, Cho EJ.}

"Role of RNA polymerase II carboxy terminal domain phosphorylation in DNA damage response." J Microbiol. 2005 Dec;43(6):516-22.

\section{Jones SN, Roe AE, Donehower LA, Bradley A.}

"Rescue of embryonic lethality in Mdm2-deficient mice by absence of p53."

Nature. 1995 Nov 9;378(6553):206-8. 


\section{Joseph Sambrook, David W. Russell}

"Preparation and Transformation of Competent E. coli Using Calcium Chloride"

Molecular Cloning, 3rd edition; Cold Spring Harbor Laboratory Press, Cold Spring Harbor, NY, USA, 2001

\section{Kaku S, Iwahashi Y, Kuraishi A, Albor A, Yamagishi T, Nakaike S, Kulesz-Martin M.}

"Binding to the naturally occurring double 553 binding site of the Mdm2 promoter alleviates the requirement for p53 C-terminal activation."

Nucleic Acids Res. 2001 May 1;29(9):1989-93.

\section{Kastan MB, Bartek J.}

"Cell-cycle checkpoints and cancer."

Nature. 2004 Nov 18;432(7015):316-23.

\section{Keyse SM.}

"Dual-specificity MAP kinase phosphatases (MKPs) and cancer."

Cancer Metastasis Rev. 2008 Jun;27(2):253-61.

\section{Kim SJ, Hwang SG, Shin DY, Kang SS, Chun JS.}

"p38 kinase regulates nitric oxide-induced apoptosis of articular chondrocytes by accumulating p53 via NFkappa B-dependent transcription and stabilization by serine 15 phosphorylation."

J Biol Chem. 2002 Sep 6;277(36):33501-8.

\section{Koutsodontis G, Kardassis D.}

"Inhibition of p53-mediated transcriptional responses by mithramycin A."

Oncogene. 2004 Dec 9;23(57):9190-200.

\section{Kranz D, Dohmesen C, Dobbelstein M.}

"BRCA1 and Tip60 determine the cellular response to ultraviolet irradiation through distinct pathways."

J Cell Biol. 2008 Jul 14;182(1):197-213.

\section{Kruse JP, Gu W.}

"Modes of 553 regulation."

Cell. 2009 May 15;137(4):609-22.

\section{Kubbutat MH, Jones SN, Vousden KH.}

"Regulation of p53 stability by Mdm2."

Nature. 1997 May 15;387(6630):299-303.

\section{Kurki S, Peltonen K, Latonen L, Kiviharju TM, Ojala PM, Meek D, Laiho M.}

"Nucleolar protein NPM interacts with HDM2 and protects tumor suppressor protein p53 from HDM2-mediated degradation."

Cancer Cell. 2004 May;5(5):465-75. 
Lafarga V, Cuadrado A, Lopez de Silanes I, Bengoechea R, Fernandez-Capetillo O, Nebreda AR.

"p38 Mitogen-activated protein kinase- and HuR-dependent stabilization of p21(Cip1) mRNA mediates the $G(1) / S$ checkpoint."

Mol Cell Biol. 2009 Aug;29(16):4341-51.

Lakin ND, Jackson SP.

"Regulation of p53 in response to DNA damage."

Oncogene. 1999 Dec 13;18(53):7644-55.

Lambert PF, Kashanchi F, Radonovich MF, Shiekhattar R, Brady JN.

"Phosphorylation of p53 serine 15 increases interaction with CBP."

J Biol Chem. 1998 Dec 4;273(49):33048-53.

\section{Lane DP.}

"Cancer. p53, guardian of the genome."

Nature. 1992 Jul 2;358(6381):15-6.

\section{Le Guezennec X, Bulavin DV.}

"WIP1 phosphatase at the crossroads of cancer and aging."

Trends Biochem Sci. 2010 Feb;35(2):109-14.

\section{Lee HJ, Hwang HI, Jang YJ.}

"Mitotic DNA damage response: Polo-like kinase-1 is dephosphorylated through ATM-Chk1 pathway."

Cell Cycle. 2010 Jun 25;9(12).

Leng RP, Lin Y, Ma W, Wu H, Lemmers B, Chung S, Parant JM, Lozano G, Hakem R, Benchimol S.

"Pirh2, a p53-induced ubiquitin-protein ligase, promotes p53 degradation."

Cell. 2003 Mar 21;112(6):779-91.

Levine AJ, Momand J, Finlay CA.

"The p53 tumour suppressor gene."

Nature. 1991 Jun 6;351(6326):453-6.

\section{Li M, Luo J, Brooks CL, Gu W.}

"Acetylation of 53 inhibits its ubiquitination by Mdm2."

J Biol Chem. 2002 Dec 27;277(52):50607-11.

Linke K, Mace PD, Smith CA, Vaux DL, Silke J, Day CL.

"Structure of the MDM2/MDMX RING domain heterodimer reveals dimerization is required for their ubiquitylation in trans."

Cell Death Differ. 2008 May;15(5):841-8. 


\section{Livak KJ, Schmittgen TD.}

"Analysis of relative gene expression data using real-time quantitative PCR and the 2(-Delta Delta $C(T)$ ) Method."

Methods. 2001 Dec;25(4):402-8.

\section{Lou Z, Chen J.}

"BRCA proteins and DNA damage checkpoints."

Front Biosci. 2003 May 1;8:s718-21.

\section{Lu X, Nannenga B, Donehower LA.}

"PPM1D dephosphorylates Chk1 and p53 and abrogates cell cycle checkpoints."

Genes Dev. 2005 May 15;19(10):1162-74.

\section{Macůrek L, Lindqvist A, Voets O, Kool J, Vos HR, Medema RH.}

"Wip1 phosphatase is associated with chromatin and dephosphorylates gammaH2AX to promote checkpoint inhibition."

Oncogene. 2010 Apr 15;29(15):2281-91.

Mah LJ, Vasireddy RS, Tang MM, Georgiadis GT, El-Osta A, Karagiannis TC.

"Quantification of gammaH2AX foci in response to ionising radiation."

J Vis Exp. 2010 Apr 6;(38). pii: 1957. doi: 10.3791/1957.

\section{Manning G, Whyte DB, Martinez R, Hunter T, Sudarsanam S.}

"The protein kinase complement of the human genome."

Science. 2002 Dec 6;298(5600):1912-34.

Mason SL, Loughran O, La Thangue NB.

"p14(ARF) regulates E2F activity."

Oncogene. 2002 Jun 20;21(27):4220-30.

Matozaki T, Suzuki T, Uchida T, Inazawa J, Ariyama T, Matsuda K, Horita K, Noguchi H, Mizuno H, Sakamoto C, et al.

"Molecular cloning of a human transmembrane-type protein tyrosine phosphatase and its expression in gastrointestinal cancers."

J Biol Chem. 1994 Jan 21;269(3):2075-81.

Mattia M, Gottifredi V, McKinney K, Prives C.

"p53-Dependent 21 mRNA elongation is impaired when DNA replication is stalled."

Mol Cell Biol. 2007 Feb;27(4):1309-20.

McLure KG, Lee PW.

"How p53 binds DNA as a tetramer."

EMBO J. 1998 Jun 15;17(12):3342-50.

Moll UM, Wolff S, Speidel D, Deppert W.

"Transcription-independent pro-apoptotic functions of p53."

Curr Opin Cell Biol. 2005 Dec;17(6):631-6. 


\section{Montes de Oca Luna R, Wagner DS, Lozano G}

"Rescue of early embryonic lethality in mdm2-deficient mice by deletion of p53."

Nature. 1995 Nov 9;378(6553):203-6.

\section{Moon SH, Nguyen TA, Darlington Y, Lu X, Donehower LA.}

"Dephosphorylation of gammaH2AX by WIP1: An important homeostatic regulatory event in DNA repair and cell cycle control."

Cell Cycle. 2010 Jun 12;9(11).

Moorhead GB, Trinkle-Mulcahy L, Ulke-Lemée A.

"Emerging roles of nuclear protein phosphatases."

Nat Rev Mol Cell Biol. 2007 Mar;8(3):234-44.

Moustakas A, Kardassis D.

"Regulation of the human $\mathrm{p}$ 1/WAF1/Cip1 promoter in hepatic cells by functional interactions between Sp1 and Smad family members."

Proc Natl Acad Sci U S A. 1998 Jun 9;95(12):6733-8.

\section{Mullis KB, Faloona FA.}

"Specific synthesis of DNA in vitro via a polymerase-catalyzed chain reaction."

Methods Enzymol. 1987;155:335-50.

\section{Nakada S, Chen GI, Gingras AC, Durocher D.}

"PP4 is a gamma H2AX phosphatase required for recovery from the DNA damage checkpoint." EMBO Rep. 2008 Oct;9(10):1019-26.

\section{Nüsse M, Egner HJ.}

"Can nocodazole, an inhibitor of microtubule formation, be used to synchronize mammalian cells? Accumulation of cells in mitosis studied by two parametric flow cytometry using acridine orange and by DNA distribution analysis."

Cell Tissue Kinet. 1984 Jan;17(1):13-23.

\section{Osaki M, Oshimura M, Ito $\mathbf{H}$.}

"PI3K-Akt pathway: its functions and alterations in human cancer."

Apoptosis. 2004 Nov;9(6):667-76.

\section{Owens DM, Keyse SM.}

"Differential regulation of MAP kinase signalling by dual-specificity protein phosphatases."

Oncogene. 2007 May 14;26(22):3203-13.

\section{Patterson KI, Brummer T, O'Brien PM, Daly RJ.}

"Dual-specificity phosphatases: critical regulators with diverse cellular targets."

Biochem J. 2009 Mar 15;418(3):475-89. 


\section{Rardin MJ, Wiley SE, Murphy AN, Pagliarini DJ, Dixon JE.}

"Dual specificity phosphatases 18 and 21 target to opposing sides of the mitochondrial inner membrane."

J Biol Chem. 2008 May 30;283(22):15440-50.

\section{Rizos H, Scurr LL, Irvine M, Alling NJ, Kefford RF.}

"p14ARF regulates E2F-1 ubiquitination and degradation via a p53-dependent mechanism."

Cell Cycle. 2007 Jul 15;6(14):1741-7.

\section{Roy SK, Srivastava RK, Shankar S.}

"Inhibition of PI3K/AKT and MAPK/ERK pathways causes activation of FOXO transcription factor, leading to cell cycle arrest and apoptosis in pancreatic cancer."

J Mol Signal. 2010 Jul 19;5:10.

\section{Saito J, Toriumi S, Awano K, Ichijo H, Sasaki K, Kobayashi T, Tamura S.}

"Regulation of apoptosis signal-regulating kinase 1 by protein phosphatase 2Cepsilon."

Biochem J. 2007 Aug 1;405(3):591-6.

\section{Saito Y, Gopalan B, Mhashilkar AM, Roth JA, Chada S, Zumstein L, Ramesh R.}

"Adenovirus-mediated PTEN treatment combined with caffeine produces a synergistic therapeutic effect in colorectal cancer cells."

Cancer Gene Ther. 2003 Nov;10(11):803-13.

\section{Sakaguchi K, Herrera JE, Saito S, Miki T, Bustin M, Vassilev A, Anderson CW, Appella E.} "DNA damage activates 553 through a phosphorylation-acetylation cascade."

Genes Dev. 1998 Sep 15;12(18):2831-41.

\section{Sanchez-Prieto R, Rojas JM, Taya Y, Gutkind JS.}

"A role for the p38 mitogen-acitvated protein kinase pathway in the transcriptional activation of p53 on genotoxic stress by chemotherapeutic agents."

Cancer Res. 2000 May 1;60(9):2464-72.

\section{Seki N, Hattori A, Hayashi A, Kozuma S, Ohira M, Hori T, Saito T.}

"Structure, expression profile and chromosomal location of an isolog of DNA-PKcs interacting protein (KIP) gene."

Biochim Biophys Acta. 1999 Jan 18;1444(1):143-7.

Shieh SY, Ikeda M, Taya Y, Prives C.

"DNA damage-induced phosphorylation of p53 alleviates inhibition by MDM2."

Cell. 1997 Oct 31;91(3):325-34.

\section{Shinozaki T, Nota A, Taya Y, Okamoto K.}

"Functional role of Mdm2 phosphorylation by ATR in attenuation of p53 nuclear export."

Oncogene. 2003 Dec 4;22(55):8870-80. 
Shiomi Y, Masutani C, Hanaoka F, Kimura H, Tsurimoto T.

"A second proliferating cell nuclear antigen loader complex, Ctf18-replication factor $C$, stimulates DNA polymerase eta activity."

J Biol Chem. 2007 Jul 20;282(29):20906-14.

Siliciano JD, Canman CE, Taya Y, Sakaguchi K, Appella E, Kastan MB.

"DNA damage induces phosphorylation of the amino terminus of p53."

Genes Dev. 1997 Dec 15;11(24):3471-81.

Suzuki K, Okada H, Yamauchi M, Oka Y, Kodama S, Watanabe M.

"Qualitative and quantitative analysis of phosphorylated ATM foci induced by low-dose ionizing radiation."

Radiat Res. 2006 May;165(5):499-504.

Tan NY, Khachigian LM.

"Sp1 phosphorylation and its regulation of gene transcription."

Mol Cell Biol. 2009 May;29(10):2483-8.

Tang X, Hui ZG, Cui XL, Garg R, Kastan MB, Xu B.

"A novel ATM-dependent pathway regulates protein phosphatase 1 in response to DNA damage." Mol Cell Biol. 2008 Apr;28(8):2559-66.

Tian B, Yang Q, Mao Z.

"Phosphorylation of ATM by Cdk5 mediates DNA damage signalling and regulates neuronal death." Nat Cell Biol. 2009 Feb;11(2):211-8.

\section{Torres M.}

"Mitogen-activated protein kinase pathways in redox signaling."

Front Biosci. 2003 Jan 1;8:d369-91.

\section{Trinkle-Mulcahy L, Lamond AI.}

"Mitotic phosphatases: no longer silent partners."

Curr Opin Cell Biol. 2006 Dec;18(6):623-31.

\section{Villiard E, Brinkmann H, Moiseeva O, Mallette FA, Ferbeyre G, Roy S.}

"Urodele p53 tolerates amino acid changes found in p53 variants linked to human cancer."

BMC Evol Biol. 2007 Sep 28;7:180.

\section{Vogelstein B, Lane D, Levine AJ.}

"Surfing the p53 network."

Nature. 2000 Nov 16;408(6810):307-10.

\section{Wang B, Matsuoka S, Carpenter PB, Elledge SJ.}

"53BP1, a mediator of the DNA damage checkpoint."

Science. 2002 Nov 15;298(5597):1435-8. 
Wu Q, Gu S, Dai J, Dai J, Wang L, Li Y, Zeng L, Xu J, Ye X, Zhao W, Ji C, Xie Y, Mao Y. "Molecular cloning and characterization of a novel dual-specificity phosphatase 18 gene from human fetal brain."

Biochim Biophys Acta. 2003 Feb 20;1625(3):296-304.

Wu Q, Huang S, Sun Y, Gu S, Lu F, Dai J, Yin G, Sun L, Zheng D, Dou C, Feng C, Ji C, Xie Y, Mao Y.

"Dual specificity phosphotase 18, interacting with SAPK, dephosphorylates SAPK and inhibits SAPK/JNK signal pathway in vivo."

Front Biosci. 2006 Sep 1;11:2714-24.

Wu X, Nguyen BC, Dziunycz P, Chang S, Brooks Y, Lefort K, Hofbauer GF, Dotto GP. "Opposing roles for calcineurin and ATF3 in squamous skin cancer."

Nature. 2010 May 20;465(7296):368-72.

Yamasaki S, Yagishita N, Sasaki T, Nakazawa M, Kato Y, Yamadera T, Bae E, Toriyama S, Ikeda R, Zhang L, Fujitani K, Yoo E, Tsuchimochi K, Ohta T, Araya N, Fujita H, Aratani S, Eguchi K, Komiya S, Maruyama I, Higashi N, Sato M, Senoo H, Ochi T, Yokoyama S, Amano T, Kim J, Gay S, Fukamizu A, Nishioka K, Tanaka K, Nakajima T.

"Cytoplasmic destruction of p53 by the endoplasmic reticulum-resident ubiquitin ligase 'Synoviolin'." EMBO J. 2007 Jan 10;26(1):113-22.

Yoon HS, Chen X, Yang VW.

"Kruppel-like factor 4 mediates p53-dependent G1/S cell cycle arrest in response to DNA damage." J Biol Chem. 2003 Jan 24;278(4):2101-5.

Zama T, Aoki R, Kamimoto T, Inoue K, Ikeda Y, Hagiwara M.

"Scaffold role of a mitogen-activated protein kinase phosphatase, SKRP1, for the JNK signaling pathway."

J Biol Chem. 2002 Jun 28;277(26):23919-26.

Zama T, Aoki R, Kamimoto T, Inoue K, Ikeda Y, Hagiwara M.

"A novel dual specificity phosphatase SKRP1 interacts with the MAPK kinase MKK7 and inactivates the JNK MAPK pathway. Implication for the precise regulation of the particular MAPK pathway."

J Biol Chem. 2002 Jun 28;277(26):23909-18.

Zhang J, Bao S, Furumai R, Kucera KS, Ali A, Dean NM, Wang XF.

"Protein phosphatase 5 is required for ATR-mediated checkpoint activation."

Mol Cell Biol. 2005 Nov;25(22):9910-9.

Zhang Y, Xiong Y, Yarbrough WG.

"ARF promotes MDM2 degradation and stabilizes p53: ARF-INK4a locus deletion impairs both the $R b$ and 553 tumor suppression pathways."

Cell. 1998 Mar 20;92(6):725-34. 


\section{Konstantina Marinoglou}

Hannoversche Str. 10

37075 Göttingen

Germany

phone: +49 (0)163-6825158

email: kmarino@gwdg.de

\section{Education:}

$10 / 2006-10 / 2010$

$10 / 2006-03 / 2007$

$08 / 2006$

09/2005 - present

06/2003 - 03/2005

09/2000 - 03/2005

09/1997 - 06/2000

Laboratory Techniques \& Experience:

MSc. \& PhD work

Diploma Thesis work
$\mathrm{PhD}$ position in the Department of Molecular Oncology, University of Göttingen, Germany

MSc in Molecular Biology (Grade A) "Analysis of p53 in Drosophila" Dept. of Molecular Oncology, Uni Gö

MSc exams (Grade B)

Studying within the MSc/PhD Molecular Biology program of International Max Planck Research

School.

Diploma thesis

Dept. of Molecular Genetics, University of

Athens, Greece

Diploma in Biology (7,33 out of 10) University of Athens, Greece

Higher Secondary School education, National greek exams (19,3 out of 20) $3^{\text {rd }}$ Nikea High School, Nikea, Greece

Drosophila \& Mammalian cell culture, DNA and siRNA transfections, reporter assays, immunofluorescence, cell viability assays, western blot, dsRNA preparation \& purification, using automated pipetting and microscopy to perform a HTS.

Basic molecular techniques, cloning, DNA and RNA purification from different sources, PCR, working with radioactive phosphorus and bacterial phages, screening of phage libraries. 
Skills:

Languages

Greek (native)

English (fluent)

German (good)

Computers

Use of Microsoft Office, internet, Bioinformatic tools, Special programs for scientists (BioEdit, Vector NTI), NCBI databases and software,

Flybase, ApE.

Project Management

Drug Discovery Course

Advanced Methods \& Secondary Skill courses Training in handling automated pipetting and microscopy systems Scientific communication

Scholarships:

$04 / 2009-10 / 2010$

DFG Stipend (GRK 1034)

$01 / 2009-03 / 2009$

GGNB Bridging Stipend

$10 / 2006-12 / 2008$ Lichtenberg Stipend (Niedersachsen)

$09 / 2005-09 / 2006$ Stipend International Max Planck Research

School

Interests:

Reading, guitar playing, team sports such as volleyball, tae kwon do, computer games. During 20072009 member of the International PhD Symposium "Horizons in Molecular Biology" organizing team, especially involved in the organization of the Horizons Career Fair for scientists.

Reference:

Prof. Dr. med. Matthias Dobbelstein

AG Molekulare Onkologie

GZMB

Justus-von-Liebig Weg 11

37077 Göttingen

Germany 